$$
\begin{aligned}
& \text { K-QK } \\
& 711 \\
& \text { M42 } \\
& \text { B } 3419802
\end{aligned}
$$




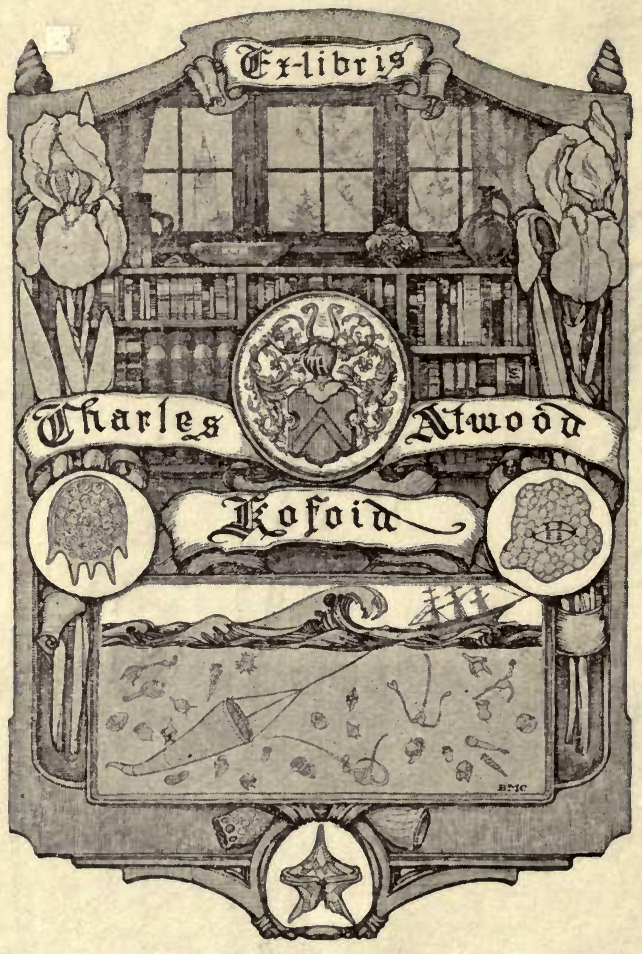


snanced - 


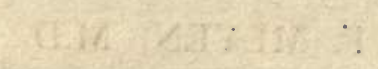

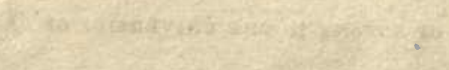

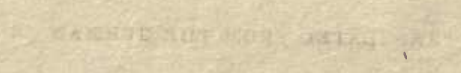

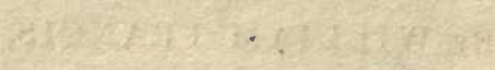

Haing

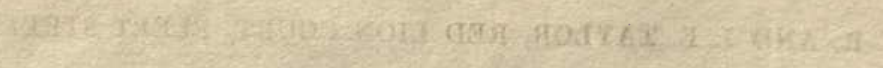

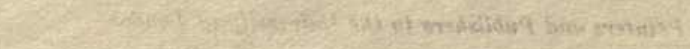




\section{REPORT ON THE PROGRESS}

\section{VEGETABLE PHYSIOLOGY}

DURING THE YEAR 1837.

IBY

F. J. F. MEYEN, M.D.

PROFESSOR OF BOTANTTIN THE UNIVERSITY OF BERLIN.

TRANSLATED FROM THE GERMAN

By WILLIAM FRANCIS,

ASSOCIATE OF THE LINNEAN SOCIETY.

\section{O N D N :}

R. AND J. E. TAYLOR, RED LION COURT, FLEET STREET, Printers and Publishers to the University of London. 



\section{ADVERTISEMENT.}

The present Translation was undertaken as a contribution towards the supply of a want of information, felt and acknowledged in this country, respecting the labours of Continental Naturalists, and especially those of Germany. In sending it forth so long after its announcement, the Translator feels that an apology is due to his Subscribers; but his undertaking has met with an encouragement insufficient to render it probable that the publication of the work can pay its cost. Should it, however, obtain this measure of success, he will feel pleasure in devoting some portion of his time to the translation of future Reports. He has already received a reward which he cannot too highly prize, in being brought into communication with the able and kind friend who has devoted a portion of his valuable time to the revisal of the work during its progress.

In the translation, the German has been closely ad- 
hered to, and when French or English papers have been reported on, the originals have been consulted. For those errors which may have escaped him, the Translator requests the indulgence of his Reader, and has only to hope that his undertaking may assist his countrymen in exploring a field of science rich in interest, and which amply repays the time and labour spent in its cultivation.

$$
\text { W. F. }
$$

Oct. 1, 1839. 


\section{R E P O R T}

\section{ON \\ VEGETABLE PHYSIOLOGY.}

THE study of Vegetable Physiology advances with rapid steps, the small number of its labourers annually increases, each year adds to the importance of its results; and we already look forward to the time when a decided separation of vegetable physiology from descriptive botany must take place, for it appears that these two sciences cannot simultaneously be pursued by one and the same botanist to such an extent as the present time demands. The number of anatomico-physiological publications of the past year is extremely great ; and it is morphology especially which has engaged during that period the largest share of attention; at present a contest awaits it similar to that which previously vegetable anatomy had to undergo, where not a single observation was admitted without opposition. So also morphology must not be the work of speculation, but should be founded wholly and solely on the observation of nature; studied in this way, it will become a doctrine easy to comprehend, which will enlarge to a great extent our knowledge of the nature of plants.

From the active interest which has been taken in vegetable physiology, and from the immense increase of materials, this report becomes from year to year a more arduous undertaking; as, however, it is of some utility for the diffusion of the science, the reader will kindly overlook those faults with which such a thankless task must always be accompanied. The in- 
terest evinced with regard to these reports both in England and in France by translations*, as well as by the kind transmission of some memoirs, which otherwise would not have come so early under our view, convinces us that the naturalists of those countries will feel a greater desire to possess a more general knowledge of our very numerous German labours in this branch of science than heretofore.

I shall endeavour in future that the report may always appear sooner, perhaps in the month of March ; by which some periodicals, it is true, which are constantly in arrear, will be left over. In the present report we have been able to avail ourselves of the valuable Annales des Sciences Naturelles only as far as the September Number for 1837 ; for to the 6th of May 1838 we did not possess in Berlin the later numbers. I must also remark, that of the larger general works which appeared during the past year on vegetable physiology, such detailed reports have not been given as of the smaller publications and separate memoirs; since this would have been a task beyond the powers of the reporter.

\section{On the Spiritual Life of Plants.}

M. v. Martiust has published his views on the soul of plants, with which I may commence the present year's report. It appears, observes M. v. Martius, as if natural philosophers were in general not inclined to admit in the essence of the plant these two spheres, body and soul, as if they would concede a soul only to animals and man. It is usual to regard as the essential predicate of the soul, perception such as it appears in animal life; and, as in the vegetable kingdom, we are acquainted with very few phænomena which admit of our concluding upon a power of perception in plants, they have been declared not to possess a soul. Von Martius points out, that even animal forms sink so low in the scale of organization, that all the characteristics of animal life disappear in them; on the other hand indications of vegetable life display

* The English translation here referred to was published in the 68th, 69 th, 70th, and 71st Numbers of the London and Edinburgh Philosophical Magazine, to the pages of which Journal I shall have frequent occasion to refer the reader.-TRANSL.

† Reden und Beiträge über Gegenstände aus dem Gebiete der Naturforschung, Stuttgard und Tübingen, 1838. 
themselves; whilst in the more highly developed vegetable forms, phænomena occur which belong to animal life, such for instance, as the manifold various motions which have been observed in plants : in fact that animal life and vegetable life appear in no way to be so decidedly separated from each other, and for that reason, therefore, a soul cannot be admitted in animals alone and deried to vegetables. Even the predominant growth and the propagation of plants appear to indicate that they are not confined to the circle of rigid necessity; and we must recognise in them a kind of predetermination, a tendericy to the ideal, consequently a higher vital principle, a soul. The soul of plants is much less complex than that of animals ; it is in fact, in itself, of a more obscure and undefined nature. Perception, imagination, consciousness, sensation, desire, volition, appear here to have sunk into the night of a gloomy, confined existence, and the narrow path of analogy and induction towards this subjęet, unattainable by our inquiries, is open to us but for a short distance. The vegetable soul must not however be compared with the soul of man, or with that of the higher animals, but rather with the nucleus or that point of the axis only, around which the life of the lowest and most simple animals revolves. Von Martius thinks that we can admit of no organ of soul in plants; yet we may probably succeed, as I think, in our time in discovering this organ even in plants; the nervous system has, as is well known, been already observed in vegetables by some learned botanists, although others, it is true, have not been able to convince themselves of the fact.

A series of phænomena are moreover enumerated, such as the specific susceptibility of plants for the actions of light, heat, air, moisture, \&c., which, without a certain degree of sympathy and of perception, without a kind of internal consciousness, could not possibly have effect. Perhaps in them all the various grades of spiritual action combine to produce one single obscure idea. The more general and intense the irritation which acts upon plants, the more powerful is the perception. The sleeping and waking of plants, as also their hybernation, correspond exactly to the similar phrenomena in animals, only that these states in plants are involuntary. The soul of the plant is diffused throughout it; in so far how- 
ever as the vegetable soul acts according to its nature formatively, plastically, one might say that it is situated in the more highly organized plants principally in the node, in which the vegetable powers slumber.

This latter opinion might however be disputed, as might generally the entire current doctrine of the composition of plants of internodes, on which subject we shall subsequently have occasion to speak more in detail. With respect to the rest I agree perfectly with M. von Martius; nay, it is to me inconceivable how all those phænomena of the vita sensitiva of plants can be thought to be explained by the indefinite expression of irritability.

Von Martius next enumerates the other manifold processes which the vegetable soul has to superintend when the plant is propagating by sexual intercourse, and concludes these observations with the following words : "Among intricate perceptions and ideas, a dark sensibility and consciousness, a sympathy, a stimulus, an increase of this to affection, probably also a kind of memory in the repetition of certain physical actions; all this we may deduce from the various habits of plants, if we compare them with analogous relations in animal life. We are not however able to trace in them a higher sense, understanding, or free will."

With the preceding is immediately connected a memoir by M. v. Martius*, which treats of the immortality of plants. The idea of the immortality of plants is the next step to the proof of the existence of a vegetable soul; but M. v. Martius himself observes in the introduction, that it is true that many. scientific men, to whom the power of comprehending the transcendental has been imparted in a lower degree, will regard the consideration of such a subject as a digression; he however believes that the greater part of mankind are so organized, that they will adopt conclusions, and acquiesce in consequences, which rise above the world of sensible contemplations and perceptions into the higher world of the spirit. The conviction of the immortality of plants can however in no case be deduced from any proof derived from the nature of plants, but it must be peculiarly the conception of the individual mind.

L. C. p. $261-286$. 
"In the corporeal life of the plant there exist intention, tendency, and means for their attainment; nay, we even see this controlled by the fitness of time, in the same way as in more highly endowed man. The plant, like the animal, has inward intentions to fulfil outwardly, fulfils them like the latter, and indeed, in the same way, more or less perfectly, according to the various conditions of which they consist. There is therefore only a difference of degree between the unknown unity which predominates over all this activity, and which in man is termed his soul, and the spontaneous power analogous to this soul which the plant exhibits in action during its whole life," \&c. We do therefore an injustice to the plant when we consider it as not being like the animal endowed with a common primary force, penetrating through all parts and directing them all to certain actions. From these views, however, it would result, that all inorganic bodies are also endowed with a soul, a thought, which has been already asserted in the most ancient times; nay, Von Martius arrives at the conclusion, that everything earthly, and therefore also the plant, possesses a soul, and the numberless fraternity of similar creatures which act so prominent a part in the universal life of our planet, are, according to their scale, governed by a soft peaceful spirit, an Anima blandula, trepidula.

\section{On the Phanomena of Nutrition and Growth in Plants.}

M. E. Ohlert* has published some observations on the structure and growth of the fibrils of the root; but deserving of more especial attention are those experiments which he performed on the function of the spongioles, and of the lateral surfaces of the fibrils. The decortication of the spongioles was also observed by M. Ohlert in various plants; it is more evident in roots which are developed under water. In other cases these membranes split into small rags, which still for some time adhere to the spongioles of the roots. M. Ohlert very rightly observes, that the decortication of the spongiole begins first at the upper end and then further downwards; at last the loosened membrane holds merely to the apex. I know however of instances where the loosened epidermis has

* Einige Bemerkungen über die Wurzelzasem der höheren Pflanzen.Linnea, 1837, p. 609-631. 
quite peeled off at the spongiole and become destroyed, while further upwards it still adheres firmly; a similar case also came under M. Ohlert's observation. The calyptra upon the spongioles of the thick aërial roots of the Pandani, to which DeCandolle first drew attention, are frequently to be seen in the Botanic Garden of Berlin; they are for the most part thick membranes, consisting of several layers of cells, which are here torn off from the hinder part of the root by the rapid growth of the spongiole; after some time this decortication is repeated in the part of the root which has grown subsequently. M. Ohlert's experiments respecting the elongation of the fibrils have completely confirmed Du Hamel's discovery that this elongation takes place only at the extremities.

He has endeavoured to prove by observations, that the current opinion, that the roots absorb exclusively by the spongioles and not with the lateral surfaces, is erroneous, or at least, that the reasons brought forward to prove this are not sufficient. Young plants of Pisum sativum, Lupinus luteus and Calendula officinalis were so placed with their roots in water that only the radicles were immersed about three lines deep in it. Even after a few hours the roots were withered, and after a few days quite dry; only that part of the root which was inserted in the water retained its turgescence. Upon this a quantity of plants were so placed in water, that the extremities of the fibrils projected out of the water, while the entire lateral surfaces were immersed. Also when the apex was coated with gum-lac varnish, the plants continued to grow extremely well if the entire surfaces of the fibrils were under water. From these experiments he concludes, that the fibrils do not absorb the moisture by the spongioles, but at the sides, or over the entire surface. I can however hardly agree with this conclusion; for I can also bring forward experiments which prove that the apex is, and indeed very actively, engaged in the process of absorption; this subject, as also my observations on the structure of the spongioles, are accurately detailed in the second part of my Vegetable Physiology, in which are refuted the received opinions respecting the so-called spongioles of the root, which do not exist in nature. It must certainly be admitted that plants absorb with the whole surface of their roots; this surface however is in many cases, and espe- 
cially at certain places, so changed, that the absorption is there diminished and gradually disappears entirely.

M. de Mirbel* has also in a few words treated of the structure of the terminal ends of the fibrils, and has controverted the spongioles being peculiar organs of the apices of the roots.

M. Dutrochet $\dagger$ has given in the complete edition of his physiological works, a very valuable memoir on endosmosis, which, from its highly important results, is of the greatest value to vegetable physiology.

M. Dutrochet endeavoured in the first place to determine what effect various degrees of temperature would have upon the endosmosis of one and the same solution. The crecum of a fowl was fixed to a glass tube, and this filled with a solution of gum in 10 parts of water, and placed in distilled water, at a temperature of $4^{\circ}$ Reaum.; the solution of gum had attracted within $1 \frac{1}{2}$ hour so much water that the apparatus indicated an increase in weight of 13 grains; and in a water at $25^{\circ}$ to $26^{\circ}$ the increase in the same space of time amounted to 23 grains. In order to be able to give the results of such observations with the greatest certainty, he constructed a peculiar apparatus, which he calls Endosmometer; by means of this instrument the velocity of the endosmosis in various substances was measured, or rather the quantities of the fluid which ascended in the endosmometer during a fixed time. For instance, sugar-water of the specific gravity 1.047 attracted in $1 \frac{1}{2}$ hour so much water into the endosmometer, that the instrument indicated $3 \frac{1}{2}^{\circ}$. On the other hand, a solution of sugar of 1.258 spec. grav. indicated in the same time $19 \frac{1}{2}^{\circ}$. The result of these experiments was this - that the velocity of the endosmosis produced by the various densities of the same inner fluid, is in proportion to the excess of the density of the inner fluid over the density of the exterior water.

M. Dutrochet also determined by a series of experiments the force with which the endosmosis takes place in various substances, and at various densities of these substances; and it is the results of these experiments which are of such importance to vegetable physiology. The apparatus with

- L'Institut. 1837. p. 311.

+ Mémoires pour servir à l'histoire anatomique et physiologique des Végétaux et des Animaux. A vec un A tlas de 30 planches. Paris, 1837. 2 vol. 
which these experiments were performed is very similar to those twofold bent glass tubes employed by Stephen Hales, when he endeavoured to determine the force with which the crude sap ascends in the vine: the end of the shank must here however be blown out in a funnel or bell shape, in order thus to present a larger surface of membrane to the endosmosis. In the first bend of the tube an aperture must be made, which may be closed by a glass stopper, through which the various fluids employed for the experiments may be poured, and a scale is fixed to the outer long shank. Now when the endosmosis is allowed to proceed in this instrument, the fluid contained in it rises by the absorption of the external water; and if some mercury has been placed in the two exterior shanks of the glass tube, this mercury is pressed downwards in the inner shank by the raised column of air and forced upwards in the exterior shank, which can then be nicely measured by the scale there fixed. By similar observations M. Dutrochet arrived at the result, that the force with which water is absorbed in the endosmosis, is more powerful according to the proportion in which the density of the fluid in the interior of the instrument stands to the exterior water. Sugar solutions of $1.035,1 \cdot 070$, and of 1.140 spec. grav. were prepared; the latter consisted of about one part of sugar and two of water. The excess in density of these fluids above the density of the water was in the proportion of $1,2,4$. The solution of sugar of 1.035 spec. grav. sucked up into the instrument so much water during twenty-eight hours, that the column of mercury was raised $10^{\prime \prime} 7^{\prime \prime \prime}$. The second solution caused the mercury to rise in thirty-six hours to $22^{\prime \prime} 10^{\prime \prime \prime}$; and the third solution of $1 \cdot 140$ density, in forty-eight hours to $45^{\prime \prime} 9^{\prime \prime \prime}$. The observations were made at a temperature of $16 \frac{1}{2}^{\circ}$ Reaum., and it is evident from them, that the force of the endosmosis is subject to the same law as its velocity. Similar experiments were now performed with several other substances; and M. Dutrochet arrived at the result, that a solution of albumen exhibits the most powerful endosmosis; after this sugar, then gum, and last and weakest of all, gelatin; these substances indeed, with respect to the strength of their endosmosis, are expressed in numerals in the following proportion: solution of albumen 12, sugar 11 , gum $5 \cdot 1$, and gelatin 3 . 
After these highly interesting discoveries of M. Dutrochet, it is hardly possible to doubt that the force with which the crude sap ascends in the vine and other plants is nothing more than the action of endosmosis, which is carried on by the innumerable cells of the extremities and hairs of the root with their saccharine juices upon the moisture of the soil.

M. Dutrochet * has in a subsequent memoir announced a change in his views respecting the conducting organs of the sap; formerly he regarded the spiral vessels as such, at present the fibrous ligneous cells. The structure of these elementary organs, he observes, is peculiarly adapted to serve for the ascent of the fluids. These fibrous tubes terminate at both ends in extremely fine points ; their cavities are the finest capillary tubes, and the end of the lower tube is articulated with the end of the upper tube. M. Dutrochet states that he is convinced that the ends of these tubes possess free apertures, and in this manner communicate one with the other. These supposed apertures at the ends of the ligneous tubes have as yet been observed by no German phytotomist, and I am rather inclined to doubt their actual existence ; nay, it even appears that such apertures are quite superfluous; for it is well known that the crude nutritive sap does not proceed from below upwards through the tubes of the ligneous body, but that it can even, and indeed almost as quickly, permeate laterally, where M. Dutrochet has not yet observed these apertures.

I will cite a passage in opposition to this view from $\mathbf{M}$. Unger's contributions to our knowledge of parasitical plants $\dagger$, where this illustrious physiologist has also laid down his belief respecting the function of the elementary organs of plants, which almost perfectly coincides with my own. The spiral vessel, he says, and the prosenchymatous cell in some degree allied to it, is certainly rather destined originally to conduct the nutritive fluid than to preserve it and prepare it for chemical changes; while the parenchymatous cells must rather be regarded as reservoirs of nutrition. The parenchymatous cells

* Recherches sur les conduits de la sève, et sur les causes de sa progression.-Mém. pour servir à l'histoire anat. et phys. des Végét. el des Anim. i. p. 368 .

† Ann. des Wiener Museums, ii. p. 25. 
are, however, in my opinion, not merely reservoirs of the nutritive substances, but the nutritive substances are formed in them, and then proceed from them through all the formations.

M. A. Poiteau* has also published some observations on the efflux of the sap from the divided stem of scandent plants, which may be entirely explained in the present state of the science. He cut the stem of a climber right through, and noticed that at neither of the two surfaces of section did water exude; if, horrever, a piece of the stem, about 4 feet in length, was cut off, the water contained in it flowed out immediately $t$. I have already frequently remarked that this water is contained in the metamorphosed spiral vessels, which in the stems of climbers, as in the vine, are so large that they can no longer act as capillary tubes, and therefore the efflux of the sap from the divided ends of the stem of such plants is entirely subject to the pressure of the atmosphere; it takes place instantaneously if the end of the cut stem is placed vertically, on the contrary, very slowly if this lies in a horizontal position. If, on the other hand, we separate the upper part of the stem, which is still clothed with its leaves, from the root end, no water can flow out of the end of the first portion, because the transpiration of the leaves, when their number is sufficiently great, developes a force by which the water is retained in the large spiral vessels. This fact has been proved by numerous experiments in the second part of my Vegetable Physiology. The reason still remains to be explained why no water proceeded from the surface of the section of the lower end of the stem of the climber, as M. Poiteau observed to be the case. It has been proved by numerous observations, that the tears of vegetables, i.e. the efflux of their crude nutritive sap above the level of the wounds which are inflicted on the stems of such plants, are to be ascribed entirely to the endosmosis of the fibrils, and that this phrnomenon only takes place if the plants, as during the production of leaves and buds, require a large quantity of nutriment.

On the circulation of the sap in Chara a paper by M. Du-

* Note sur la Liane des voyageurs.-Ann. des Sciences Naturelles, Avril 1837, p. 233.

† Lond. and Edin. Philosophical Magazine, vol. xi. p. 525. 
trochet* has appeared, which, together with phænomena long since known, contains also many new facts. Notwithstanding all the numerous observations which have been published in Germany respecting the structure of the Chara, M. Dutrochet commences with a description of this remarkable genus of plants, from which no one certainly would obtain a just notion of it. Mention is made of a central and of a cortical system of the Chara, which latter, in order to be able to observe the circulation in the central system of $C$. flexilis, must be taken off. It is hence evident that M. Dutrochet has had before him a Chara with compound cuticle, probably C. vulgaris, but certainly not $C$. flexilis, - a case which also occurred to a celebrated philosophical botanist of Germany, who has written a great deal respecting the circulation of sap in plants.

The artificial removal of the outer cuticle in Ch. vulgaris has long been known; and if the plants be kept during winter in a room, these membranes genierally disunite of themselves and fall off in great pieces. M. Dutrochet also observed that the course of the sap-current in the cells of the Chare is. indicated by the position of the green globules, which are arranged in lines one after the other on the inner surface of the cells; and is at present of M. Amici's opinion, that those green globules are the seat of the motion which is observed in the cells of these plants. M. Dutrochet has however seen, (which is likewise not new) that there is a circulation of the sap in such cells of the Charce as possess no green globules on their inner surface; and this is the case in all other plants where hitherto these motions in the sap of the cells have been observed; therefore the source of the motion cannot be sought for in those green globules. He has entirely overlooked the fact that a similar circulation occurs in all the cells of the so-called cortical layer of the Chare; but it seems as if, of all the innumerable memoirs which have appeared on the Charce and the circulation of their sap, M. Dutrochet had read no other than that of M. Amici.

M. Dutrochet bound round the lower part of the cell of

* Observation sur la Chara flexilis. Modification dans la circulation de cette plante sous linfluence d'un changement de temperature, d'une irritation mécanique, de l'action des sels, des acides, et des alcalis, de celle des narcotiques et de l'alcool.-Comptes Rendus, etc. Nos. 2. 3.4. Dec. 1837. p. 775. 
a Chara, and noticed the separation of the general circulation thus caused; an internode tied in three places exhibited four distinct circulating currents, which even continued when the adjacent parts were cut off.

M. Dutrochet examined the influence of various temperatures on the circulation in the Charc, and likewise noticed that it still continues at the freezing point of water, but proceeds very slowly. But Corti had previously observed that a cold of $2^{\circ}$ to $5^{\circ}$ killed the plants; in general, however, we may say that actual freezing kills the plants and causes the circulation to stop. M. Dutrochet observed that the circulation increased in rapidity with higher degrees of temperature, which was the case up to $27^{\circ}$ Cels.; but he did not remark that not only at one and the same temperature this motion varies exceedingly in the several cavities according to their different ages, but that even in the cells of the so-called bark and in those of the interior cavity the velocity in the circulation differs. On the application of a higher degree of heat, says M. Dutrochet, the motion is at first somewhat slower, but gradually rises, and finally arrives at the usual rapidity; but water at $45^{\circ}$ Cels. killed the plants irrecoverably.

M. Dutrochet endeavours to show that the influence of light is indispensably necessary to the preservation of the current in the Chara, reasoning from views according to which light is considered as the means for the fixing of the carbon from the carbonic acid of the air. Light appears to me to exercise no immediate influence on the circulation of the sap in the cells of the Chara, for I kept for several months plants of Chara in a dark situation, carefully covered, but observed in them, at a temperature of $7^{\circ}$ to $8^{\circ}$ Reaum., motions quite as active as these plants exhibit in summer, even at a higher temperature. M. Dutrochet placed several Charce in a perfectly dark situation, at a temperature of $14^{\circ}$ to $20^{\circ} \mathrm{Cels.}$. and observed that the motions of the sap became in most of them slower, indeed discontinued completely within twentyfour to twenty-six days in the younger plants, which had at the same time faded. According to my own observation, this fading of the Chare is quite peculiar ; the fact is, that the cells of the outer cuticle decay and fall off, and then only the inner membrane remains, which in Ch. vulgaris exhibits 
but very few small green globules on the inner surface, and therefore has then a faded appearance. The terminal joints of these plants are still, however, as beautifully green as the fresh plants, let them remain ever so long in darkness; and the motion in their cells ceases only at death.

M. Dutrocheí placed a Chara in water from which the air had been extracted, and closed the tube under mercury; the circulation continued even under these circumstances for twenty-two days, and ended only with the life of the plant; the effect therefore was almost analogous to that produced by a complete absence of light. Corti had previously observed that the circulation of the sap in Charce became slower when the plants were placed in oil or in milk. Corti placed some Chare in the receiver of an air-pump, and, rarifying the air as far as possible, left the plants in this situation during fortyeight hours. The circulation had discontinued; but after the plants had been placed in fresh water, it began anew in the space of from eight to twelve hours.

M. Dutrochet has also attentively observed the influences of mechanical causes on the circulation in the Chara. Every pressure and every mechanical irritation of the cells produce a momentary decrease in quickness, and even a complete cessation of the circulation, which is, however, soon restored, the effect being entirely proportioned to the force of the action. Actual injury of the membrane, even by the point of a needle only, causes a sudden cessation of the motion, which then never returns. Injuries have precisely the same effect on Charce as on other plants in whose cells similar circulations occur. If we cut off a single branch of a Chara, the motion ceases for a long time in the adjacent cells; in Vallisneria indeed this frequently lasts for ten to twelve minutes, until the motion in the cells of the prepared section again recommences with perfect activity. M. Dutrochet states that he has also observed that the simple cell of the Chara exhibits slight convulsive motions if one of the knots of an internode be pierced, and when the outer cortical membrane is pared off. In these cases also, the series of green globules are asserted to be the cause of the motion, for they are said to contract at times in a zigzag direction, similar to muscular fibre, while the membrane of the cell takes no part in this. I have 
not yet had an opportunity of verifying the correctness of these statements.

A very interesting series of observations has been instituted on the effects on the circulation of the sap in Charce of chemical substances, whose actions on the excitability of animals are known. A portion of a Chara was placed in a solution of caustic potash, containing about $\frac{1}{2} \frac{1}{00} 0$ of this substance; the motion at first became slow, but five minutes afterwards it was again very strong. After twenty-five minutes the motion again became slower, and in thirty-five minutes entirely ceased. Lime-water increased the motion in the cells of Chare in from two to three minutes: this remarkable result I am able to confirm. Momentary immersion of the Charce in limewater did them no harm, but if suffered to remain in it from four to five minutes the circulation ceased. In a solution of tartaric acid ( 1 part to 50 of water) the circulation continued in the cells for ten or twelve minutes only; in a weaker solution of this acid (1 to 1000 water) the motion became very slow; but five minutes afterwards it regained its activity by the reaction of the vital forces. After three quarters of an hour the circulation became feeble, and after one hour entirely ceased.

A similar result was obtained with a solution of sea salt, and M. Dutrochet came to the conclusion, that strong doses of salts and of acids put a decided end to the circulation in Charce, but that the same substances in smaller quantities causes it is true a stoppage in the beginning, but that subsequently this injurious action is overcome by the vital forces of the plant, and the motion is to be observed afterwards as before. Meanwhile the case is exactly similar with the vegetative processes of other plants. The motion in the cell of a Chara which had been placed in a solution of extract of opium (1 part to 14 of water) ceased entirely six minutes after immersion. After a quarter of an hour it recommenced very slowly, but after half an hour it was entirely suspended. In a weaker solution of opium (1 part to 288 of water) the effect was similar, but after ten minutes the circulation again returned and continued, it is stated, with increased velocity for eighteen hours. In a solution of opium, only half as strong, the circulation became somewhat slower, but subsequently returned with great vivacity. 
The action of alcohol on the circulation resembles that of opium. Similar observations have also been made on other plants: these will chiefly be found in a Dissertation by Schübler and Zeller*.

M. Becquerel $\uparrow$ has performed a series of interesting experiments with the view of discovering the nature of the force which causes these circulating currents of the sap in the cells of the Chara. M. Amici and many others regarded this activity as one similar to the galvanic power, produced by the piles of green globules with which the inner surface of these cavities is lined. The discharge of small piles through Chare twisted in a spiral form produced no change in their circulation; whence the conclusion was drawn, that the motion in the Charce is not caused by electricity, but by some other force, with whose nature we are as yet entirely unacquainted. On the other hand, the observations on the effect of continued currents on the circulation in the Chara lead to other interesting results. The passage of electricity causes at first a torpidity of the motion, which adapts itself entirely to the strength of the charge, and acts at the same time on both currents, i. e. on the ascending and descending. When the pile has been rendered by a certain number of plates so strong that its action immediately stops the circulation, this, after a short interval, recommences under the influence of the electric current, and returns to all its former activity. If we double the number of pairs of plates, the circulation again stands still, and this may be continued in such a manner that by the action of a powerful pile the circulation will stop for several hours. By a gradual removal of the plates the circulation returns so much the quicker; however no disorganization is caused by the passage of an electric current. Thus then the action of electricity on the circulation of the sap in the Chare coincides with that of heat, excepting that no acceleration was caused by the electricity, which is observed under the action of heat; however, I am inclined to think that this is only indirect, as the vegetation of the plant is hereby raised in in-

- Ueber die Einwirkung verschiedener Stoffe auf die Vegetation, \&c. Tübingen, 1826.

+ Influence de l'électricité sur la circulation du Chara-Comptes Rendus, 1837, p. 784 . 
tensity, at least the velocity of the motion in the cells does not depend on the degree of heat.

M. Morren* has published some views on the circulation of the sap in Dicotyledons, in which he observes that Mohl's discovery of an intercellular substance must lead to a more correct idea respecting the organs of circulation. But it has many years ago, in my opinion, been proved by several physiologists that the intercellular passages of plants only convey air, and these occur only in such plants where the close union of thickened septa is said to take place by the so-called intercellular substance. In last year's report this subject was treated of at great length + , and I am convinced by recent observations still more decidedly, that the intercellular substance is no distinct substance, but consists of the thickened superposed cellular septa. I recommend for such observations old leaf-petioles of species of Rheum and the old stems of cucurbitaceous plants.

M. Morren regards the pleurenchymatous cells of the wood as the route of the ascending crude nutritive sap, for which some explanation may be necessary, as this denomination is not yet generally adopted in Germany. I proposed the word pleurenchyma to designate the tubes of the liber in 1830, I subsequently discovered that the so-called ligneous cells possess a similar structure with the tubes of the liber, and distinguished in the first part of my Vegetable Physiology short pleurenchymatous cells and elongated pleurenchymatous cells; the latter comprise the tubes of the liber, the former the ligneous cells, which in Germany are more frequently designated by the name of prosenchymatous cells, by which I understand the ligneous cells of the Coniferce. M. Morren has very correctly mentioned the fact, that the crude nutritive sap ascends in the wood not only from below upwards, but also passes in a horizontal direction and even obliquely through the wood, exactly in the same way as the circulation of the sap takes place from cell to cell in the diachyma of the various organs. M. Morren is, however, a'so of opinion, that these short pleurenchymatous cells are of the same origin and

* Considérations sur le mouvement de la sève des Dicotyledones.-Bullet. de l'Acad. de Scienc. de Bruxelles, 1837, p. 300.

+ Lond. and Edin. Philosophical Magazine, vol.xi. p. 435. 
purport as the other cells, and are produced as it were from spheroid cells, the so-called merenchyma, and therefore the fibrils of the root must also be considered as such cells which take their origin in the root-stem, \&c. Much may, however, be objected to this notion; the fibrils are exceedingly delicate parenchymatous cells, and parenchyma and pleurenchyma differ, not merely in the form of their cells, but also in their functions. Pleurenchyma rather serves merely to conduct the saps; the short pleurenchyma conveys the crude nutritive sap in its ascent, the long pleurenchyma (tubes of the liber) conducts an elaborated formative sap from above downwards. In the parenchymatous cells the assimilation of the absorbed nutritive substances takes place : they respire through the intercellular passages, while in the pleurenchymatous cells no respiration can exist on account of the want of intercellular passages. I have enumerated in my Vegetable Physiology several cases where intercellular ducts occur even between the tubes of the liber, for instance, in Asclepiadee and Apocynea ; and that in these cases the tubes at the same time convey a milky fluid, which abounds in globules! The origin of the radicular fibrils from the parenchymatous cells may easily be observed.

M. Morren next enters into a special consideration of an inversely grafted branch of a Camellia, in order to show that the direction in the ascent of the sap may not only be inverted for some hours, but even for the whole lifetime of the plant. The first, as is known, was long since scientifically proved by Stephen Hales, and I have also endeavoured to show * that the ascent of the sap in separated branches is caused entirely by the transpiration of the leaves, \&c., consequently the direction of the sap may be varied at the will of the experimenter. The ideas of ascent and descent in the motion of the crude nutritive sap are evidently not altogether correct; the crude sap is always conducted to those parts of the plant which are in want of it, and therefore it is also conveyed to the bud of a cutting, even when this is grafted inversely on to the stock. The vacuum which must arise from the transpiration of the young bud and of its leaves is immediately filled with the fluid which lies nearest to it, and in this way the crude

- Pflanzen-Physiologie, vol. ii. Berlin, 1838. 
sap ascends from the stock through the wood of the scion into the eye, which may be proved by experiments.

M. Mirbel* has laid before the French Academy a highly interesting treatise on cambium and the mode of formation of cells and vessels in vegetables. The earlier statement, that cambium is a cellular mucilaginous mass of extreme delicacy, is therein confirmed, and M. Mirbel is of opinion that his doctrine of the origin of vessels (probably spiral vessels are intended), which originate from cells whose diagonal septa are destroyed, is generally adopted, which, however, is not at all the case. I shall not go further into the contents of this communication at present, as M. Mirbel will probably very soon publish this work in a more complete form; it contains very beautiful drawings of the formation of the new ligneous cells from the cambium, and the thickening of their sides by the formation of new layers from the latter.

M. Girou de Buzareingues $\uparrow$ has on the other hand produced a memoir on the structure and growth of the new woody layers of dicotyledons, which it is true is full of new observations and views, but will hardly gain much credit. I at least cannot concur with him in one single point. In last year's report $\ddagger$ I had occasion to notice a paper of M. Girou's, in which the most erroneous observations and false views on well-investigated subjects of vegetable physiology were contained; it is much the same with the present memoir. M. Girou writes and works constantly without any regard to the labours of his predecessors, and this neglect of the observations of others is the cause that the results of his own are as if vegetable physiology had first been studied last year.

M. Dutrochet $\S$ has laid before the French Academy of Sciences some observations on the nature and development of cork, without being acquainted with the observations of $\mathbf{M}$. Mohl, which were noticed at p. 58 $\|$ of last year's report. M.

* Observations sur le cambium et sur quelques modes de formations utriculaires ou vasculaires dans les végétaux.-Compte Rendu, 1837, p. 295. L'Institut, 1837, p. 311.

† Mém. sur l'accroissement en grosseur des exogènes.-Ann. des Scienc. d'Hist. Nat. 1837, Mars, p. 129-166, avec 3 planches.

¥ Lond. and Edin. Philosophical Magazine, vol. xi. p. 526.

$\S$ L'Institut de 1837, p. 10.

II Page 53, \&c. of the translation in Lond. and Edinb. Phil. Mag. for January 1838, - TraNsL. 
Dutrochet mentions a species of ash, whose branches, from eight to ten years old, develope cork; after this time the development of cork ceases. I have published similar observations on the Metrosideri*, and have indicated the structure as also the development of the suberose layer in relation to the other cortical layers. The other statements of M. Dutrochet were previously known.

M. Decaisnet presented to the Acad. des Sciences a memoir on the family of the Lardizabalea, which contains some interesting observations on the structure of the stems of dicotyledons, especially with reference to the Menispermea and Aristolochice. As the memoir will probably very soon appear, we delay our notice, as the abstract in the Institut is too short for our purpose. The remarkable structure of the stem of the genus Cissampelos has also been noticed by me in my Vegetable Physiology, p. 374.

M. Link has published the second part of his AnatomicoBotanical Drawings for elucidating the fundamental doctrines of botany ; they are accompanied with Latin and German text. In last year's report I drew attention to this useful undertaking, which must add much to the general diffusion of phytotomical doctrines. The drawings are very neatly and beautifully executed on stone, and in the present part there are several which render the distinctions between monocotyledons and dicotyledons, Coniferce, Cycadea, and so forth, very prominent, and on that account may be recommended to the attention of geologists.

M. Morren $\S$ endeavours to show that the priority in the discovery of the increase of cells by simple division belongs to him, as he had published already in 1830 the observation, that every fourth part of his beautiful genus Crucigenia (an Alga), on being magnified, again subdivided into four smaller cells, and so on. In last year's report this subject was treated of at length, p. $20 \|, \& c$., and I stated M. Dumortier to be the discoverer of this interesting fact, which was published in

* Pflanzen-Physiologie, i. p. 411, \&c.

+ L'Institut, 1837, p. 317.

\pm Berlin, 1837, fol.

\$ Bulletin de l'Acad. Royale de Science, \&c. de Bruxelles, 1837, p. 300.

II Page 386 of the translation in the Lond. and Edinb. Philosophical Magazine for Oct. 1837.-Transl. 
1832. He was at least the first botanist who recognised the importance of the facts from which we might conclude with certainty on the increase of the cells by separation; and M. Mohl has noticed this important subject more fully in Conferva glomerata. Suppositions and simple conjectures that cells increased in such a way had frequently been given out, but there is a very great difference between the origin of new cells in the way stated, and the formation of the pollen vesicles, which originate in a manner similar to the albumen of seeds, and M. Morren can hardly lay claim to the discovery of these facts. It was well known for instance that all the cells in a Conferva, proceed from the few cells of the spore, but nevertheless we did not then know in what manner the increase of the cells took place; we were acquainted with the elongation of the spores in several Hyphomycetes, and the extension of these spores to the development of the young plant; but yet we had no distinct idea of the process contemporaneously in action.

M. Morren has since then continued his observations on the separation of the cells in the Conferva, and thinks he has succeeded in recognising in Conferva dissiliens all the circumstances at the formation of the diagonal partitions; he observed in this plant that the cells were elongated, and the mass therein contained was divided in the centre into two parts by a transparent free space, which was formed of a mucous fluid, which from its destination he supposes to be an intercellular substance, and names it inter-chromula (inter-or meta-chromulaire or Metendochromique). The condensation now begins from the periphery of this substance, by which the union with the common cell is at the same time effected, and as this advances more and more towards the centre, the double membrane thus formed takes the place of the transparent fluid substance, so that now each single portion of the endochrom possesses its distinct membrane.

M. Dutrochet's memoir on the respiration of plants, which was but shortly noticed in last year's report, p. 56*, has since been published entire $†$; the results of this work coincide however very little with the views of many other physiologists,

- Page 536 of the translation in the Lond. and Edinb. Philosophical Magazine for Dec. 1837.-TRANSL.

+ Recherches sur les organes pneumatiques et sur la respiration des végétaux. In the collective edition of the Memoirs of M. Dutrochet, i. p. 320. 
and quite as little with those I have endeavoured to diffuse on this subject; so that a more detailed elucidation of the statements from which these results are drawn is quite necessary.

M. Dutrochet complains of those botanists, who think that animal life has nothing in common with that of plants; according to his opinion, with which in so far I entirely agree, life is not different in its fundamental phænomena in all beings. It has frequently been admitted, that those phænomena, which in vegetables are comprehended under respiration, are exactly opposed in their results to the respiration of animals : M. Dutrochet does not take this view, but according to him the respiration in plants consists as in animals in a fixation of the oxygen, while I have endeavoured to show in my Physiology (ii. p. 150.), that the respiration of plants, like that of animals, consists in a carbonization of substance, as in both oxygen is inspired and carbonic acid expired.

In examining the organs of plants which carry on the process of respiration, M. Dutrochet relates the opinions of MM. Link and Amici, according to which the spiral vessels and their appendages should be regarded as the pneumatic apparatus of vegetables. However M. Link is not at all of this opinion in his recent works, but states that aggregations of air are even found in the intestinal canal of animals, yet this exists for very different purposes. The conveyance of air is evinced very decidedly in the cells of the pith, and nothing can be more certain than that the medulla serves to convey and elaborate the absorbed sap for the young shoots. M. Dutrochet was formerly of opinion that the large spiral vessels in the wood of the vine conducted the nutritive sap, and even at the present time considers this to be correct, but thinks that it is to be attributed solely to this cause, that so long as the leaves are wanting, no transpiration is indicated, and that the sap consequently collects in the spiral vessels.

The spiral vessels are therefore said to be the pneumatic organs in the wood, while distinct large cells are found in the bark conveying air, which are supposed to be situated in the interior of the bark, and to communicate one with the other. I must confess that I have no idea of these cells, which are said to carry on the process of respiration in the interior of the bark, wholly leaving out of view, that it is not probable 
that nature would employ the spiral vessels in the wood and distinct cells in the bark to effect the respiration in plants.

In my Vegetable Physiology, I have, on the contrary, endeavoured to show that the intercellular system serves for the respiration in plants ; and it is only those elementary organs, surrounded by intercellular passages or large air cavities situated in the immediate vicinity, in which an actual assimilation of the absorbed nutriment takes place; for as the respiration in animals produces an amelioration of the blood, $i$. e. of the elaborated nutritive and formative sap, so in vegetables the respiration causes an amelioration of the nutritive sap, which is elaborated in every cell of the parenchyma : and, if we compare the structure of animals with that of plants, we shall at once perceive that a respiration, which is to agree in its results with that of animals, can take place in plants in no other way. If we follow up the connexion which exists between the intercellular passages, air cavities, stomata, and the spiral apertures of the cuticular glands, the view which I take in common with M. Unger, that the intercellular passages carry on the process of respiration in plants, will become more than probable. When the cuticular glands are covered with resins, as is frequently the case in the Coniferce, this must be regarded. as a purely accidental aggregation of the excretion in the cavity of the epidermis.

The leaves are, however, the organs which possess in the greatest number the above-mentioned arrangements for respiration. M. Dutrochet notices the difference of opinion respecting the destination of leaves with reference to their function; some botanists have compared them as absorbing organs to the aërial roots, others on the contrary have declared them to be the lungs of plants. To this latter opinion M. Dutrochet adheres in common with many other botanists. The leaves of plants exert on the nutritive sap contained in them a similar action to that of the act of respiration in the lungs of animals on the blood; and the sap descending from the leaves, the formative sap is that which in some degree may be compared to the blood of animals, as of it the new masses are formed.

Observations have long since shown that plants during the greatest part of the day-time absorb oxygen : to explain this phænomenon M. Dutrochet draws attention to the important 
discovery of M. Theod. de Saussure, that porous bodies, and especially such as abound in carbon, possess the property of attracting and compressing certain gases : thus, for instance, carbon can absorb $9 \frac{1}{4}$ times its volume of oxygen. It is possible that the absorption of oxygen in plants takes place in a similar way, at least the quantity of oxygen consumed coincides with the number of stomata and air cavities in certain plants. All porous bodies however do not possess this property of compressing gases; magnesia and lime for instance are exceptions.

The contents of the remaining portion of this work have partly been published in earlier papers, and we have moreover partially noticed the essential points in our last year's report*.

Dr. Schleiden $t$ has published some observations on the luxuriant development of various plants in water containing carbonic acid. The springs in the valley of Göttingen abound in free carbonic acid, especially the basins near the Wehnder paper-mill, and there is here found a rich and luxuriant vegetation, which in spring appears several entire weeks earlier and continues in autumn much later than at other spots of the same district. Dr. Schleiden thinks that the free carbonic acid in the water exercises a favourable influence on the vegetation, which certainly may be the case; for observations have shown, that during the vegetation of plants in solar light, the addition of a very small quantity of carbonic acid in the surrounding atmosphere produces a much more powerful disengagement of oxygen than takes place in the common atmosphere.

In the memoir on the soul of plants, M. v. Martius $\ddagger$ has stated his views on the nutrition of plants. The whole force of vegetable life evinces itself most prominently in its indications of assimilation, as here inorganic matter must be converted to organic, and have form given to it. This is an essential character, in which plants differ from animals, as these for the most part take up only organized nutriment. The plant, says M. v. Martius, derives its nourishment from the earth, the water, and the atmosphere; but I think I am able to prove

* See Lond. and Edinb. Philosophical Magazine, vol. xi. p. 536.

+ Notiz über die Einwirkung freier Kohlensäure auf die Ernährung der Pflanzen.-Wiegmann's Archiv, p. 279, 1837 ; and Annals of Nat. Hist. p. 235. No. IX.

‡ Reden und Vorträge, \&c., p. 244. 
with much certainty that plants are also nourished by the reception of organic substances, and that the reception of these as well as of inorganic substances, which are presented to the roots in a dissolved state, is effected entirely according to the fixed laws of physical forces.

[By a long series of experiments it has been proved that plants will not grow in a soil of inorganic substances; if, however, organic substances be presented to them for nutrition they vegetate, and fix in their green-coloured parts by the influence of solar light the carbon from the carbonic acid of the air ; it is chiefly the leaves which perform this function. After the fall of the leaves they are converted into humus, and this again presents to the roots of the plant the necessary nutriment.-REP.]

M. v. Martius supposes that plants, in all the operations of their vegetable life, act according to a certain law of preference, therefore with that power which in the human mind becomes will. The plants are thus said to choose from the manifold nutritive substances at their disposal those to which they are especially partial; however, I am of opinion that all correctly performed experiments, from which at least we must reason until more recent ones shall have proved otherwise, tend to show that vegetables cannot choose their nutriment.

The Rev. J. B. Reade* has published several elementary analyses, which would lead us to admit a very remarkable difference in the chemical composition of cellular membrane and of spiral vessels in the same plant. The analyses were performed in the laboratory of Mr. Rigg, but unfortunately the method is not stated. Mr. Reade extracted from the roots of the Hyacinth the spiral vessels from the surrounding cellular tissue by rubbing them between the fingers, and then both substances were subjected to separate analyses. He obtained:

\begin{tabular}{|c|c|c|c|}
\hline \multicolumn{2}{|c|}{ Spiral vessels. } & \multicolumn{2}{|c|}{ Cellular tissue. } \\
\hline Carbon & $41 \cdot 8$ & Carbon & $39 \cdot 2$ \\
\hline Hydrogen & $1 \cdot 1$ & Oxygen. & $7 \cdot 14$ \\
\hline Nitrogen & $4 \cdot 3$ & Nitrogen & $3 \cdot 9$ \\
\hline Water & $51 \cdot 8$ & Water & $48 \cdot 5$ \\
\hline Residuum & $1 \cdot 0$ & Residuum & $1 \cdot 0$ \\
\hline & 100 & & 100 \\
\hline
\end{tabular}

* On the Chemical Composition of Vegetable Membrane and Fibre.Lond. and Edinb. Philosophical Magazine, vol. xi. p. 421. 
These results are in many respects so remarkably at variance with all that we are as yet acquainted with respecting similar subjects, that we must at the outset doubt their correctness. The small quantity of carbon of these substances, which according to his statements would even be less than that in starch and in gum, is in itself highly improbable, even if no similar analyses had yet been made. According to these statements, the cellular tissue is said to contain an overplus of oxygen and the spiral vessels an overplus of hydrogen, which, however, is not confirmed by analyses in German laboratories. Mr. Rigg is also said to have long ago discovered that the perigonium of the hyacinth contains oxygen in abundance, while the pistil and pollen show a surplus of hydrogen, so that Mr. Reade thence arrives at the conclusion that fibre (probably spiral fibre is here intended !) contains hydrogen, and cellular membrane oxygen in abundance, and indeed in such proportions that these gases form water when the organs are analýsed together.

With respect to the analyses of the spiral vessels and cellular tissue from the root of the hyacinth, I must observe that it is a most difficult, and in the hyacinth even an impossible undertaking, to prepare the spiral vessels in so great a quantity, i. e. entirely freed from every kind of cellular tissue, as is necessary for any elementary analysis : besides, the spiral vessels snap very easily in the hyacinth, and at the utmost we could only succeed in preparing some pure fibre. Moreover we are not informed in what manner Mr. Reade convinced himself of the purity of the substances employed. Each individual cell of the cellular tissue must be separated piecemeal, and then cleansed several times with alkalis, acids, alcohol, æther, and water, if we desire to obtain a result on the composition of membrane. Thus also the considerable amount of nitrogen, which these analyses indicate, is probably only to be ascribed to the nitrogenous substances contained in the cells ; for the numerous careful analyses of cellular tissue, of wood, \&c., hitherto performed, give no nitrogen at all, or at least only so much that it may justly be regarded as a foreign constituent. Mr. Rigg has even made various analyses of the different parts of the flower of the hyacinth ; he thus first separated the epidermis, then the cellular tissue situated immediately beneath the epidermis, the spiral vessels, and the longer cells 
which traverse the parenchyma in bundles, and subjected each of these four substances to separate analysis, which, remarkably enough, have given results exactly corresponding to the expectations. I may be excused, however, for giving my own opinion repecting the division of the flower into these four substances. It would I think be impossible to obtain such quantities as would be necessary for the analysis, even were the division to be made under the microscope and a whole year devoted to the purpose. And if the substances for analysis have not been employed perfectly separated, it does not attain its end. Above all, however, the antithesis in the composition of cellular membrane and spiral fibre, which is said to be indicated by predominant hydrogen and oxygen, is inadmissible.

In support of some of the above-mentioned suppositions, I will notice some elementary analyses which Prof. Mitscherlich has instituted with the greatest accuracy; flax fibres, pure cellular tissue from the interior of the pith of the elder, and pure spiral fibres from the flower of a Musa were employed. All these substances were previously cut small, then purified in every respect from foreign ingredients, and constantly tested with the microscope, so that no doubt might remain as to the substances which were to be subjected to analysis being as pure as possible. According to these analyses, the flax fibre contained in 100 parts 45.98 carbon; the pure spiral fibre of the Pisang 48.88, and the cellular tissue of the elder pith $50 \cdot 65$ carbon. Hydrogen and oxygen were present in the same proportions as in water; yet, unfortunately, all the analyses indicated some superfluous hydrogen, which proved less the more accurately the analysis was made. Nothing was observed of any superfluous oxygen or nitrogen. The perfect combustion of the substances had to be effected by passing a current of oxygen, as an accurate mixture of them with the oxide of copper could not be effected; and probably the occurrence of superfluous oxygen is to be ascribed to this method, which it is intended to ascertain by further experiment.

In a second paper* Mr. Reade has endeavoured to prove

- Further observations on the structure of the solid materials found in the ashes of recent and fossil plants.-Lond. and Edinb. Philosophical Magazine, vol. xi. p. 413. 
that potash, lime, and silica enter as organizable substances: into the structure of plants. The reasons which Mr. Reade mentions in support of this consist, properly speaking, only in the observation, that we find in the white ash of coal the form of the elementary organs of those vegetable parts which have been burnt, and that this skeleton consists partly of potash, lime, and silica. As far back as two years ago M. Göppert* made mention of a potash and lime skeleton, which remains after the combustion of plants, and exhibits completely the perfect form of the cells and of the other elementary organs. This occurrence of potash and lime in the form of the elementary organs after their combustion, is however not at all of the same character as the siliceous case, which is so very striking in many land and water plants; for if those alkalis and earths are present in the interior of the elementary organs, they must be precipitated, on the evaporation of the moisture, upon the sides, and after the combustion retain the form of the cells, spiral vessels, \&c. The more accurately the cells of plants are divided and purified by acids, alkalis, \&c. the less ashes do the membranes and fibres present after combustion, asfrequently repeated experiments have shown: however, even if the adherent alkalis and earths are separated as far as possible, yet all cellular membrane, and even the extremely delicate spiral fibres, exhibit a trace of ashes, and this presents itself in the form of the burnt elementary organs. Thus Prof. Mitscherlich found that the delicate flax fibres which I had divided and purified in every possible way produced almost one-tenth per cent of such ash, which presents itself in the form of extremely fine membranes partly indicating the form of the fibre. The cellular tissue of the elder pith, which is more difficult to purify, as the single cells cannot be comminuted by attrition, gave a far greater quantity of ash, for 0.5945 parts of pith produced 0.0105 of ash. In the ashes of the flax, Prof. Mitscherlich found a trace of silica and also potash and lime : the ashes of the elder pith contained on the contrary no silica, but much lime and traces of potash and alumine. It may therefore be admitted now almost as certain that these alkalis and earths occur in the substance of the parietes of the elementary organs; but it does not there-

\footnotetext{
* Poggendorff's Annalen, vol. xxxviii. p. 568.
} 
fore follow, as Mr. Reade supposes, that these substances must be regarded as constituent parts of the elementary organs. M. Morren many years ago (1830) suggested the supposition that silica must be considered as a constituent substance of the cellular membrane, but this met with no reception; for it is easily conceived that the presence or absence of these alkalis and earths in the membrane depends entirely on the contents of the inclosed fluids.

The most important points respecting the occurrence of crystals in plants may at present be considered as known. I have given a very detailed account*, and M. Unger has also published a memoirt on the same subject, accompanied with a plate of beautiful drawings. M. Unger has confirmed the statement, that the crystals are not formed in the intercellular passages, but in the interior of the ce!ls. I, on the other hand, have observed several cases in which exceptions to this rule occur. M. Unger states for instance, that the crystalline glands, which are situated on the walls of the aircavities of Myriophyllum spicatum, are contained in distinct projecting cells, and he has even figured these cellular walls; however, in all the cases which have come under my notice, I have not been able, even with the most recent instruments, to see the cellular walls which inclose the crystalline glands; this has also happened to Treviranus and Mirbel. As however I can see with my instruments even the single crystals of which those glands consist much more correctly than M. Unger has represented them, I am inclined to think that the cellular membrane figured as surrounding the crystalline glands does not exist.

In the work above cited I have enumerated several similar cases where the deposition of crystalline masses takes place at the exterior of the cells, and have drawn attention to the manner in which the formation of crystals is to be understood. In some cases, as in the Charce, the crystals form externally by mere precipitation of the basal carbonate of lime, the carbonic acid which held these in solution being absorbed by the plant. If we place Conferva in lime water, small calcareous crystals

- Neues System der Pflanzen-Physiologie, i. p. 212-246.

+ Ueber Krystallbildungen in den Pflanzenzellen.-Annalen des Wiener Muscums, iii. p. 1. 
form on their surface, the carbonic acid being extracted from the plant and combining with the lime. All the cases in which it may still be doubtful whether the solitary crystals are surrounded with a cellular membrane or not, have been fully treated of; but it would occupy too large a space in this limited report, were I to enumerate the new facts from the memoirs published by me during the past year. I shall therefore only touch on my own labours of that period when the facts therein contained stand in contradiction to the observations of others.

In M. Unger's observations on the frequency of crystals in plants, he remarks, that it is not strictly determined whether the age and locality of the plant contribute essentially to this, although it may certainly be admitted. I think, however, that physiology is at present pretty clear as to this point; for we know, that plants absorb all that the soil offers them in a dissolved state, that the quantities of the various substances which are absorbed bear an exact proportion to the degree of solution in which these exist, and also to the quantity of the solution which passes through the plants. The solid substances remain in the plants, for the water is evaporated; and then the various acids produced in the plants, as also those which are imbibed, can carry on the process of their affinity. The age of the plant, the age and vital condition of the single parts, the transpiration which is different at the various parts, and the degree of solubility of the substances to be crystallized, are all circumstances which explain the manifold occurrence of crystals in vegetables. In the cells containing oxalic acid, oxalate of lime will be formed. No amylum can have existed if the oxalic acid was contained in the cell previous to the existence of the lime, for this is converted by the slow action of acids into sugar, \&c. And thus might we explain the remarkable phænomenon mentioned by M. Unger (l. c. p. 5.): "Amylum, green-coloured cellular sap globules, coloured cellular sap, cells with crystals, \&c., all these occur frequently in single but neighbouring cells, and in the cells themselves we do not see the reason of these various formations."

M. Unger notices the difficulties which are opposed to the observation of the crystalline forms, but has figured the various forms of the crystals contained in several plants, for in- 
stance, those of Strelitzia Regina, Papyrus antiquorum, Rheum undulatum, Yucca gloriosa, Musa paradisiaca, and $M$. coccinea, and those of Maranta zebrina, and has treated this point more crystallographically. Many of these statements do not agree with my observations, but a short time will prove the correctness of the one or the other; it appears however to me that a rich field is here opened to the crystallographer, for frequently the most beautiful crystals with all their variations are innumerable in the same plant. The crystals of obtuse form, which M. Unger has figured from Strelitzia Regina, as well as most of those in Maranta zebrina, and in the pith of the Peperomice and species of Piper, consist of gypsum; in the latter plants I have found them along with crystals of oxalate of lime.

As an appendix to the memoir on the crystalline formations of plants, M. Unger has published some notices on the milk sap or vital sap vessels (proper vessels) of plants, and at the same time promises on some future occasion to show how the circulation of the sap, which takes place in these vessels, is generally carried on. Probably M. Unger will be able to explain this phænomenon which has hitherto remained problematical. He also thinks he has put an end by his observations to the dispute respecting the independence of the milk sap vessels by the following statements: "The milk sap vessels are only a portion of the vascular fasciculi (those bundles of organs are here intended which in most plants become lignified, and on that account are termed ligneous fasciculi): they form, it is true, one system of sap-conducting canals, connected by frequent anastomosis, but nevertheless appear to be more closely allied to the parenchyma than to the system of vascular fasciculi." This view is said to be favoured, first by the position of these vessels in the bark or medullary substance, and secondly by the genesis of thevessels themselves. The origin of the vessels however rests on the following observations: M. Unger observed in a longitudinal section from the medulla of Ficus bengalensis, which is represented in fig. 1. of the memoir on the crystalline formations in plants, several parenchymatous cells placed perpendicularly on one another, differing from the adjacent cells by their contents, which resembled that of the other milk sap vessels. This, says $M$. Unger, can evidently be regarded as nothing else than the 
commencement of a proper vessel, which probably in this case endeavours to produce a new anastomosis between two trunks having a longitudinal course, and the horizontal cellular walls still appearing in the form of delicate intermediate parietes, as those parts which in the further progress of development are gradually obliterated. Subsequently he calls these statements and suppositions a history of the development of the proper vessels, and thinks that the formation of the spiral tubes is exactly similar. My observations on this subject are quite opposed to the suppositions of M. Unger. In the earlier stage, the walls of these vessels are not yet perceptible, and the milky sap is found as it were between the cells in uninterrupted currents : at a later stage, the sides of these vessels gradually increase in thickness and become more and more distinct from the adjacent cellular walls; nay, in some parts of plants, as for instance, in the root, \&c., they are furnished by the adjacent cells with more or less strong constrictions, so that even forms similar to those designated by C. H. Schultz as articulated vessels arise.

"Since these vessels," observed M. Unger, "are developed from cells, the peculiarities in respect to the structure of their parietes may also necessarily be applied to these vessels. As we may regard the parietes as formed of two more or less adherent lamellæ (or, according to my opinion, as originally a simple membrane gradually dividing into two lamellæ), we can scarcely deny to the proper vessels one constituent part of its external boundary peculiar to them alone," \&c.

I have in my memoir on the Secreting Organs of Plants (Berlin, 1837, 4to.) and in my Vegetable Physiology (ii. p. $370-428$ ), expressed myself in more distinct terms on this subject; I think that botanists must admit the peculiar parietes of the milk sap vessels, because they really exist in nature, and are evident to every one who searches for them; if, however, M. Unger has not yet observed the circulation of the sap in the vessels of Ficus bengalensis, he will probably notice it hereafter, for it really exists.

M. Mandl* has published some results of his observations on the milky sap of plants, which highly deserve the attention

* L'Institut de 1837, p. 127. 
of naturalists. M. Mandl fancies he has discovered that the milky sap of almost all plants contains Infusoria of various forms. In the Euphorbice these Infusoria are said to be highly developed, but unfortunately the description indicates that M. Mandl has not seen Infusoria, but those minute spiculæ previously discovered by Rahn*, which mostly consist of amylum. The motions and contortions of these amylaceous spiculæ which M. Mandl pretends to have seen do not however exist in nature. I have recently figured the most remarkable forms of these amylaceous spiculæ of the Euphorbiat.

Some notices have recently been published by E. Solly, jun. $\ddagger$ on the milky sap of the cow tree of South America. Gigantic cow trees were found in the neighbourhood of $\mathrm{Ca}$ racas, the smooth stems of which rose to the height of 60 feet, while the crown, 40 feet above the ground, spread forth its branches, 24 feet in length, on all sides. If incisions were made in the bark, down to the wood, the snowy stream flowed out very rapidly, so that within a quarter of an hour a flask might be completely filled. The vessels conducting this milk are situated in the interior brown layer of the bark. The milk from one of these trees was forwarded to England, and carefully examined by Mr. Solly; it was however evidently spoiled, and consisted of 62 parts of water and acetic acid, 30.5 galactin and some gum, gluten, \&cc. Mr. Solly has designated by the name of galactin the waxy substance which is contained in so great a quantity in the milk of the cow tree; it was regarded as common vegetable wax, but differs from bees' wax in several very remarkable properties. Galactin is dissolved by cold sulphuric acid and decomposed by warm; it does not form oxalic acid with nitric acid.

M. Aug. de St. Hilaire $\S$ has published an extract from M. C. H. Schultz's memoir on the proper vessels, which the French Academy of Sciences honoured with the prize in 1833. The extract contains little more than what has previously been published by M. Schultz, and as we may look forward to the

* Meyen's Report for 1835, p. 32.

+ Pflanzen-Physiologie, ii. tab.ix.

$\ddagger$ On the Palo de Vacca, or Cow Tree, of South America.-Lond. and Edinb. Philosophical Magazine, 1837, xi.p. 542.

$\S$ Ann. des Scienc. Nat. 1837, i. p. 257. 
appearance of this celebrated and original memoir in the present year, I consider it more advantageous to reserve my views on its results for the next report.

It is well known what importance M. Schultz attaches to the milky sap or proper vessels, but it is still better known that other botanists do not concur in his views; we find that the most distinguished physiologists of our time have entirely contested the most important points of these doctrines. Hitherto I was the only observer who defended against unjust attacks the statements respecting the circulation of the sap and the existence of a distinct vascular system, as M. Schultz and several others had previously taught. I did not proceed further into this theory of the circulation in plants, for my own observations differed almost constantly from those of M. Schultz. Notwithstanding this general opposition of physiologists, M. Schultz still asserts, that the vegetable kingdom can, properly speaking, be naturally divided only in accordance with his discoveries respecting the circulating system as laid down in his system of plants. I perceive this at lcast from a eulogium of this system, which a scholar of M. Schultz, a student from England, by name Ch. S-n, has published under the form of a review of Meyen's New System of Vegetable Physiology, $\mathrm{i}$. Berlin, 1837, in the November Number of 1837 of the Jahrbuch für wissenschaftlichen Kritik. In this anonymous production it is plainly stated that my system of vegetable physiology does not fulfil its object, because no notice is taken of the application of M. Schultz's discoveries to the basis of a natural system of plants. I need only remark by way of explanatory appendix, that $\mathbf{M}$. Schultz has a considerable share in the editing of the above Journal.

As to the utility of a system of plants, be it founded on actual or alleged anatomical or physiological discoveries, the opinion of systematists alone can decide, and these (I will only mention M. DeCandolle,) have declared themselves totally against the system of M. Schultz. 
Anatomical Observations on the Elementary Oryans of Plants.

M. Unger* has observed in the genera Helosis and Langsdorffia extremely thick-sided parenchymatous cells with large and ramified dotted ducts; in Helosis brasiliensis thirteen layers of such thickened cellular walls were enumerated, and in Langsdorffia hypogea even to the amount of thirty layers, which are traversed by dotted ducts, whose diameters measured between 0.0017 and 0.0652 ; they are very neatly figured. The ramification of such dotted ducts was however published by me some time previous. M. Unger is of opinion that such thick-sided cells occur in most plants, while I can find them only in a proportionately very small number. Some cases where these thick-walled parenchymatous cells make their appearance under very remarkable circumstances, I will here enumerate. I have observed that the hard masses of the so-called stones in the inside of pears consist of larger or smaller aggregations of such thick-sided cells, similar to those discovered by M. Mohl in Hoya carnosa. The parietes of these cells increase at times so much in thickness that their cavities almost entirely disappear, and the mass becomes harder than horn and is indigestible. Du Hamel (Book, III. cap. 2.) has already given a very diffuse but elaborate report on the occurrence of stones in pears. According to him, the stones are diffused through the whole substance of the pear, and their presence is said not to be accidental. The occurrence of these hard masses is fully discussed by Du Hamel, but in my opinion more elaborately than exhibited in nature. This substance, he remarks, appears to fall into fine white granules which remain somewhat transparent, so that some of the vessels which ramify in them can be observed. Now these fine granules are the simple cells with thickened walls, and the ramified vessels present themselves under modern microscopes in the shape of ramified canals in the substance of the cellular parietes. The circumstance of the soft cellular tissue around the hard masses being more or less radiately arranged, is especially worthy of attention.

* Beiträge zur Kenntniss der parasitischen Gewächse.-Annalen des Wiener Museums, ii. p. 38.

+ Neues System der Pflanzen-Physiologie. Berlin, 1837. I. S. 25. 
The septa of the parenchymatous cells of Eriophorum vaginatum in full-grown specimens are generally very thick towards autumn, but at the extremities of the rays of this radiate cellular tissue, which form the oblique septa in the airducts of this plant, other distinct expansions are found, connecting the extremities of the rays*; and a number of simple and ramified dotted ducts also occur in these, by which the communication in the adjacent cells is facilitated. The forms of this radiate tissue, which originate from these expansions of the radial extremities, are among the most interesting hitherto observed.

Thickened parenchymatous cells occur even in the interior of the soft substance of the petals, and they are very abundant in dots and are frequently very irregularly formed, for instance, in Magnolia grandiflora.

Similar cells with thick walls, only somewhat elongated, were found by M. Unger at the margins of the ligneous bundles of Helosis and Langsdorffia; he calls them prosenchymatous cells, yet I think that they are only protended thick-sided cells of the parenchyma, similar in every respect to those which occur at the sides of the ligneous bundles of common Monocotyledons : I do not however recognise them as cells of the liber. In Langsdorffia five to eight only of such thick-sided cells are united into a bundle, but in Helosis they are situated in the form of a half-moon at the inner sides of the bundles, while in Langsdorfia they are abundantly diffused through the entire stock, both within and at the exterior of the vascular circle. M. Unger supposes that for this reason a similarity in the structure of the stem of Helosis and Langsdorffia with that of the stems of ferns may be inferred. I have also found in the stem of Pandanus anastomosing ligneous bundles peculiar to these parasites.

The occurrence of spiral tubes in all true parasites is at present well ascertained; and M. Unger has also convinced himself of their occurrence. The spiral tubes of the Rhizanthece belong mostly to the reticulated and porous, and have short articulations.

I have published a memoir on the epiderrnis of vegetablest,

* Neues System der Pflanzen-Physiologie, Berlin, 1837, i. p. 5.

+ Wiegmann's Archiv, 1837, p. 211-228. 
in which I have principally brought together all that we actually know respecting the structure of this substance at the present day. I showed that even Ludwig was acquainted with the cuticle and first started this term; that further, this term must, it is true, be retained in vegetable anatomy, but that the cuticle is decidedly no distinct membrane enveloping the surface of the cells of the epidermis, and much less can it, as M. Valentin endeavoured to demonstrate, be considered as an intercellular substance. I referred to cases in which it might be distinctly seen, that even the cuticle, be it ever so thick, is composed of the upper sides of the cells of the epidermis, for the lateral lines of union of those cells are seen to traverse the cuticle, and indeed quite to the surface. This is best seen on any well-prepared horizontal section of the leaves of Aloe candicans. I have also drawn attention to an aperture peculiar to the cuticle*, and which is situated immediately above the true stomates of the epidermal glands. In the genera Aloe and Agave this peculiar formation is very common. I call it a prostomate (Vorspalte); between it and the true stomate of the epidermal gland there exists a greater or less space, which is also filled with air, and is continued through the stomate into the respiratory cavity.

I also drew attention $†$ to some peculiarities in the epidermis of various Orchidea. In Pleurothallis and Stelis the epidermis of the leaves exhibits peculiarly formed funnel-shaped cavities, which traverse the whole layer of the cells of the epidermis, and project as deep again into the subjacent cellular mass. Pleurothallis and Stelis offer epidermal glands with stomata only on the under surface of the leaf; these cavities, however, occur on both surfaces, on the upper surface more frequently. than on the under. The cells, more immediately connected with the formation of these cavities, mostly contain large drops of oil, which are sometimes found in almost all the cells of the epidermis of the upper surface of the leaf. As I imagined I had observed that these cavities were not closed, but open, and might thus effect a free communication between the atmospheric air and the diachyma of the leaf, I regarded them as representatives of the stomata. M. Schleiden, in the following

* Pflanzen-Physiologie, Tab. V. fig. 1.

+ Wiegmann's Archiv, 1837, p. 421. 
number of the Archiv, which, however, appeared only this year, demonstrated that most of these observations were in some respects erroneous, in others incomplete. He observed that the cavities were not open, but closed by a membrane somewhat above their centre; he further saw that the cells of the epidermis, contiguous to the cavities, were peculiarly arranged; and lastly, that the cellular parietes adjacent to the cavities had a reticulate porous appearance which is represented in his drawings.

M. Schleiden connects these formations with the cavities which originate in various plants by the falling off of the hairs, with which the leaves are so frequently clothed in the bud. He says that I had long since found quite similar formations on the under surface of the leaves of Nymphcea odorata, but the history of their development had been followed by him in 1833. M. Schleiden found that the leaves of Nuphar luteum, so long as they remain in the bud, are-clothed with long silky hairs which subsequently fall off, and then exhibit open cavities, which have the appearance of round scattered cells. I have at this moment no leaves of that plant at hand, but unfortunately this explanation of Dr. Schleiden is not applicable to the leaves of the Nymphcee examined by me, as N. odorata, cœrulea, alba (also the small variety). The round cells on the under surface of the leaf of these Nymphrea may be observed in the buds, and their outer side, somewhat vaulted, projects above the surface of the epidermis; a similarly formed cell is situated immediately below each of these round tabular cells, and both together have in general the same longitudinal diameter as the adjacent cells of the epidermis. I compare these round cells on the leaves of the Nymphree with those similar cells observed by me on the leaves of Zea Mays*, of Saccharum officinale, \&c., which sometimes grow into hairs, but in most cases remain undeveloped. And this is undoubtedly the case in the Nymphae, for some of them exhibit in their developed state hairy under surfaces of the leaf.

The examination of the leaves of Pleurothallis ruscifolia in various stages of development, which I have only lately been able to perform, taught me to correct my error, but also showed, that M. Schleiden may in his otherwise highly valuable

* Pflanzen-Physiologic, i. Tab. V. fig. 20. 
observations commit oversights. Those peculiar formations on the epidermis of the leaves of Pleurothallis, the closing of which by means of a cross septum had escaped me, and had thus given a false indication of their probable design, originate in simple petiolated glands, which first appear as simple cells of the cellular layer situated immediately beneath the epidermis. The epidermis is in these cases actually broken through, even the cuticle accompanies the surface of the funnel-shaped hollow, which has originated in this rupture, far down into the hollow, but not to the bottom, as M. Schleiden has represented it. Just as in other cases similar ruptures in the cellular layer of the epidermis are closed by epidermal glands with their stomata, so in Pleurothallis the closing of these funnel-shaped ruptures is accomplished by means of the simple glands. At its first appearance on the young leaf the gland presents itself as a simple cell, which is only a little longer than the vertical height of the cells of the epidermis, and at the end projecting beyond the surface of the epidermis is swollen into a club : its form is then similar to the gland of Helleborus foetidus. This club-shaped swelling subsequently separates by the formation of a diagonal septum, which still remains for some time as a vesicular cell, sometimes it is divided a second time by a longitudinal partition, but subsequently always falls off, upon which the peduncle remains in the funnel-shaped rupture of the epidermis, and its cellular septum subsequently becomes intimately united with the surrounding surface of the cuticle. Not unfrequently this cell, which has served as a pedicel, divides again by the formation of diagonal walls into two or even into three smaller cells, which latter case however is very rare. The secretion of an oily substance takes place more or less abundantly in the remaining pedicels, as also in the contiguous cells; and the peculiar arrangement of some small cells around the base of the glandular pedicels (which always originate from the subsequent separation of the larger) is similar to that which occurs at the base of many hairs, where they are raised with these above the surface of the plant. I also found on a very young leaf an entire glandular apparatus, such as is commonly situated between the cells of the epidermis of Pleurothallis, projecting beyond the surface of the leaf. 
M. Mohl has published a memoir on the structure of the porous vessels of dicotyledons*, and I have also treated of this subject in the fifth chapter of my work, but I have called these porous ressels dotted spiral tuibes.

M. Mohl adopts two varieties of dotted spiral tubes; in the one the walls are lined equally on both sides with dots or pores, according to M. Mohl's statement ; the oak, alder, \&c.., offer examples; while in the other variety the tubes exhibit a totally different structure at various parts, as in the lime, the Italian poplar, and in many other woods. In the lime, the walls of these ducts, which abut on the ligneous cells, have all the appearance of spiral tubes capable of unrolling, while the other walls, by means of which these vessels cohere among themselves, exhibit the series of dots, which are always situated between two convolutions of spiral fibre. It is evident, therefore, from these observations, says M. Mohl, that the dotted spiral ducts belong to the system of spiral tubes, and the most essential part of their formation consists in this: that between the coils of the spiral fibre there is a dilated membrane, on which, between every two fibres, a series of dots is situated. According to my view all the coils of spiral fibres are clothed with a fine membrane, and the coils of fibre take some part in the formation of the dots by reciprocal cohesion. In proof that the dotted spiral tubes belong to the system of true spiral tubes, I have mentioned a case in the stem of a gourd, where at times the large spiral tubes are not metamorphosed into dotted tubes, which in this plant is otherwise very frequently the case.

M. Mohl does not consider it as improbable that the thickening of the membrane of spiral vessels may be effected by the deposition of new layers upon their inner surface, exactly as with the thickening of cellular membrane; and I have actually observed this in several cases, representations of which are given in my Vegetable Physiology, plate III. figs. 15 and 16.

M. Mohl and I also agree in the explanation of the structure of the dots, namely, that they are formed precisely in the same way as the large dots of coniferous and cycadeous wood; this indeed could not but be expected with the use of

* Abhandlungen der mathem. physik. Klasse der Akad. der Wissensch. zu München, 1837, i. p. 445. 
such perfect instruments ; for most of the incorrect observations of former times can only be ascribed to the defective microscopes of that period.

M. Mohl compares the development of the porous vessels with that of cells, as series of thin-sided cell-like cavities constitute their base, in which the spiral fibres are then formed. M. de Mirbel had already started a similar notion, that vessels are formed from cells, and the observation of the porous tubes in the earliest stages of their development is said to prove this. About this time the individual cells are frequently found perfectly closed, and the thin membranous diagonal partitions subsequently disappear, while they remain in many cases during the whole lifetime of the plant, but take a structure quite different from that of the lateral partitions, which has already been demonstrated in various plants. I am well acquainted with the cases which might lead observers to the above views, but I also know of numerous cases in which the very opposite may be observed, where both the simple as well as the metamorphosed continuous spiral tubes separate in the course of development more or less completely by constriction, and form articulations arranged in series.

The cross partitions of the single articulations of the metamorphosed spiral tubes are either broken through by a very large aperture or by a number of fissures and longitudinal pores: nay, even the oblique partitions of the large dotted tubes in the wood of some species of Ephedra are pierced, and that by the large round holes, which generally occur in them arranged in two parallel rows. M. Mohl observes that phytotomists have considered these horizontal sides as lateral sides of the tubes, which was also probably owing to bad instruments, for the inclination of these horizontal walls to the lateral is so exceedingly small, that they may even be regarded as inclined terminal surfaces of the prosenchymatous cells, with which the superposed cells stand in connexion; $I$ at least have declared in favour of this latter opinion. The disappearance of the horizontal walls in the dotted spiral tubes is, as M. Mohl thinks, to be compared to the formation of the vessels of the latex, which also are said to originate from cells standing above one another, as M. Unger (see p. 30) has tried to render probable by a drawing. The most varied views 
exist however on this subject, and are as diametrically opposed to one another as those on the metamorphosis of the spiral tubes. According to M. Schultz, constrictions and the formation of articulations of the proper vessels originate with the advancing age of the plant; in the young state these vessels were still unarticulated. According to my observations, the proper vessels are neither in their youth nor old age provided with cross partitions, but exhibit in the latter state some constrictions which are independent of external circumstances. According to M. Mohl, the continuous vessels of the latex originate from cells, whose cross partitions disappear, to which, in consequence of numerous researches on this subject, I am decidedly opposed.

The distinction between dotted and reticulated spiral tubes consists, according to M. Mohl, in this; that in the latter the organic matter used for the further development of the vessels does not deposit itself in the form of a membrane between the coils of the spiral fibre, but goes to increase the spiral fibre itself, both with respect to its thickness as well as to its breadth. In the dotted (porous) spiral ducts of dicotyledons, on the contrary, this substance is deposited in the form of a membrane between the coils of the spiral fibre on the original membrane of the vessel.

Neither can I concur in these statements : the thickening of the walls of both those stages of metamorphosis of the spiral tubes takes place in quite a similar manner; the principal reason for the change into reticulated and into dotted spiral tubes is to be found only in the arrangement of the individual coils of the spiral fibre. If the coils are widely apart they may fall merely into annular tubes or be metamorphosed into reticulated spiral tubes; on the contrary, if the coils are close together, only striped and dotted spiral tubes and not reticulated can originate. This is very easily confirmed in stems of Cacti, in the inflorescence of Musa, \&c.

On the occurrence of spiral fibre and of pores in the cellular septa of the leaves of Sphagnum much has already been written; but, as it appears, this subject will be first cleared up in the present year (1838), and that by my having now discovered the cause which gave rise to the different views of various observers on this subject. Even many years ago there existed a 
great difference in the observations and in the views on the structure of the leaves of Sphagnum; several other botanists and myself regarded the fibrous formations occurring on the inner surface of the cellular walls of those plants as spiral fibres, similar to those which occur in the cells of anthers; and M. Mohl, who, on the contrary, declared these spiral fibres to be partial thickenings of the cellular walls, has at present also adopted the former view, the correctness of which can no longer be doubted. It is however very different with respect to the observations on the occurrence of large round apertures on the partitions of the cells in Sphagnum: Moldenhauer was the first to observe them; I denied their existence, which however was again confirmed by M. Mohl. Although I again took in hand my plants of Sphagnum, and observed with a microscope by Ploessl, yet I could never find the alleged pores, but either perfectly symmetrical septa, as I have correctly figured them in my Vegetable Physiology, i. pl. III. figs. 10 and 11, or such as possessed circular, verrucous prominences, which seen from the side projected beyond the surface of the cells; but seen from above, presented mere circles, indicating the circumference of those verrucous prominences. These circles were regarded by Moldenhauer and Mohl as open apertures, whereas I had always observed them closed, even when I had coloured the cellular partitions brown by means of iodine. M. Mohl* replied to these statements very fully and forcibly in a separate Inaugural Dissertation, and maintains the existence of pores in the septa of the cells of Sphagnum; however, as I first noticed during the past summer, both conflicting parties are right and wrong. A very great quantity of forms of Sphagnum, and among them principally Sphagnum acutifolium, which grows about Berlin in very beautiful specimens, exhibit quite smooth and unruptured septa, and $I$ have never found pores in them, although I have made frequent observations on them. Other forms, on the contrary, exhibit the verrucous circular prominences; and others, among which is the common Sphagnum palustre, present large circular pores in the septa, which originate in the falling off of the

* Anatomische Untersuchungen über die porösen Zellen von Sphagnum, Inaug. Dissertation von $\mathrm{Ph}$. Schlayer. I regard Prof. Mohl as the author of this, as well as of all other dissertations occurring in this report.-MEXEN. 
little warts*. An observer must be very unskilful, who having such a Sphagnum before him should overlook the pores. It follows from the above, that it cannot be laid down as a general rule, that the septa of Sphagnum are perforated by great pores, for there are some which remain to the very end of their life destitute of them.

At the end of the above dissertation M. Mohl has published various observations against the metamorphosis of spiral fibre into annular fibre, a phænomenon which he designates as one founded upon no fact and purely hypothetical, while I have again defended this alleged hypothesis. The annular spiral ducts originate only from those simple spiral tubes whose sides consist of a single or of few spiral fibres; thus I observed in a common bean an annular duct, which belonged to a spiral tube of two spiral fibres. In order to show the improbability of this division of the spiral fibre into definite portions, M. Mohl asks by what force could such a division of the spiral fibre be effected. However, this question may easily be answered; for can we not actually observe in a thousand other cases a similar division of simple threadlike formations into pieces of a like size, especially the constriction of such into articulations and sporangia? But even the separation of the spiral fibre is actually to be seen in some places, as for instance, in Cactus cylindricus, where the spiral fibres, which there generally occur separated in rings, are very large ; it is only necessary to assist here a little with the knife, and the spiral fibre breaks or falls into the proper position, which always corresponds to the other free extremity, so as to form with this a perfectly closed ring. The reason that the division of the spiral fibre does not take place under our eyes, as is the case with many similar phænomena, is evidently this; because this process happens at the very earliest formation of the spiral tubes, and hitherto no one has observed the formation of spiral fibre. If we examine long portions of the beautiful simple spiral tubes in the stem of Tradescantia and of the common bean (Vicia Faba) we observe that in the course of the complete spiral tube some small places occur where the spiral fibre has become converted into rings; nay, below these rings, there exist again frequently some, which still consist of Pflanzen-Physiologie, ii. 52. 
two or three coils of spiral fibre; and this very appearance seems to indicate that they have been formed by dissolution from the common spiral fibre.

M. Corda* has made the interesting discovery, that the sporangia of the genus Trichia possess the same structure as the elaters of the Jungermannia, that therefore they are elongated cells on whose inner side spiral fibres coil ; hitherto no formations of spiral fibre were known in the fungus tribe. These elaters form the hairy tissue of the genus Trichia, and are situated between the rounded masses of spores. The number of the spiral fibres varies in the elaters of the different species of this genus; in Tr. varia it is simple or even double; in $T r$. nitens there are more than ten fibres, in $T r$. chrysosperma ten to eleven, in Tr. fallax and Tr. clavata six to seven, in $T r$. Lorinseriana and rubiformis five such fibres wound spirally and parallel. The epidermis of the elater-cell is simple, smooth, folded, or furnished with warts, which frequently disappear at the ripening of the spores.

From these observations M. Corda proceeds to general considerations on the resemblance in form of the spiral fibrous cells and of the spiral vessels. Attentive observation of nature, observes M. Corda, will recognize with us in the spiral fibrous cell of the lower forms the rigid image of a constant and necessary form of organ in its higher members (the spiral vessels). M. Corda found in Nepenthes destillatoria the spiral fibrous cell, as such, at its highest stage of development ; it is diffused in great quantity in the parenchyma of all parts of this plant and conveys air! This important discovery is only a confirmation of the view, according to which cellular membrane is composed of spiral fibres, in favour of which I am at present acquainted with hundreds of facts. M. Corda however errs very much if he thinks that the short articulated spiral tubes are without enveloping membrane, a subject which is treated of at length in my Vegetable Physiology, $i$. 399. M. Corda once more recommences the dispute respecting the destination of the dotted ducts, for he fancied he had demonstrated, on his tour through Germany, that these ducts are vessels by passing a hair through their cavities! (?) Un-

* Ueber Spiralfaserzellen in dem Haargeflechte der Triehien. Prag. 1837. 
fortunately he gives no definition of vessel and cell; were this done, it would be possible to show directly, that in this case it is merely a dispute about words, which I have endeavoured to put an end to in my Physiology, i. p. 78, \&c.

M. Biot* has coloured the flowers of white hyacinths red, by absorption of the sap of Phytolacca decandra, an experiment performed more than a hundred years ago, and which since then has been frequently repeated by various observers, but not always with success.

\section{Anatomico-physiological and Chemical Researches on the Colours of Vegetables.}

We have also obtained in the past year very important additions to the doctrine of the colours of plants. M. Mohl † has especially examined in an anatomical and physiological point of view, the winter colours of those plants which retain their leaves during this period of the year; he divides these plants, in reference to the preservation of their leaves, into several, although not very accurately defined, groups. In one portion of the plants growing wild, or frequently cultivated in the neighbourhood of Tübingen, all or most of the leaves developed in summer pass not only through the winter, but also the following or even several summers. These plants form the first group, to which belong most of the Conifera, Hedera Helix, Iberis sempervirens, Sempervivum, most of the species of Sedum, Empetrum nigrum, Azalea, and all other plants with coriaceous and evergreen leaves.

A second class of leaves, which remain green during winter, is formed by those biennials, or even perennials, which have rosettes formed from the so-called radicle leaves, which are developed in the course of the preceding summer or autumn in the plants grown from seeds, or from buds which shoot out from the rhizoma. The rosettes retain their freshness during the winter but die off in spring, and this takes place from without inwards; frequently the inner leaves only partially die off. The life of these leaves extends only to the next period of vegetation, and under this group are classed

* L'Institut, 1837, p. 1 .

+ Untersuchungen über die winterliche Färbung der Blätter. An Inaugural Dissertation, Tubingen, 1837. 
the species of Plantago, Dipsacus, Echium vulyare, Verbascum Lychnitis, Thapsus, nigrum, \&c., many Syngenisiste and Umbellifere, species of Lychnis and Potentilla, Fragaria vesca, \&c.

The third class contains partly annuals, which have germinated in autumn, but flower in the following spring, and partly perennials, which have developed new branches in autumn. They differ from the plants of the second group, properly speaking, only in this respect, that their leaves form no rosettes spread out on the soil, but have a longer stem which is covered with leaves in every stage of development. Under this section M. Mohl includes a great portion of the grasses, for instance, Bromus mollis, many Euphorbia, Veronice, Antirrhinum majus, Cerinthe minor, Senecio vulgaris, Sonchus oleraceus, Hypericum perforatum, \&c. The leaves of these plants live very rarely through a whole year.

The first question M. Mohl endeavours to solve is, whether the red colouring of the leaves in winter is a phænomenon independent of the autumnal colouring of dying leaves, and of the red colouring of leaves in the process of development, or whether it must not rather be ascribed at times to the one, at times to the other of these causes? A number of plants are enumerated whose leaves are perfectly green in summer, but during winter assume a more or less deep red tint and in summer again become green, which for instance may be observed in various species of Sedum, Sempervivum, and also on the ivy. In the leaves of the second and third divisions we must ascribe the origin of the red colour to the influence of the winter cold, as here the leaves in all stages of development take this reddish or brownish tint. As, however, we find, says M. Mohl, on the same plants, leaves which have this red colour in the winter but die in the spring, while other leaves become red-coloured in the same way, and do not die in the spring but again become green and continue to grow, \&c., we are justified in denying this connexion between the production of a red colour and the dying off of the leaves, and must admit that the production of the red colour in leaves in autumn and in winter is owing to a change in the physiological functions of the leaves occurring at this season, but that the falling off of the leaves is only accidentally contemporaneous with that 
period, while in others it takes place many months afterwards. The red colour is generally produced by the perforations of insects and by the development of Entophyta, where the leaf merely suffers an interruption in its normal development, but which is not accompanied with death.

M. Mohl, on the other hand, points to a resemblance which appears to exist between the production of the red colour in leaves and that in fruits; this might perhaps be compared with the process of ripening of the juicy envelope of fruits. M. Mohl supposes that the formation of red colour in fruits is independent of nutrition, as fruits even ripen when separated from the plant in an immature state: much however might be adduced against the adoption of this view, and I cannot concur in it.

In leaves, it is the cold, observes M. Mohl, which interrupts their vegetative process, and causes, when light acts on the leaves, red colour to be formed in them. In pericarps, the development of which is a more complicated process, it is the warmth which favours the perfect development, and thus hastens the last period of life. As the result of these observations it may be admitted that the formation of colours accompanies various interruptions of the normal process of vegetation of the leaves and of their elaboration of the crude sap; on the other hand it must be considered as merely accidental that it occurs in those cases in organs near death, since it happens, as I have stated above, frequently in leaves which continue to live for some time and again become green.

If leaves which have become red in winter be examined, we find the chlorophylle little or not at all changed, but perceive together with this a red colour in the cells, which, for the most part, is situated in the cells of the epidermis. I have however frequently observed red-coloured cellular sap containing green-coloured globules, even in the green cortical layer. It is more seldom that red cellular sap is developed only in the outer layers of the diachyma of leaves; in this case also, says M. Mohl, it is found in leaves which recommence their vegetation in spring more confined to the outer cells, as in Chelidonium majus, Hedera Helix, \&c., while in leaves which die off in spring the formation of colour affects nearly all the cells of the diachyma, as in Isatis tinctoria. 
M. Mohl justly doubts, on second thoughts, whether the origin of the red cellular sap can be explained in the cases above-mentioned by a dissolution and change of the chlorophylle, as the green globules of the sap occur in the red sap as beautifully coloured as in general.

M. Berzelius* has examined the autumnal colour of plants in a chemical point of view; he only observed red leaves in trees and shrubs whose fruits are red. However this does not stand good for the whole vegetable kingdom, for M. Mohl and many others have mentioned various plants in which red leaves occur with fruits of a different colour. M. Berzelius examined the foliage of the cherry tree, and especially that of the red currant, which frequently appears as red as the ripe berries. The colouring matter was extracted with alcohol, which after distillation left behind a red fluid, that had first to be filtered from the precipitated resins and fats. The colouring matter is soluble in water, and agrees therefore probably with the red substance which M. Marquart extracted from red flowers, and declared to be an acidulated anthocyan. M. Berzelius terms this red colouring substance Erythrophylle, Leafred, and is opposed to the view of this red colour being only an acidulated blue; he found it however in the fruits of the cherry tree and black currant, so that it is evidently closely related to Marquart's acidulated anthocyan.

Of considerable interest are M. Berzelius's observations on the yellow colour of leaves in autumn; this substance does not coincide with Marquart's anthoxanthin, but is a peculiar fat, an intermediate body between fat oils and resins, which retaining its property of being of difficult solution in alcohol, and smeary and greasy, may be bleached. He calls this substance Xanthophylle, Leaf-yellow, and prepared it by cold infusion of the yellow leaves in strong alcohol, continued for fortyeight hours. When the infusion is evaporated to less than one-eighth of the quantity, a granular substance settles on cooling, and by continued distillation a yellow soft smeary substance is obtained, which, like the granules above-mentioned, presents the colouring substance of the yellow leaves. The

* Ueber die gelbe Farbe der Blätter im Herbste und über den rothen Farbestoff der Beeren und Blätter in Herbste.-Ann. der Pharmacie, vol. xxi.p. 257-264. 
solution of this substance in alcohol is so precipitated by water that a pale yellow milk is formed. Xanthophylle is dissolved by æther and becomes brown in concentrated sulphuric acid. Respecting the formation of the xanthophylle from chlorophylle M. Berzelius observes, "We have every reason to suspect, that with the disappearance of the green colour and its change into yellow, the xanthophylle is produced from the chlorophylle by a change of the organization of the leaf effected by cold, and the alteration in the organic process thus caused." It was not possible to produce this change artificially.

The brown colour of the foliage has nothing, says M. Berzelius, in common with the yellow; it is produced by an extract at first colourless, which becomes brown by the action of oxygen; yet it may also be observed in this latter case, that all the cellular membrane of the leaf has acquired a brown colour which cannot be extracted even by digestion in weak alkaline solutions. The various proportions in which this brown extract occurs with the xanthophylle give the autumnal colours of the leaves a number of tints.

Notwithstanding all the beautiful researches which have been made of late years on the formation of colours in plants, both in anatomical as well as chemical respects, we are yet very far from the solution of this enigma, as we shall perceive immediately from the following observations.

M. J. Decaisne* has published a very elaborate examination of Rubia tinctorum, and allied species, which are cultivated for the purpose of obtaining the madder or red colour. I shall have occasion to notice this work frequently, but shall here only mention those observations which relate to the formation of the well-known colouring matter of these plants.

M. Decaisne is convinced from numerous observations that the colouring substance in Rubia tinctorum, and in general in the Rubiacea, does not occur in peculiar vessels or secretory organs, but in the interior of the elementary organs. It is usual to employ only the root in the preparation of the colouring substance, in which it occurs in great abundance; if how-

* Recherches anatomiques et physiologiques sur la Garance, sur le développement de la matière colorante dans cette plante, sur sa culture et sa préparation, suivies de l'examen botanique du genre Rubia et de ses espèces. Bruxelles, 1837, 4 to. avec $10 \mathrm{pl}$. 
ever the stem of full-grown plants be examined, larger or smaller spots are here and there found, where the cells and spiral vessels are filled with it.

In the living root of the Madder only yellow colouring matter is observed, which fills in its dissolved state the various elementary organs. In very young roots the colour is still weak, but the older the plant the more intense it is. Here therefore the yellow colouring matter is dissolved in the cellular sap, an observation which I made some years ago in a different plant in its young state. This yellow substance is evidently of quite a distinct nature from Marquart's anthoxanthin, which is mostly a resinous extractive of very difficult solution. As soon as the yellow sap of the Madder root comes in contact with the atmosphere it takes a red colour, and a granular substance forms in this red sap. Even the cotyledons, as soon as the young plant has come forth, contain in their cellular tissue a yellow sap, which, on their being cut, very soon took a deep red appearance. This change of the yellow cellular sap, in fine sections placed under the microscope for observation, M. Decaisne has elucidated by a number of drawings. The cells are seen with fainter or deeper yellow saps, and in other cells this sap has taken a faint rosy tint, while frequently some of the intermediate cells are still quite yellow; at other places the red sap has already become deeper, and has formed a granular precipitate in the cells. When recent roots of the Rubia were perfectly dried and then microscopically examined, he observed that, although all moisture had disappeared, the cells still exhibited a yellow colour; whence he concluded, that the colouring substance is a solid, which was previously in a dissolved state in the sap, yet he could not observe it as a distinct body. I have not, it is true, examined the roots of the Rubia, but in the yellowcoloured cells of the stalk the same may be observed; and here the yellow colouring substance, after the water of the sap has been evaporated, is partly absorbed by the sides, while the remaining portion rests on their surface.

M. Decaisne also performed various experiments in order to learn more accurately the causes which changed the yellow sap of the fresh Rubice, as soon as it came in contact with atmospheric air, into red. He placed fine sections of the root in 
boiled water, and observed that they retained their yellow colour in perfectly closed vessels. Other sections were then exposed to the direct influence of various gases and isolated under quicksilver : the result of these experiments was, that oxygen and some degree of moisture must be looked upon as the causes producing the change of the yellow substance into red; oxygen alone, i. e. without moisture, produced no change in the colour. The red colour of the Madder is therefore, as M. Decaisne observes, a chemical product, entirely independent of the vitality of the plant, to which, however, belongs the formation of the yellow sap. It results at least from these interesting observations, that our knowledge of the bases of vegetable colours is not yet very far advanced. We have in this case an instance of the transition of a perfect yellow colour into the most beautiful red, and this produced by the influence of oxygen and the presence of water.

The roots of young madder plants afford but little colouring matter; from the age of eighteen months they may be used with advantage, but their colouring substance keeps on increasing to an age of three years.

M. Decaisne also performed a series of experiments to investigate the influence of light on the production of the colouring substance in madder plants; for this purpose he grew young plants exposed to various degrees of light. They were placed in glass cases which were covered with cotton, others in coloured glasses, as under red, yellow, or green glass. Another plant was grown under white glass; a third remained exposed to the open air, and a fourth was buried in the earth and covered to the height of 3 feet with loose soil. The plants which had been covered with cotton had in eight days lost so much of their colour as to appear quite pale; the plants under red glass exhibited this change of colour in a still greater degree, and those under other glass were in a similar condition. In general, these experiments on the growth of plants under coloured glasses afforded as few results as those enumerated in my first year's report (1835). According to Osann's observations, only 34 rays of light pass through red glass, while 966 are held back; light green glass transmits 630 and retains 340. We hence see how varied is the quantity of light which arrives at the plants grown under such coloured glasses;

E 2 
but we already know from other experiments by Alex. v. Humboldt, DeCandolle, and others, what a small quantity of light plants absolutely require, and that the formation of vegetable colours does not proceed from the direct influence of light.

The plant, which had been grown under ground, exhibited a change of the yellow colouring substance, namely, of the sap globules coloured by chlorophylle into the yellow colour, which was dissolved in the cellular sap; M. Decaisne has even observed this change of the chlorophylle at various periods, and has thus been enabled to follow it up more accurately; he has also elucidated these observations by several highly instructive coloured illustrations. I have observed this change of the chlorophylle into a yellow colouring substance, soluble in the cellular sap, in young plants of Viciu Faba, which had been grown immediately on their appearance in a dark situation; at the same time cells with red coloured sap also occurred. All these colours disappear if the plants are exposed for some time to light.

We have finally to notice M. Mohl's * observations on the occurrence of chlorophylle in the green coloured cellular sap globules, a subject which is for the first time specially mentioned in this memoir. About the same time a separate section of my Vegetable Physiology (i. p. 200) was devoted to the same subject: "Occurrence of coloured cellular-sap globules." The results of these observations are as follows : M. Mohl and I agree that the chlorophylle appears in the cells of plants partly in an amorphous and partly in a granular form. This and other facts respecting this questionable subject were published by me some years agot to refute Treviranus' view, that the cellular sap is never of a green colour, which is now confirmed by M. Mohl. The occurrence of amorphous chlorophylle in the cells of Conferve is noticed by Mohl, and a number of perfect plants are enumerated in which amorphous chlorophylle occurs together with granular in the cells. In Phanerogamæ, observes M. Mohl, amorphous chlorophylle is generally met along with granular chlorophylle in the

- Untersuchungen über die anatomischen Verhältnisse des Chlorophyll's. -An Inaugural Dissertation. May 1837, Tübingen.

t Year's Report for 1835. Wiegmann's Archiv., part III. 1836, p. 90. 
same cells, forming an appendix to the granules, or greater masses, presenting an amorphous gelatine in which the chlorophylle granules are immersed, \&c. These various forms are found for instance in the parenchymatous cells of leaves of many cellular plants, as in Sedum, Sempervivum, Pinus Strobus, \&c. I showed * that these amorphous masses are spread over the inner walls of the cells, and are frequently accompanied with common green globules. In the cells of the vertical layer of leaves this occurrence of amorphous chlorophylle is especially common, so that, for instance in the Cycader, the entire walls of these cells are at times clothed with it.

M. Mohl attempts to fix distinctions between the granules, which lie in the chlorophylle and the chlorophylle granules themselves, although it appears probable to him that they stand in very close connexion with each other. Here my observations do not agree with those of M. Mohl ; for the chlorophylle is properly speaking neither granular nor amorphous, but it adheres in the granules to a semi-solid mass which is penetrated by it, and the amorphous chlorophylle is consequently a gelatinous semi-fluid mass more or less coloured by chlorophylle. Of what this gelatinous substance, the basis of the amorphous chlorophylle, consists, it is difficult to determine, the quantity at the disposal of the operator being too small. The case is quite different with the substance serving as substratum to the granules coloured by the chlorophylle, which M. Mohl erroneously terms chlorophylle granules. Both M. Mohl and Dr. Schleiden † endeavour to prove in opposition to my views that they are not granules, but solid masses, which however I published two years ago $\ddagger$.

The case of granular masses being mistaken for vesicles occurred very frequently, even till within a few years, and the microscope alone was the cause, showing in some similar globules so strong a shadow round the object, as to lead to the conclusion of the presence of a distinct enveloping membrane, which even occurred to M. Mohl at that period respecting the amylum granules.

We come now to the most important subject treated of in

- Physiologie, i. p. 202.

† Beiträge zur Kenntniss der Ceratophylleen.-Linnæa, 1837, p. 331.

‡ Year's Report for 1835. Wiegmann's Archiv., 1836, p. 90, \&c. 
M. MohY's memoir. He observed, in Chara flexilis, from one to four well-defined granules situated in the interior of each of the green globules which clothe the inner surface of the cells, and which were coloured blue by iodine, and consequently consisted of amylum; the surrounding green envelope became on the contrary brown. This fact I confirmed, having observed it accidentally during the past year on Chara flexilis, and indeed on cells that were in a state of decomposition; but I also found that it is very variously circumstanced in different individuals, not only in C. vulgaris, but also in Chare with simple cuticle, which had grown for years in my room. In most cases the green cellular sap globules were coloured brownish by iodine, especially in the young thriving branches; in other individuals, and even in single cells, there might frequently be seen a very regular division of these green elliptic granules into two or three smaller ones and of a rounder form; the green enveloping mass, of which at first the whole consisted, at the same time gradually disappeared, and it was now evident that the newly originated globules were coloured blue by iodine. Although I constantly grow Chare in my room, yet I have never been able to discover the causes by which the formation of the amylum granules in the green globules which clothe the inner surfaces of the cells of the Chara, is effected; in Chara vulgaris it might frequently be observed in old cells growing in the dark, where the outer cellular layer had separated by decomposition from the membrane. We however know that new branches are developed from the axes of such old plants though the individual continues to live; it therefore appears to me that the occurrence of the amylum in such cells is destined for the nutrition of the young plants; but in no way can it be laid down as a general rule, that the green cellular sap globules of the Charce have amylum granules for nuclei. I can at any time show Chara whose green globules indicate not a trace of amylum.

M. Mohl also found that the larger green globules which so frequently occur in various Conferva, contain a nucleus which is coloured blue by iodine; but neither is this found at all times in Conferva, as I have shown by repeated observations*. M. Mohl's further observations go to prove the oc-

- Note.-Amylum is also present at times in the Closteria under similar 
currence of amylum even in the green globules of the more highly developed plants, which is very easy in many water plants and also in some succulent land plants; it was observed in Tradescantia discolor and in Vallisneria spiralis, where each globule exhibits a large amylum nucleus. Dr. Schleiden (l.c. p. 531.) observed the sap globules of Ceratophyllum, and states that they consist of amylum surrounded by chlorophylle. Similar observations were made and published by me eleven years ago on Vallisneria, and three years back on Tradescantia, Zanichellia, \&c., but explained in a different manner, and as it appears more correctly; I observed that the amylum granules in Vallisneria and in the other plants mentioned, where they occur in the cells situated near the surface, were coloured by chlorophylle, and this metamorphosis of amylum into chlorophylle begins at the surface and increases the more the globules are exposed to the influence of light, or in fact to the influence of a more powerful process of carbonization. This is the case with the occurrence of amylum granules in the so-called chlorophylle globules, which in nature do not exist; as Dr. Schleiden also very correctly observes, that chlorophylle is always an homogeneous, amorphous, waxy substance, but I can certainly not agree with his subsequent statement that it is spread over the amylum granules and cellular partitions. Chlorophylle, this waxy substance, is formed by the plant in very different ways, sometimes of amylum, at others of semifluid, slimy substances, which are produced in the cellular sap, at times of those more solid substances which most generally constitute the base of the green sap globules, and which assume a brownish tint with iodine, and as I suspect, consist of coagulated nitrogenous nutritive substances. These substrata are also formed in those cases where the development of chlorophylle is suppressed, but they themselves are subject under such circumstances to be dissolved and converted into other substances.

M.Mohl also found similar chlorophylle globules containing amylum which becomes blue by iodine in separate portions of many plants, for instance, in the cells of the cuticular glands

conditions, in which I have several times coloured the larger green globules, as well as all the smaller with which the Closterium was filled, blue or violet-blue, by means of iodine. - Rep. 
(termed by him porous cells), in the cells of the epidermis of Aspidium exaltatum, of Calla athiopica, in the diachyma of Abies pectinata, Pinus alba, Camellia japonica, \&c., and I have observed them in the elementary organs of the medullary sheath and in the cells of the medullary rays of various trees and climbers*.

A second variety of chlorophylle globule, immediately connected with the form just described, possesses, says M. Mohl, sharply defined outlines in common with the preceding, but is distingnished from it by each chlorophylle grain containing several amylum granules. The envelope of these granules appears sometimes smooth-edged and sometimes crenulate when it adheres to the circumference of the individual amylum granules. Similar grains are met with in the diachyma of Aspidium exaltatum, Sempervivum tectorum, and in the cells of the pith of Stapelia maculosa, \&c.

Another form of the chlorophylle grain incloses several, but very minute globules of amylum, the blue colour of which on their combination with iodine is not easily perceived, the embrowned coating of the chlorophylle being too thick. Such chlorophylle grains are found, says M. Mohl, between those of the former form passing into them through several intermediate stages, for instance, in the leaf-petioles of Pothos lanceo$l a t a$, and sometimes in other cellular layers, as in Orontium japonicum, Sedum anglicum, \&c.

The latter form constitutes those which are generally rather large, but less sharply defined than those described : under a high magnifying power a number of very minute particles may be discerned in them, which are coloured by iodine of a deep brownish-yellow. Nevertheless, M. Mohl thinks that these minute granules also consist of amylum, in which opinion however I cannot agree; for after previous extraction of the chlorophylle with rether a yellowish white mass remains, which is coloured brown by iodine, and the cellular sap globules coloured by chlorophylle occur in most plants in this form.

M. Mohl now starts the question, whether the amylum granules are formed first and the coating subsequently deposited around them, or whether the chlorophylle is first formed and

* Physiologie, i. p. 372, \&c. 
the granules subsequently originate in it. M. Mohl decides the question in accordance with his observations of nature; in some cases the chlorophylle is first formed, and the amylum granules subsequently developed, as for instance, in the Spirogyra, Link, and in the Chara, as I have previously mentioned; but in other cases the amylum is found first, and then the formation of the chlorophylle takes place. The third case, and which is the most frequent, M. Mohl has not noticed, where the formation of the chlorophylle stands neither previously nor subsequently in connexion with the formation of amylum, where it has for substratum a semi-solid yellowishwhite substance which is coloured brown by iodine.

But even in the Conferva and in the Spirogyrce it may pretty generally be stated that the formation of the chlorophylle proceeds from the amylum; for it is the amylum granules which are dissolved at the formation of the seed in the Spirogyra, unite with the green mass present, and produce the substance for the formation of the two membranes which surround each seminal grain of these plants ; they then again condense, and adopt even in the seed a spiral position at the germination of the young plant which proceeds from a prolongation of the third or innermost membrane, but are again employed to produce the substance for the formation of amorphous masses coloured by chlorophylle. What is the physiological object which nature probably attains by this disposition of amylum in leaves? M. Mohl is rather inclined to answer, that it is a reserved nutriment destined to be employed in those plants which flower but once for the development of the fruit; and in the perennials, plants losing their leaves in autumn, is carried into the stem and there deposited as material (?) at the expense of which the buds are said to develop in the succeeding spring.

M. Payen* has prepared lichen starch from Icelandic moss, and after having dried it at a temperature of $100^{\circ}$ subjected it to an elementary analysis, which gave $\mathrm{C}^{12}, \mathrm{H}^{10}, \mathrm{O}^{5}$, a composition very approximate to the amylum of the higher plants. Great difference in the composition of amylum and mossamylum was not to be expected; it was however hitherto generally supposed that the latter was coloured yellowish-brown, the former blue by iodine; I have however frequently found 
that the amylum in fresh Lichens was coloured blue by iodine, and in fact lichen-amylum does not exist in the form of globules in Lichens, but forms the membranes and the contents of their elementary organs.

In a subsequent note* read by M. Payen before the Sociéte Philomatique, he observes that he had been able to see with the microscope the amylum of the Iceland moss united in small balls; M. Payen however did not notice that the septa of the cells of those plants are also coloured blue by iodine.

\section{Monographic revisions of various Families of Plants in a Physiological point of view.}

From M. Unger + we have received a very excellent work on parasitic plants, which especially treats very fully of the inrooting of the parasites on the stock plants. The inquiry relates to parasites, which are independent and individualized plants, which although not independent of other plants at their origin, are nevertheless so in the duration of their life, and in which they are, as it were grafted, and from which they almost exclusively derive their nourishment. From this peculiar vital process, more than from their form and their structure, these plants are united into a distinct group. A want of roots or root-like organs is peculiar in a higher or lower degree to all parasites, and M. Unger observes, that although we find in some of the more perfectly developed species a true rhizoma, nay, even ramified roots, this indicates far more the evident general tendency of nature to attempt variations of formation in every possible manner, within the limits of certain vital laws, than a deviation from the general rule.

The vast abundance of materials at M. Unger's disposal induced him to form a division of the parasitical plants into various groups, founded on the mode of connexion existing between the parasite and its stock. Nine such groups are established, the genera forming them enumerated, and their inrooting in the stock plants more or less completely described. The following are the groups.

1. The parasite originates immediately upon the wood of

- L'Institut de 1837, p. 145.

+ Annalen des Wiener Museums, vol. ii. p. 1. 
its supporter, and anastomoses by its vascular system with the vascular system of the nourishing plant. To this section belong Rafflesia, Brugmansia, Pilostyles, Apodanthes, Cytinus?

2. The parasite endeavours to form a kind of rhizoma, by which it suspends itself to the stock, and from which it sends forth several floriferous branches, for instance, Hydnora, Scybalium.

3. By an increased reaction (founded probably on the mode of germination), a portion of the vascular system of the nourishing plant is received in the rhizoma of the parasite, and a body formed which belongs to both plants. Under this section are classed the genera Balanophora, Cynopsole, Sarcophyte, Cynomorium, Lophophytum (?), Ombrophytum (?).

4. The parasite forms a rhizoma, the fibres of which adhere to the stock plant: for instance, Helosis, Langsdorffia.

5. No rhizoma but branched roots which are connected with the stock plant by suckers, as Lathrea.

6. Ingrafting of the parasite, as in the first group, but having roots which are sometimes provided with tubercles, sometimes have none. To this section belong the genera Orobanche, Phelipaa, Conopholis, Hyobanche, Epiphegus, Aginetia, Obolaria.

7. The roots of the parasite are intermatted with the roots of the stock plant into a kind of tuberose mat. Monotropa and Corallophyllum.

8. The parasite is developed somewhat independently, only intromitting here and there from the stem fleshy tubercles into the stock plant, as in Cuscuta and Cassytha.

9. Highly ramified roots which at times pass under the bark of the supporters, and are, as it were, infiltrated into them. Viscum, Loranthus, and Myzodendron.

In forming this arrangement, M. Unger thinks that he has established a law, according to which the lower or higher developed nature of the parasite constantly rises to greater independency and freedom parallel with the successive series of its independent relations in the inrooting.

$\mathrm{He}$ also divides the so-called false parasites with regard to their connexion with the soil into various groups. To the first 
belong Hedera Helix, Ampelopsis quinquefolia, Bignonia radicans, \&c. These plants attach themselves by means of small crampons to neighbouring objects without deriving their nourishment from them. Similar crampons (Haftwurzeln) are also observed in some semi-parasitical plants, as in Cuscuta and Cassytha; M. Unger even believes that the tubercles in $L a-$ threa, Orobanche, \&c., should be regarded as such formations, in which view I cannot concur.

Under the second group of false parasites are classed Bromelia, Tillandsia, Epidendra, and other Orchidea, as also Mosses and Lichens: the roots of these plants, in so far as they possess such, are capable of vegetating only in vegetable mould, or in the continually decaying outer bark of woody plants. In the third group of false parasites, in which the last state of limitation is found, are enumerated the twiners.

The grouping of the true parasites above-mentioned, according to M. Unger, appears to me to be too much subdivided; I for instance, should combine the three first groups, and propose various other modifications. I can in this place however only mention the most prominent points of the new observations on which. M. Unger establishes his divisions. In the history of the development of the parasites of the first group, Dr. Blume's observations on the germination of Brugmansia are related, but it appears to me as if these observations were made subsequently to the time when Dr. Blume sent me a bud of Brugmansia for examination. M. Unger thinks that R. Brown's notion of an intermediate production derived from the root of the Cissus on which Rafflesia Arnoldi is situated is erroneous; the error however is on the other side. In the Brugmansia, which is fixed on the root of Cissus tuberculatus, I found this intermediate body, which had entirely proceeded from the substance of the root, of very considerable size, just as I have figured it from a cross section in the Flora Javæ, Tab. VI. fig. 1. This intermediate body forms with its parenchymatous margins a cup in which the opened flower is seated as in a calyx. Hence it follows that at least the first two groups should be united. Whether the intermediate body is somewhat larger or smaller does not signify at present.

No rhizoma exists in Lathrae, but a highly ramified root 
which is connected with the stock plant by tubercles. M. Unger intends to publish his observations on this subject in a separate memoir.

Highly interesting is the peculiar connexion existing between the roots of Monotropa hypopithys and the roots of the stock plant (Pinus Abies, L.). According to M. Unger's discovery, it is a rhizoma-like, tuberose, irregular body, from which the inflorescence of the plant proceeds, and this body consists of a convolution of intimately matted fibrils which belong partly to the parasite and partly to the stock. This root mat is externally somewhat loosely penetrated by earthy masses, but towards the centre increases so much in closeness of texture, that the masses almost entirely disappear, and nothing is left but a tissue of roots which cannot be unravelled. The contact of the two roots, easily distinguished from each other by form, colour, and consistency, is very intimate, although no tubercles or similar organs exist, by which a direct union, an interpenetration of both, might be effected. The parasite is therefore nourished in this case by the exudation of the spongioles of the root. It must not be thought that this nourishment consists in the excrements of the roots, for I think I have proved that these supposed excrements are precisely in the same situation as the whole doctrine of spongioles of the root and tuberosities, of which nothing exists in nature.

M. Unger has also published some very interesting observations on the growth of the Cuscute. These plants are easily raised if their seeds be sown among green plants already developed. During the first period the young plant daily lengthens about an inch, the original embryo becoming dry up to that point of the stem where the first tubercle makes its appearance. The young germs would not succeed on the green leaves of Sedum album, although the tubercles of the Cuscuta had already become fixed to them. A young Cuscuta with its stock was placed under a glass and kept moist by the vapour of the water: during three days it increased in size, then made $1 \frac{1}{2}$ coil round itself and produced tubercles at this very place. The lower part of the plant now ceased to grow, while the tubercles penetrated of themselves into the substance at the entwined spots. M. Unger observed the metamorphosis of an 
original tubercle into a shoot. He also made some observations on the germination and the formation of the root of Viscum; but the observations of Du Hamel, Gaspard, and many others have left little unknown on this subject. M. Unger has however observed in several tropical species of Loranthus, that the roots having a horizontal direction are not fixed in the bark but on it, intimately surrounding the branches, and even adhering to them with their extremities.

In a second part, M. Unger gives his anatomical observations on the parasites, whose mode of insertion into the stock plant has been previously described; he concludes, that the whole of the parasitical plants may be divided in a systematical point of view into three sections. The first comprises those parasites, whose imperfect vascular bundles, having for prototype Langsdorfia, are arranged in a circle and are connected with each other by anastomoses. This section is placed parallel with the formation of the stem in Ferns. A second group is formed by those parasites in which the vascular bundles are also imperfect, but in which it appears that a peripherical formation of roots is added to that at their apices. This section comprises the genera Orobanche, Lathraa, Monotropa, Cuscuta, Cassytha; and M. Unger thinks that these plants, with respect to their anatomical structure and mode of growth, can be compared with none of the larger vegetable divisions; while the genera Viscum, Loranthus, \&c. belonging to the third section possess perfect vascular bundles and resemble dicotyledons in their mode of growth.

This mode of subdividing parasitical plants will probably meet with little acceptation; in fact I am not acquainted with anything from which it can be proved that Orobanche, Lathraa, Monotropa, Cuscuta, \&c. differ essentially in their structure and growth from other dicotyledons. It is true that Rafflesia and Brugmansia exhibit a similar deposition of ligneous bundles, or vascular bundles as they are here termed, on one another, as in ferns; but I can also produce stems of Cactus, in which something similar occurs; and therefore the drawing an analogy between the genera of parasitical plants and ferns cannot be justified. M. Unger thinks that his views on the arrangement of parasites are strengthened from the structure of their seed; this supposition is however quite as erroneous 
as the unfounded doctrine of the growth of true parasitical root plants without actual seed, which I have already lamented for many years as one of the errors of my youth. When I examined Dr. Blume's Brugmansia, the specimen which was said to have ripe seed was more than half decomposed; hence the hymenomycetous fungi in and near the seed in the figure (fig. 17.) : probably too the embryo was also wanting, although the change in form of the seed allowed of the conclusion of a fecundated condition. On the young, yet unopened flowers, I have observed the seed quite normal with its nucleus and simple coat, and have figured them in fig. 16. Pl. II. of the Flora Javæ. It must however be remembered that these observations were made in February 1837, and consequently before the appearance of the celebrated memoir on the ovule of plants; but even if $R$. Brown had not already observed the embryo in the seed of Rafflesia (of which M. Unger is ignorant), I should now, from the mere appearance of the seed in comparison with a non-fecundated ovule, no longer doubt the existence of the embryo. The Rhizanthece have therefore an embryo in their seed, and its form and development indicate in the most decided manner that they belong to the dicotyledons.

It might be imagined, says $M$. Unger, that the parasitical forms were only the shadows of types which presented themselves in a more noble independent and perfect form in another direction of the vegetable kingdom; but if he had arranged the various parasites in the natural families represented by those types, the organographical portion of this memoir, so abundant in material, would have been of a much more permanent value for systematic purposes.

The six lithographic quarto plates annexed to the memoir, contain an abundance of beautiful and faithful representations.

In the excellent monograph of the Riccice which Dr. Lindenberg* has published, there is a section which treats of the structure, growth, and generation of the Riccia, and contains numerous and highly valuable additions to vegetable physiology. The author states, that only those species of Riccice are

* Nova Acta A cad. C. L. C. Nat. Curios. xviii. p. 1. Vratislaviæ et Bonnæ, 1837, p. 361-504. c. Tab. XIX. 
destitute of roots, which grow entirely in water, and only so long as they are entirely surrounded by this element, but they send forth roots so soon as they come in contact with the soil. The roots of the Riccia are simple, very rarely branched, and their number varies, as in other plants, in different individuals. These roots of the Riccice consist in mere simple radical fibrils, as is the case in all mosses; yet in Riccia natans, where several deviations in form are already evident, these fibrils which are developed in the earth are both articulated and unarticulated. Such small variations occur even in more perfect plants; now and then even ramified fibrils are met with. But besides these delicate rootlets, M. Lindenberg has also observed in some species, in $\boldsymbol{R}$. purpurascens and natans, stronger and more rigid radicles, which at their extremity are incrassated in an oval, clavate, or globular form, and then again emit from all sides small slender fibres. He terms these roots sprouting roots, and the thick tuberosities at the extremities are developed according to his observations into new plants; but they are incorrectly designated as radical buds; they are evidently gems, the occurrence of which at the extremities of the roots of such imperfect plants is very remarkable, as in Lemna alone has anything similar been observed. In $R$. nutans they are formed even at the extremities of the simple radical fibrils, but the details have not been completely demonstrated.

M. Lindenberg regards the Riccice as those inferior plants, in which perfect cellular tissue first occurs, which can only be admitted in a certain sense; for not only in the Fungi, but also in Algæ, we find not merely very regularly formed cells, but also a regular deposition of these cells on one another, exactly as in the more perfect plants; these cells differ from the perfect cellular tissue merely in their contents and in the firmness of their walls. M. Lindenberg thinks he has found in the structure of the Riccice a confirmation of M. Kieser's theory, " that the ideal primitive form of vegetable cells, forced to deviate from their original form of a sphere or ellipsoid in consequence of their being united into an uninterrupted tissue, is the rhomboidal dodecahedron." All the cells, he observes, in the parenchyma of the Riccice are of this form, or may be reduced to it, although at the same time the constant 
tendency of the cells to retain as much of the globular form or to return to it as nearly as the reciprocal pressure, \&c. allow, is very apparent.

This supposition, however, requires at least, that those cells of the parenchyma of the Riccice should be in their origin spherical, and have been subsequently compressed. But can this be observed in the Riccice? I think I may answer the question negatively, for in the Marchantice where the cellular tissue is exactly similar to that in the Riccice, it may be observed that the development of the form of the cells is not effected in the way above described. The mathematical development of Kieser's hypothesis on the origin of the form of the cell is nevertheless quite correct, and even Stephen Hales demonstrated very decidedly that round bodies of uniform size, for instance common peas, when caused to swell in a firmly closed space filled with them, were changed by reciprocal pressure into dodecahedrons. This form, produced by external circumstances, cannot however be regarded as the ideal primitive form of those originally round bodies; and it is founded on very erroneous observations, if it be supposed that the ideal rhomboidal dodecahedral cells can round off at their edges and corners and pass into the various other forms. If the reciprocal pressure ceases, which sometimes, from the unequal expansion of certain parts, occurs, the separated cells re-assume the spherical form from which they had departed.

M. Lindenberg has given a very detailed account of the subject in question, in which we find the following observation;"that in sections of cellular tissue other forms besides the hexagonal occur, which does not prove against, but in favour of Kieser's view," i. e. that the form of the cells is that of the rhomboidal dodecahedron. However I have only been strengthened by continued observations in my views on this subject (see Phytotomie, p. 216.), nay, I could at present bring forward more detailed observations than at that time. And, in fact, it is surprising, that even now mention is made in many manuals of botany, of the rhomboidal dodecahedral form of the cells, whilst good longitudinal and cross sections place the true form of the cells immediately before the eye; I will also mention that cells of the continuous parenchyma whose form resembled 
a regular rhomboidal dodecahedron have never occurred to me : I do not even think that there is any actual similarity.

The Riccia, like all plants having a tissue consisting of several layers, possess a cuticle, i.e. an upper cellular layer, and M. Lindenberg observes very justly that it is merely a dispute about words, whether the epidermis ought to be considered as a distinct organ or merely as the upper cellular layer of the parenchyma. The form of the cells of the epidermis of the Riccice is more or less regular dodecahedral, of which, however, I could not convince myself. The cells of the epidermis are filled with green sap globules when the frond is quite thin, but uncoloured when the frond is more considerable, and the green cells then gleam through the interior of the frond, and in this way originates the greyish green colour, when dried silvery grey, which for instance is peculiar to $R$. glauca. At times the marginal cells are provided with cellular sap and even amylum granules occur in them. The rough surface of the Riccice is caused by small verrucous swellings of the upper sides of the cells. "Frequently," observes M. Lindenberg, "these vesicular prominences are and remain closed; not unfrequently however they open on the further development of the plant; either quite irregularly, as in $R$. hortorum, crystallina, the upper cellular sides disappearing almost entirely, and thus irregular cavities of various size and open above originate; or by the disintegration of some cells round or oval fissures are formed, as in Corsinia marchantioides; or lastly by some cells raising themselves higher and in the shape of warts, and these apparent papillæ open above as in Riccia fimbriata." In Oxymitra the apertures are surrounded regularly by smaller round cells. All these observations are exceedingly interesting, especially on account of the similar appearances which have here and there already been noticed in plants. I compare the apertures, with and without papillæ-like prominences of the adjacent cells of the epidermis, which M. Lindenberg has observed, to the so-called stomata of the Marchantia; the papillæ of Riccia fimbriata especially bear the greatest resemblance to the open prominences on the fronds of the Marchantice, in which the true cuticular glands which present the stoma in the centre of their two semicir- 
cular cells are entirely wanting, on which subject I have recently offered some remarks*. It appears as if these apertures served to convey the moisture of the air into the interior of the tissue of these plants ; the Riccia grow under similar circumstances as the Marchantic; at times they have too much moisture, at others too little, and these arrangements might in both cases aid in regulating the proportions. Besides, the vesicular projections on the surface of the Riccia do not always open, a phænomenon quite similar to that of the occurrence of the holes so frequently mentioned on the sides of the cells of some species of Sphagnum, on which subject we shall subsequently have occasion to treat more fully.

Although the cellular tissue of the Riccia is very compact, exactly as in the Marchantice, so that only very rarely intercellular passages occur between the cells, yet the substance of the frond, when it occurs but moderately, is abundantly traversed by air-receptacles. They arise from a gradual disintegration of the cells, are often present only here and there in the frond, and frequently quite irregular, and in the species growing in water they are found to exist constantly. When the frond is thick several series of such air-cavities originate one above the other as in the gibbosity of Lemna gibba.

All the species of Riccia which have a more fleshy frond present in the centre a still denser layer, consisting of horizontally elongated cells. In several species the under surface is moreover covered with a coloured cuticle, which consists of a single or at times even of numerous layers of small coloured cells; in old age this membrane frequently falls off of itself, and produces, by mere shining through, a colouring of the surface. This coloured layer, says the author, is chiefly the cause of all the red and violet colouring of the Riccia, with the exception of the margin, which in some cases is independently coloured. Where the margin is involute this coloured under side occurs above.

In most species of Riccia not a trace is found of a vein in the leaves; in some however bundles of pleurenchymatous cells are gradually formed. These traverse the frond longitudinally and send out ramifications on both sides; they are not met with in any species which is not provided with air-

* Ueber einige Eigenthümlichkeiten in der Epidermis verschiedenen Orchideen.-Wiegmann's Archiv. 1837, p. 423. 
cavities. I regret that the author has not explained this subject more accurately and elucidated it by drawings, as at present I have no fresh Riccice at hand; it appears to me however as if these veins consisted only of elongated parenchymatous cells, and as such form the sides of the air-cavities which gleam through the upper cellular layer. In Corsinia he however observes, that there exists a large bundle of such fibrous cells situated close together, only here and there traversed by elongated almost prosenchymatous cells, and sending out true ramifications, likewise consisting of several series of cells.

The occurrence of such veins in the Riccice would be highly remarkable, as the Marchantia evidently stand much higher and yet exhibit no such veins ; in the latter, their place is occupied by bundles of beautiful fibrils, which run exteriorly, surrounded only by ridged elevations.

M. Nees von Esenbeck had the kindness to forward to me a specimen of Corsinia for examination; it was dry, but it appeared to me to show plainly that those bundles of brown fibrous cells belong no more to the Corsinia than to other Riccia. I found however on one specimen, between the delicate fibrils, a brown fibre, which agrees with the description of the fibrous cells given by M. Lindenberg; but I can affirm that this fibre, which also presented ramifications, did not belong to the Corsinia. However, only the examination of fresh specimens can decide this point.

The Riccia are otherwise so nearly allied to the Marchantice in the appearance of their organs of fructification that they can hardly be considered as a distinct natural family.

Dr. Schleiden* has published a monograph of the genus Ceratophyllum, containing much that is new, notwithstanding all that has already been written on this subject. It is clearly shown that Ceratophyllum must be separated from the Naiades and reckoned among the Dicotyledons. The embryo has two large fleshy cotyledons and a highly developed plumula; it is inclosed in albumen, and consists of a circle of leaves, which at times is separated by an apparent internode from the cotyledons, of a whorl of six undivided leaves, and lastly of two to three whorls of forked leaves. M. Schleiden observed the embryo sac in the axis of the nucleus long before impregnation,

* Beiträge zur Kenntniss der Ceratophylleen.-Linnæa, xi. p. 513. 
in the form of a cylindrical cell, in whose apex (micropyle-end) were contained some small cells. The ovule is pendulous and provided with an integument, the pollinic cell was followed to the micropyle, and here it penetrates the aperture of the integument, expands into an irregular saccate dilatation varying in size, and then passes from thence into the nucleus until it reaches the embryo sac: immediately upon this the first trace of an embryo is visible. During this time the cells of the endosperm have expanded considerably until they have reached the chalazar extremity and quite fill it. In these endosperm cells he discovered the interesting phænomenon of the rotatory current which existed in each cell; it was a yellowish slimy fluid, intermixed with small globules, which was in motion. The current ascended from the base of the cell, in its axis, resembling an artesian spring, to the very top, where it separated into innumerable, minute, scarcely perceptible currents, which fell down the sides in all directions, in order to reunite below with the main current. The direction of the central stream is in all cases alike, namely, from the embryo towards the chalaza.

From the development of the embryo, as also from the dilatation of the lower cells, the upper ones become compressed and die from above downwards.

The stem of the Ceratophylla consists of bark covered with epidermis, of a ring of bundles of elongated cells, and of pith. The genus Ceratophyllum has no spiral vessels. Dr. Schleiden here remarks that he had discovered spiral vessels in Lemna as early as 1835. However, L. Treviranus had many years ago figured the spiral vessels in the roots of Lemna; I myself denied the fact, not being able to confirm it with my older microscope, but with the instrument of Ploessl I could also see the vessels. In Zannichellia the spiral vessels are said to disappear in the old articulations. I recollect having seen in the summer of 1835 spiral vessels both in the young and old internodes of this plant.

Whether the Ceratophylla are perennial or not is not yet ascertained; they flower from July to the middle of September. In the beginning of September flowers and nearly ripe fruit are found on the same stem. The plants contained nearly 90 per cent. water, and the ashes $\frac{5}{8}$ alumina, $\frac{2}{8}$ silica, \&c. 
The geographical distribution of this genus is very general; it is not merely confined to the northern hemisphere, for I myself saw Ceratophylla in Chili*, and other travellers have also observed them there.

Dr. Schleiden admits only one species of Ceratophyllum, and calls this $C$. vulgare; a long series of observations are enumerated to prove this view.

Asa Gray $\dagger$ has also recently written on the affinities of the genus Ceratophyllum; it appears to him that a great similarity prevails between the embryos of the genera Ceratophyllum and Nelumbium, which he endeavours specially to demonstrate, and then places the Ceratophyllacere in the immediate vicinity of the Cabombacea and Nelumbiacea. The memoir contains no new observations, nor do I find anything respecting the structure of the Ceratophyllacece.

\section{On the Propagation of Vegetables, and on the Organs that contribute to it.}

Mr. Felix Dunal, of Montpellier $\ddagger$, has made us acquainted with some interesting observations on the organs of fructification of a Marsilea, which have been made by M. d'Esprit Fabre with great accuracy. The specific name of Fabri has been assigned to this Marsilea; there can, however, be little doubt as to its being the same species described byTenore as Marsilea pubescens; this latter name must consequently be retained!

The generative organs of this Marsilea are in some respects of a different structure from those of our common Marsilea : their functions are, however, more easily recognised than in this. At the base of the petiole are situated the capsules, each on the involute side of the termination of a conical pointed pedicel, which is partly inclosed by the inferior margins of the two valves, forming the capsuliform involucrum of the inflorescence or the organs of fructification: the inclosed part therefore constitutes the receptacle, from which proceed on both sides vascular bundles which surround all the organs of fructification. As soon as the involucrum has opened,

* Meyen's Reise, \&c., i. p. 370.

+ Remarks on the structure and affinities of the order Ceratophyllacece.Ann. of the Lyceum of Nat. Hist. of New York, 1837, iv. p. 41.

† Observations d'Esprit Fabre sur la structure, le développement, et les organes générateurs d'une espèce de Marsilea trouvée dans les environs d'Agde.-Ann. des Scien. Nat., Avril 1837, p. 221, avec planches xii. et xiii. 
a mucilaginous thread makes its appearance, which bears at its side from six to ten sessile, racemose, elliptically formed, annularly curved (roulés en anneau) bodies. In the imperfectly developed state of this thread the vascular bundles which arose from the sides of the receptacle, encircle the thread and are connected with the racemose bodies, which are the male and female reproductive organs of the plant. All these statements, which are nearly complete as to the development and structure of this mucilaginous thread, are elucidated by admirable drawings. With the further development of the inflorescence the point of the thread quits the involucrum and is unrolled to a straight erect thread, which on each side bears from three to five of the organs of reproduction. The end of the thread is always naked; it is composed of an extremely delicate and almost transparent cellular tissue, the cells of which abound in mucus and contain some very minute spherical globules.

The reproductive organs are from 2 to 3 lines long and 1 thick, enveloped in a kind of mucous membrane; they contain two different kinds of bodies, which are said to be ovules or seed and anthers. In general they occur in the same organ, the ovules on one side, the anthers on the other, but so arranged that the ovules are constantly situated above and the anthers immediately beneath. In each single organ are from ten to fifteen ovules, which exhibit at one end a small yellow wart surrounded by a circular prominent capsule. The ovules are filled with a semi-transparent fluid, in which numerous globules float; the wart of each ovule is always directed towards the anther. The anthers are formed of a transparent membranous sac, in which are evident numerous pollen granules of spherical and elliptical form, which when crushed give out spermatic granules of great tenuity. The sexual difference between the two bodies described, the ovules and the anthers, is completely confirmed by M. Fabre's observations. The impregnated ovules emit roots and germinate with one cotyledon.

These observations on Marsilea pubescens are, especially at the present time, of particular interest ; I am inclined to believe there can be no doubt that these reproductive organs must be regarded as modified leaves, and that here therefore, in a case where spores and pollinic vesicles are formed in the 
same leaf in a natural way, an actual impregnation takes place, although there does not exist that difference which the other higher plants exhibit between stem and leaves. At the same time these observations confirm M. Mohl's view, that the spores of Cryptogamia and all lower plants in general, are produced, like the pollen granules of the higher plants, from modified leaves.

M. Link* has published the second part of his Elements of Botany, which contains (p. 44-331) the important chapter on the inflorescence and fruit of plants. This second part is also as rich in observations as the first, and above all I must direct attention to the morphological views of the author expressed in this work; they are the result of many years' study of nature.

The observations of M. Fritzsche † on the structuré of pollen, which we mentioned in our last year's report $\ddagger$, have now been published entire. The work is divided into two sections : the first treats of the structure of pollen in general, the second on the tunics of the pollen. The whole is written without any mention of the literature on the subject, as the perspicuity of this difficult subject would in M. Fritzsche's opinion have been thereby endangered.

The exposition of the first memoir on pollen in general begins with the examination of the anthers of Chara, which it is well known deviate very much from the general rule. The coats of the anthers of the Chare are in general composed of eight flat-pressed triangular cells, each four of which form a hemisphere; the superior hemisphere is closed, the inferior one on the contrary has at the spot where it is attached a round aperture, which is formed by semicircular excisions of the triangle that take part in its formation. The structure of these triangular cells is very fully described; they contain a clear uncoloured mucus (this mucus is stated to be coloured probably from a misprint) and the inner surface of the parietes situated towards the centre of the anthers is covered with a layer of red granules, which again exhibit in their substance a quantity of

* Elementa philosophiæ botanicæ, tom. ii. Edit. altera, Berolini, 1837.

† Ueber den Pollen. Mit 13 colorirten Steindriicken. St. Petersburg, 1837. 4to.- Printed separately from the Memoirs of the Royal Academy.

‡ Lond. and Edinb. Philosoplical Magazine, vol. xi. p. 165. 
very minute dark bodies. This arrangement of the coloured and uncoloured part of the triangular anther-cells explains the occurrence of the Arillus diaphanus with which the anthers of the Charce are surrounded. The septa are noticed, which extend in these triangular cells from the circumference to a third of the diameter. They are placed vertically between the upper and lower surfaces of the triangle, and consist of two cellular walls (because they are mere folds.-Rep.), giving this multifid cell some resemblance to a stellate cell, only that the interstices are wanting in them. In Chare with compound cuticle, as in C.tomentosa, \&c., M. Fritzsche has discovered small spiculæ, which are situated at regular distances between the two membranes of the septa. He has also found in the interior of each anther a bottle-shaped body, consisting of single cells, which projects into the centre of the anther and there supports all the other parts : this formation has hitherto been overlooked by all observers, but the connexion of the other cells and of the pollen thread with the surrounding integument has been known years ago, and we possess since 1832 and 1833 some of the most beautiful drawings of the confervoid pollen thread of the anthers of the Charce, although M. Fritzsche thinks that they have hitherto never been figured correctly. There is in fact nothing more easily perceptible with our present microscopes than this transparent delicate thread, but all earlier amplifications were insufficient for this purpose, although even with them the remarkable motions of the Spermatozoa of these plants were discovered by Bischoff, as was mentioned in last year's report*.

M. Fritzsche has observed the formation of the anthers of the Charce from a simple cell which was filled with a transparent colourless mass, which I am able to confirm, but the formation of septa which should then follow is limited only to the thickness of the triangular cells, which subsequently form the coat of the entire organ, and this formation I found to resem. ble that of the outer cellular layer on the Charce with compound epidermis.

After these remarks on the structure of the anthers of Charc, M. Fritzsche speaks of the contents of the pollen in general: the same observations and views which have already several

* Lond. and Edinb. Philosophical Magazine, vol. xi. p. 165. 
times been asserted against the Spermatozoa or spermatic corpuscules, are again brought forward; they are said to be fecula or drops of oil, in which view I do not concur; I have, however, already stated my opinion on this subject in last year's report. Starch occurs only in imperfectly formed pollinic vesicles; not rarely in Coniferce and in some water plants. I have also been able to observe in Muscari moschatum that in such imperfectly developed pollinic vesicles the masses of fecula which occur in them are converted into a gummy substance and decompose into small molecules which have a very lively motion, resembling in every respect the phænomenon described by me in the cells of Marchantia polymorpha*. In some cells of this plant there occur instead of the common green cellular sap globules some large balls of a yellowish brown substance, which have been already observed and figured by Mirbel. I followed up the formation of these masses from the globules of starch, which deliquesce and are then converted into a gum. When these globules are perfectly developed and of a yellowish brown colour, they decompose on the smallest touch into innumerable minute brownish molecules, which for days exhibit the most lively motions, having an appearance similar to the motions in solutions of indigo, gum-arabic, \&c., only somewhat more active.

The second section treats of the coats of the pollen. A simple membrane and one of a more compound structure are to be distinguished on the pollinic vesicles. Some plants exhibit but one tunic, others on the contrary three and even four. Most frequently but two tunics occur, and they are termed the inner and the outer coat; but where a duplication of one or both these membranes exists these names do not suffice, and on that account he proposes for the entire series of membranes, when they are all four present, the terms Intine, $E x$ intine, Intexine, and Exine, which however cannot be admitted, for the fact is quite different to what M. Fritzsche supposest.

The inner tunic is from its simplicity easily distinguished from the outer membrane, and chemical agents afford ample means for separating them. Concentrated sulphuric acid destroys the inner membrane, but the outer one with its ap-

* Wiegmann's Archiv, 1837, part iii. p. 428.

[ + Similar views are however entertained by H. Giraud. See his paper in the Annals of Natural History, vol. ii. p. 399.-W. F.] 
pendages is merely coloured by its action, frequently of a purple-red. The membrane and its coating are generally similarly affected, but in some cases, as in Beloperone oblongata, the membrane is coloured purple-red and its coating yellowish-brown by sulphuric acid. The outer tunic is coloured of a dark brown by iodine, and the inner membrane is said to take no colouring from a solution of iodine, like cellular membrane in general (which, however, cannot be generally asserted. - Rep.). The membrane of the outer tunic is sometimes of greater, sometimes of less consistence, not only in various plants, but at times even at different parts of the same vesicle, for instance, at the apertures; but the coatings with which the membrane is covered vary considerably. This subject is treated in a very elaborate manner, and by employing high powers of a good microscope M. Fritzsche has succeeded in bringing to light a vast number of new and interesting facts which are illustrated in the annexed plates in large and beautiful drawings. It is not possible for me to enumerate in this short report the essential facts respecting these coatings of the outer tunic ; I can only communicate the most important, and for the remainder I must refer to the memoir itself.

In several Malvacea the outer membrane is equally densely covered with a layer of transparent, cylindric, apparently solid granules, standing erect, side by side, which give it a granular appearance; the granules seem to be connected by a distinct substance; in other plants however this is not the case. In Chrysanthemum carinatum a membranous coating distinct from the granules occurs. At times the granules do not cover the entire surface of the membrane, at times they are placed regularly and connected with one another by bands, at others they are free and more or less regular. In Plantago capensis the granules are irregular, and also in irregular position. Free large equidistant granules have been observed in Jatropha pandurefolia. When the granules are united by ligaments, pollen-like connexions originate on the surface of the outer membrane, as in Ruellia formosa. The occurrence of spines on the membrane is connected with this granular coating. In Malvacee the spines are sometimes seated on the cylindrical granules, and may be separated from them; it is probable that they have no direct connexion with the outer tunic. In some 
cases cavities or canals were found in the larger spines, and Mohl's supposition that they are cellular formations which secrete oil is confirmed. These spinous formations are most remarkable in the group Cichoracee ; they stand in single regular rows, and can only be observed with advantage from the side. Among these spines of Cichoracere a connexion exists which seems to be effected by a membranous mass clothing the membrane; the series of spines appear from this cause like broad bands, and present, when observed from the side, an umbraculiform appearance.

In another class of vegetables, regular pentagonal and hexagonal figures, circumscribing walls, have their origin on the outer tunic; these are again interrupted as in Cobae scandens, and appear like piers of a bridge. In Geranium and Pelargonium verrucous bodies are situated, like statues, on the arches connecting the buttresses. (The history of the occasional formation even of some imperfectly developed pollen grains of these plants shows that all the elegant formations on the surface of the pollen granules arise from similar erect granules in juxta-position, as they so frequently occur in the Malvacea.-Rep.)

In some plants the surface of the outer tunic presented the appearance of net-work, as in Polemonium coeruleum, Gilia tricolor, Metrodorea nigra, \&c.

A separate chapter treats of the intermediate bodies which occur between the inner and outer tunics. They are most easily seen in Astrapcea, and have there in an isolated state the form of a plano-convex lens, of which the side turned towards the outer coat is covered with granules resembling the external surface of the outer coat. In other plants these granules do not exist on the outer surface of the intermediate body, or there is merely a simple ring present, as in Ruellia formosa. The intermediate bodies are situated in general at those spots where apertures exist in the outer tunic which are closed by them, and these intermediate bodies have a far greater extent than the apertures, on which account they cannot be considered as belonging to the outer membrane. In Alcea rosea, where these apertures in the outer membrane are very numerous, their inner surface is clothed with densely juxta-posed globular granules, which are said to be the intermediate bo- 
dies. In Campanula Medium and in Cucurbita Pepo they are also found; and M. Fritzsche starts the opinion that they should be regarded as diseased pollen granules. In Scabiosa pubescens he found two such intermediate bodies, which appeared to be encased one in the other. (These intermediate bodies of M. Fritzsche are cells and their contents, which occur in the pollen vesicles of numerous plants, and have been overlooked by him. When these cells in the interior of the vesicles have large cellular nuclei, as in many Liliacea, such a case as is related of Scabiosa pubescens becomes intelligible.Rep.) The intermediate bodies, however, also occur in some forms of pollen which have no apertures, as in Pinus and $L a-$ rix, where the pollinic vesicle has two outer linings. The drawing given of the pollen of Pinus sylvestris is one of the most unsuccessful; in nature it has quite a different aspect.

The subject of the second part of M. Fritzsche's memoir is the form of the pollen. He first treats of the pollen masses and then of the pollen grains; the former occur in the Orchidea, Asclepiader, and in the genus Inga, which was previously known. The individual grains, of which the pollen mass of the Orchidece consists, possess but one tunic, and therefore the inner one according to M. Fritzsche, yet the structure of this membrane but too plainly evinces that it is nearly related to the outer ones of other kinds of pollen. In the grains of the genus Asclepias he has not only observed two tunics but even an exintine.

Then follows a natural division of the pollen grains, according to the number of tunics.

1. Pollen grains with one tunic.-To this section belong Caulinia fragilis, Zanichellia pedunculata, Zostera, and Najas major. The confervoid pollen described in Zostera was discovered, described, and figured many years ago by my friend Nees von Esenbeck.

2. Pollen grains with two tunics.-Under this section are classed almost all the forms of pollen, and we may properly speaking regard those cases where fewer or more than two membranes occur as exceptions. They divide themselves into two groups, according to the presence or absence of the apertures in the outer coat; cohesions occur in both cases.

A. Grains without apertures.-The peculiar geniculated 
pollen grains of Ruppia are here described. Then follows the ellipsoid form of many Monocotyledons, which M. Fritzsche has drawn with a fold, as in Lilium, Pancratium. Cohesions of two, as in Lilium candidum, and of four, as in Phillydrum lanuginosum and Anona tripetala, are enumerated. More rarely two opposite folds occur, as in Tigridia Pavonia ; on the contrary, frequently symmetrical longitudinal folds, as in Plumbago capensis. Globular pollen forms are more rare. Strelitzia exhibits them with an homogeneous outer coat; Canna presents small spines, and regular warts appear in Jatropha pandurcefolia. In Sowerbaa juncea the groove goes quite round the vesicle, and the outer coat is thus divided into two halves. Allied to this is the interesting form of the pollen of Thunbergia fragrans and several species of Berberis. In Commelina colestis a large tabular piece takes off, which lies on the aperture as a lid, and several such lids occur in the genus Passiflora, where again a number of varieties originate by the division of the lid, which are all minutely described and figured. That portion of the outer tunic where the apertures are closed by distinct lids is termed the skeleton of the tunic. In Scabiosa the lid appeared as if merely formed by the granular lining of the outer tunic.

B. Grains with apertures.-These forms are again subdivided into two sections, according to whether the apertures consist in fissures of various lengths, or form circular holes. Three fissures, as in Geissomeria longiflora, is the smallest number observed. In many Cyperacea four to five unsymmetrical fissures are found; the form of Carex pracox is figured where the inner tunic presents peculiar thickenings.

The position of the fissures on the tetrahedral forms of the pollen of some species of Corydalis and Basella is very remarkable. The pollen of Talinum patens exhibits twelve fissures, and Polygonum amphibium many more, the outer tunic forming twelve regular pentagonal fields, each of which is surrounded by five regular fissures.

The group of pollen grains with round apertures presents a greater variety of forms; one aperture in the Graminea, two apertures in Banksia and Justicia Adhatoda. Three apertures are most frequent and occur in many plants in connexion with three longitudinal grooves, which in general hide the 
apertures. Rarely three apertures without grooves, as in Morina persica. A number of peculiar forms are here fully described which had partly been previously published. Some cases are also mentioned where all the grooves are not provided with apertures, yet in this case the pierced grooves stand in a definite proportion to the unpierced.

Lastly, there are forms with a cellular (?) texture of the outer pollen membrane; in some cases only a part of these fields which have the cellular appearance are provided with apertures, as in Phlox; in others, on the contrary, all the fields have apertures, as in Gomphrena globosa.

3. Pollen grains with three tunics.-Where a greater number of tunics exist than in the second division, the additional ones must not be regarded as new tunics, but duplications either of one or the other. In the pollen of the Coniferce the inner tunic is doubled, in the Onagrea the outer one; nay, M. Fritzsche alleges that he has observed a duplication of the inner tunic in Clarkia elegans. (If the pollen of Pinus, Larix, Taxus, and Juniperus, be observed comparatively in this respect, we may easily be convinced that no reason exists for the admission of such duplications.-Rep.)

4. Pollen grains with four tunics.-Clarkia elegans, species of Enothera and Encharidium concinnum are here enumerated.

I have published some observations on the Spermatozoa of Jungermannia*, which exactly resemble those described by M. Unger in the anthers of the genus Sphagnum. I noticed the occurrence of these Spermatozoa of the Jungermannia in the interior of lenticular compressed vesicles (cells ?); in each vesicle there was a single worm-like creature with thick cephalic extremity and thin tail, and situated quite at the margin of the vesicle, so that the filiform tail can run round the margin of the entire vesicle and again touch the head. These cells containing the Spermatozoa are very large and in great quantity in the anthers; and in some genera of mosses they are enveloped in gelatinous mucus, which swells by absorption of water, causes the anther to open and expels the whole mass from it. On the solution of the gelatine in water these

* Wiegmann's Archiv, 1837, i. p. 430. 
cells are set free and then commence a constant rotation round their axis, sometimes to the right at others to the left. The enveloping vesicle appeared at times to be absent, and I then thought I could perceive that the Spermatozoa moved in a spiral direction. As these observations were made on a tour to the Tyrol, the last circumstanee could not be exactly made out; subsequently, however, I have convinced myself that in the Jungermannia and in mosses the Spermatozoa quit the cells at a certain period of their development and then move in numerous ways, but generally determined by the spiral rotation of their tail. The Spermatozoa of the species of Sphagnum which have been so accurately observed by M. Unger are also developed, as I have noticed, in the cells; but I have not been able to perceive their division as stated by M. Unger, although I have recognized it in the Spermatozoa of animals.

In the splendid work of M. Lindenberg* there is also a chapter on the development of the female organs of fructification of the Riccia, whence it is concluded that the Riccia have no distinct permanent disk, but the whole frond must rather be considered as such, and the last cellular layer beneath the epidermis is the spot where the fruit at the time of maturity momentarily dwells, or as in the Corsinia arrives there even previously. The formation of the fruit begins quite deep, immediately above the under epidermis of the frond a small dark spot originates which appears as a cavity, around which the cellular tissue is compressed. This spot soon exhibits a distinct yellowish-white membrane which forms a globular sac, and is provided with an apex. In this sac are developed the disk-like bodies, whence the spores originate. The fruit, however, in its further development gradually ascends, while the cavity which was occupied by it in its earlier stages is again closed by the expansion of the cellular tissue. The fruit of the Riccia consists of two membranes, an inner the true sporangium, and an outer the pericarpium, which, like a calyptra, falls off when the spores have become ripe. In Spherocarpus and Oxymitra the outer tunic separates entirely, it becomes a distinct coat, and the calyptra then again appears as a membrane coherent with the sporangium in the interior of that tunic. At the formation of the spores in the

* 1. c. p. $392-404$. 
Riccice M. Lindenberg found the number 13 predominant, while M. Mohl considers 14 to be the general rule.

The following observation was made on the germination of the spores of $R$. crystallina, glauca, and fuitans. In the first fourteen days merely a swelling of the margin of the spores could be perceived; between the fourteenth and twentieth days this margin expanded at one, or simultaneously at several places. The expansions finally formed cells, but the further development could not be observed. The fructification of the spores is effected by the turbid fluid which proceeds from the apertures of the anthoid organs, and flows over the surface of the fronds.

M. Martens* has observed in the Botanical Garden of Louvain, a hybrid between Gymnogramma calomelanos and G. chrysophylla, to which Bory de St. Vincent $†$ proposes to apply the name of G. Martensii. At the same time the latter gentleman observes, that this hybrid formation appears to occur quite commonly in nature, for he had received several well-preserved specimens of this plant through L'Herminier from Guadeloupe, where it grows among the two above-mentioned Gymnogramma. He also enumerates several other ferns that might be considered as hybrids, which it is true is merely founded on suppositions, to which however I am partially inclined to assent.

The experiments on the artificial propagation of plants by leaves have also been extended. In a memoir by E. Otto, W. Brackenridge, C. Plaschnick, and C. Bouchéł, gardeners in the Royal Botanical Garden of Berlin, several new observations of the kind are enumerated; the work originated in a prize question which had for many years been proposed by the Horticultural Association, as to the best mode of increasing plants by cuttings, and it obtained the prize as the best of the answers communicated. The memoir is divided into four parts, which treat of the propagation of plants by true cuttings, by root cuttings, by gem cuttings, and by leaf cuttings. In the latter section it is stated that several species of Theo-

* Hybridité dans les Fougères.-L'Institut, 1837, p. 228.

+ L'Institut de 1837, p. 280.

† Verhandlungen des Vereins zur Beförderung des Gartenbaues in den Königl. Preuss. Staaten. xiii. $1^{\text {s }}$ Heft. Berlin, 1837, p. 7. 
phrasta, Aloe, Echeveria, Gloxinia, and Cotyledon, may be propagated by leaves; healthy leaves of these plants are chosen, they are cut off close to the stem, and then placed singly in small pots in a light sandy soil. The leaves are covered with a bell-glass which must be open at the top. In the course of eight weeks the leaves become cartilaginous, put forth roots, and then very soon a young plant appears above ground.

It is desirable that this subject should soon be more fully investigated, for we know at present that the emission of young plants from leaves may take place in several ways; first by a production of true buds, as in Bryophyllum, and partly also in Ceratopteris; and secondly, by a previous formation of gems, as in Ornithogalum thyrsoides, Ranunculus bulbosus, cabbage leaves, \&c. In M. DeCandolle's Vegetable Physiology, (ii. p. 118.) M. Rœper has brought together several other cases of the kind.

I have again drawn attention to the increase of mosses by gems*, in which way, at least, several species of mosses propagate quite as plentifully as by true spores; Mnium androgynum, L., is the most known in this respect. A drawing annexed to the article of the extremity of a similar gemmal petiole exhibited a number of petiolated gemmæ which subsequently drop off from the stalks which become brown. Mr. G. Dickie has also published several observations on the same subject†; he saw in the gemmæ of Bryum (Mnium) androgynum on their first appearance nothing more than simple minute transparent vesicles of an oval form. I perceived in them immediately after their first appearance extremely delicate greenish masses which were converted into globules, and were again partially employed in the interior for the formation of new parietes. Mr. Dickie says, that these gemmæ in their mature state contain a substance of granular appearance, but no mention is made of their cellular structure ; the drawings unfortunately can hardly be termed recognizable. According to my subsequent observations, there is first formed in the simple elongated vesicle which occurs as the

* Einige Worte iiber das Vorkommen von Brutknospen bei den Laubmoosen.--Wiegmann's Archiv, 1837, i. p. 424.

+ Observations on the Gemmæ of Bryum androgynum.-Magazine of Zoology and Botany, vol. ii. p. 226. 
first state of the gem, one or several horizontal walls, and then these newly originated cells are more or less regularly divided by longitudinal septa into smaller cells : during this time the circumference constantly increases until the whole formation is completed. Mr. Dickie also repeated the experiments on the germination of the gemmæ, which had been long before instituted, described, and figured in Germany; he saw the first radicle make its appearance at the side of one extremity, and it appeared as if it had proceeded from the interior and had broken through the membrane.

Mr. Berkeley's* observations on the second membrane in the Asci of some Fungi, as in Sphceria populina, pedunculata, \&c., will require new observations to be made on this subject with the aid of modern microscopes.

M. Schwann $†$ has published a series of interesting experiments on vinous fermentation, which appear to give another direction to the answer of the question respecting equivocal generation. He discovered that vinous fermentation is constantly connected with the development of a peculiar fungus, which he proposes to name Saccharomyces, Sugar Fungus. He had also accurately observed the development of a similar fungus in beer-yeast, when this subject was published in the Institut du 23 Nov. 1836, by M. Cogniard-Latour. I did not enumerate the latter observations in last year's Report, in order to compare them simultaneously with those of $\mathbf{M}$. Schwann, as these interesting discoveries evidently belong to both naturalists. M. Cogniard-Latour observed that the mash an hour after the addition of yeast exhibited some single globules resembling those contained in the yeast; an hour afterwards some of these globules had doubled, while it appeared as if the second globule had been expelled from the first. The second globule soon became of the same size, and subsequently no single globules were found; nay, finally always three, four, or more such globules were found adhering. M. Cogniard-Latour came directly to the conclusion that the

* On the existence of a second membrane in the Asci of Fungi.-Maga. zine of Zoology and Botany, vol. ii. p. 222.

+ Vorläufige Mittheilungen betreffend Versuche über die Weingährung und Fäulniss.-Poggendorff's Ann. der Phys. und Chem. vol. xli. p. 184.

G 2 
globules of the mash had originated from seed in the globules of the yeast; he also states that twice he observed the flowing of some fluid out of those globules of the yeast. M. Schwann's observations on this subject are however much more accurate, and I am able to confirm them were there any need of it. He saw in the beer-yeast most globules cohering in series; they were partly round, but for the most part oval granules of a yellowish white colour (they are perfectly colourless in achromatic instruments.-Rep.), which partly occur singly, but generally in series of $2-8$ or more. Usually one or more distinct series branch off obliquely on such a series. In short, the whole is an articulated and ramified plant. M. Schwann observed, that the new articulations grew forth at the ends of the terminal articulations, as the articulations to form new branches were emitted laterally. During the fermentation of the expressed juice of the grape similar plants were observed, which presented but a small difference from those of the beeryeast, only that such long threads as are perceptible in the latter were not noticed in the vinous fermentation. In the recently expressed juice nothing of these plants is perceptible; at $20^{\circ}$ they may be observed in thirty-six hours, and M. Schwann could observe the increase of their volume under the microscope in the interval of from half an hour to an entire hour; they are here more globular, and generally only two are adherent together.

I have also been able to observe the growth of new articulations from the ends of older ones in plants from beer-yeast and also in vinous and apple ferments. The process is very interesting and may be followed completely; the individual articulations subsequently separate and again grow on under favourable circumstances. Each articulation of this plant is a distinct independent plant, which immediately continues to grow when disturbed in its adherence; or each articulation must be regarded as a spore of the plant. If the single articulations, in which state the plants in the thick beer-yeast are generally found, are mixed in the mash, they continue to grow, and in thinner fluids the plants become very large; their branches extend radiately in all directions. I boiled the plants from beer-yeast for ten minutes, and yet I observed their fur- 
ther development when again brought under the microscope ; and M. Cogniard-Latour* exposed them to various degrees of cold; but even after the action of a cold $90^{\circ}$ cent. they still retained the property of decomposing sugar.

Similar plants occur in cider ferment; they are articulated and ramified in the same way as in the beer-yeast, but their joints are mostly three times as broad as long, and I also observed on them an increase by mere separation, although rarely.

M. Schwann demonstrates the connexion between the fungus described and vinous fermentation: however it is probably yet too soon to explain the phænomena of fermentation from their development; first, because the formation of the fungus is carried on much earlier than the development of carbonic acid in the fermenting fluid, and then there are several other plants which are developed more or less at the same time with them in the fermenting fluid,- several of which, in connexion with the former, are described under the untenable genus Mycoderma, Persoon and Desmazières; nay, if the supposed species of Mycoderma had not been figured by Desmazières $\dagger$ we certainly should never have had a clear notion of them. Desmazières described a Mycoderma vini, glutinis farinula, malti-juniperi, malti-cerevisia, and cerevisia, but here two entirely distinct things are constantly united which do not at all belong to one another; namely, the small articulated fungus previously mentioned, which we call Saccharomyces after M. Schwann's proposal, and form at present the species Saccharomyces vini, cerevisia and pomorum, occurring in all fermenting substances, together with a larger confervoid one, the formation of which is also in many respects highly remarkable. To this place belongs the confervoid fungus which Amici observed in the sap of the weeping vine, the growth of which also takes place very rapidly, so that the elongation can be observed in a few minutes. This confervoid fungus is more or less shortly articulated in various fermenting substances, frequently unarticulated and unramified for some length, and then the articulations form at the branches, frequently over the whole thread at more or less regular distances, and then again, especially towards the end of the branch, the articula-

* L'Institut, 18 Feb. $1837 . \quad$ No. 199, p. 73.

+ Ann. Scienc. Nat., tom. $x$. 
tions swell to a globular form, subsequently disunite, and again develop to new plants; yet rarely will two fluids be found in which these plants are quite similarly circumstanced. In the expressed juice of a Borsdorfer apple, a fungus of this kind, of great beauty, was formed together with the Saccharomyces; several large, almost globular flocks, frequently of the size of a pea, were present in the fluid, which were separated from one another, and always consisted of a very large, or rather innumerable coils, of such single confervoid fungi, at the basis probably adherent. I observed this very interesting form for many weeks, and placed a single flock in a watch-glass with pure water, and so that the branches came to lie close at the surface ; to prevent the evaporation of the water the whole was covered with a plate of glass. In the lapse of from eight to ten days new radiate bundles were evident, and among these might be observed several which proceeded from the globular separated articulations of the original confervoid fungus, while others had developed fruit and represented nothing else than Mucor Mucedo when growing in water.

This form of the Mucor growing in water is but slightly different from the aërial form, and even the outer membrane of the sporangium may be observed on it. Mr. Berkeley* has observed the origin of this confervoid fungus in currant wine, and also noticed that it developed the organs of fructification of Mucor clavatus. The drawings which Mr. Berkeley has given prove sufficiently that in both cases we have observed one and the same species; I however consider the Mucor as M. Mucedo, and am of opinion, from actual frequently repeated observations, that $M$. clavatus is merely a small variety of $M$. Mucedo, and cannot be regarded as a distinct species.

From this observation, which I repeated, I conclude that the Mycodermes are undeveloped vegetable forms, and, as some other observations show, belong to the genera Mucor, Pennicillum and Aspergillust. And here also belong the greatest

* On a Confervoid State of Mucor clavatus, Lk.-Mag. Zool. and Bot., vol, ii. p. 390.

+ Note.-I would here especially enforce upon botanists the necessity of at last directing their observations to the development of the lower forms of Fungi, a subject which will be in the highest degree rewarded although the number of the so-called species and genera of recent times will frightfully disappear.-Dr. Meyen. 
number of species of Agardh's supposed genus Hygrocrocis, as $H$. acida, vini, rosa, atramenti, salvia, \&c.

In the fermenting fluids occur however several other things of difficult determination; thus I noticed in the beer-yeast excessively delicate confervoid forms, which are generally somewhat longer than the single articulations of the Saccharomyces, but are at the most only one-tenth in breadth; they are not of like length, and increase by division into still smaller threads. They are only sufficiently evident with a magnifying power of 300. In the expressed juice of the grape I observed, besides the two above-described plants, a delicate white sediment, which adhered to the glass at the margin of the fluid; it was formed of innumerable perfectly round and equally sized bodies, which were about one-tenth the size of the articulations of the Saccharomyces, and in the course of from three to four days disappeared entirely.

The number of vegetable forms which occur in the fermenting juices of fruits is consequently very great, and whether the phænomena of fermentation depend on the one or the other cannot be decided. M. Schwann instituted some observations with the vinous fermentation, whence he concluded that in vinous fermentation as also in decomposition it is not the oxygen of the atmospheric air which produces it, but that it is a substance destructible by heat contained in the atmosphere. A solution of sugar was mixed with yeast, exposed for ten minutes to the temperature of boiling water, then brought into a small bottle under mercury, and some heated air (one-fourth to one-third of the volume of fluid) conducted into it. The bottles with the heated air were then closed with a stopper and placed aside in a temperature of $10^{\circ}$ to $14^{\circ}$; they evinced however no phænomena of fermentation, while other bottles with the boiled fluid, into which however no heated air had been conducted, were in the course of four to six weeks broken into pieces from the development of the gas. The phænomena which M. Schwann observed in these experiments are in effect very remarkable, but they might probably be explained in some other way: the temperature of boiling water, it is true, does not destroy the Saccharomyces as previously stated; but we also know that even the germination of the seeds of higher plants does not take place in perfectly boiled water, although exposed to the atmosphere. 
M. Trog*, of Thun, has published some general observations on the propagation of fungi by Mycelium and by spores, confirming several statements previously published in various works. The recent observations on the occurrence of spores in the higher fungi were not then known to M. Trog. The question how the sowing of the spores of fungi is effected in nature is treated of at great length: it appears highly probable to the author, that the spores of the Hymenomycetes are partly suspended in the air, carried everywhere by the wind, and adhere to all bodies, or as it were are precipitated from the air by rain. Thus for instance after some rainy days numbers of Mycenes, dung fungi, \&c., are seen to shoot forth, which had been probably sown in this manner. Some examples are also enumerated to give weight to the notion that the spores of fungi float partly in the air; for instance, if the divided membrane of a laminated fungus be placed with the lamellæ downwards on paper, the spores, as is commonly known, fall on the paper ; as soon however, says M. 'Trog, as the lamellæ, from sinuosity or from becoming vaulted, are not in contact with the paper, these spots on the paper appear without any spores, because the current of air is sufficient (even in closed rooms) to carry them away. I repeated this experiment, but found the explanation nearer at hand: the falling down of the spores is mechanically prevented when the lamellæ are pressed together by their lateral surfaces. The second statement is very remarkable : place a Peziza or Helveila on dark paper, and from time to time, especially on a little shaking, it will be perceived how many of the asci empty themselves all at once with rapidity of their spores, a smoke being seen to ascend from their hymenium, which however immediately disappears, and even after several hours no considerable traces of their fall can be noticed around the fungus; consequently they have remained in the atmosphere or have been carried away by it. The other statements have long since been proved to be insufficient.

M. Schwabe + has published some observations on the Oscillatorice of the hot springs of Karlsbad, which correct in several points the labours of his predecessors. He too feels the

* Ueber das Wachsthum der Schwämme. Flora 1837, No. 39.

+ Ueber die Algen der Karlsbader warmen Quellen. Mit 2 Tafeln Abbildungen. Linnæa, 1837, p. 109-127. 
great want existing at the present day in the systematical definition of this genus and its species; for the most opposite things have been described under the name Oscillatorice, and again frequently the most similar forms have been enumerated as distinct species. When one has observed for years the growth of the Oscillatoria daily in one's study, and noticed the manifold changes of form in one species, it is really almost impossible to conceive how travellers venture, during a short stay at Karlsbad, to describe twenty, thirty, and even more new species of this genus,-a case which really occurred recently.

M. Schwabe has limited his observations only to some few of these plants of the sources of Karlsbad, and he has therefore succeeded in observing something useful respecting their structure and propagation. The separation of the genus Mastigonema from Oscillatoria cannot however be adopted; for the very plant belonging to it, is to be regarded as the representative of the true Oscillatoria: It is interesting to see that the sporangia or spore-threads of Nostoc anisococcum, Spr., have been described and figured as four distinct species of Spharozyga; these supposed species of Spharozyga stand in the same relation to the Nostoc as the Oscillatoria Flos aquae to our common small Nostoc. The complete history of the development of the Alga, which M. Schwabe has figured and described as Fischera thermalis, is of great interest; this probably is presented to us by the same M. Fischer to whom natural history is indebted for one of the most interesting discoveries of recent times*.

M. Morren + gives, with an accurate description of the structure of Conferva dissiliens, his views on the various generative functions which are said to belong to this plant. He says that the cells of this Conferva contain an almost homogeneous mass, an endochrome, in which some distinct globules occur which are converted into transparent vesicles yellower than the rest of the mass, and exhibiting in their interior dark spots of a brown or red colour. These larger globules which occur in all true Conferva and have hitherto been regarded as similar to the cellular sap-globules in other plants, are considered by

*.The discovery here alluded to is probably that of the shields of some Infusoria being composed of silex.-W. F.

† Bulletin de l'Acad. de Bruxellles, 1837, p. 303. 
him to be the male generative system, which performs on the other portion of the endochrome a true impregnation. This view would appear however to be a mere hypothesis, when we observe the formation of the spores in the Spirogyre by conjugation, as in these plants all the cells contain the larger globules, which M. Morren regards as the male generative system, and yet germinating seeds are only formed in the conjugated cells.

I have published* some observations on the brownish vesicles which characterize the cavities at the extremities of the Closteria by their active molecular movement. Gruithuisen discovered this motion twenty-six years ago, and he subsequently observed a current of minute globules which occur at the margins of the Closteria, and may be compared to that in the Chara. I pursued these observations somewhat further, and remarked that they consist in two currents of minute globules proceeding in opposite directions, and are evident both on the concave and convex sides of the Closteria. Other observations showed that these brownish vesicles pass out of the cavities at the extremities of the horns, and that they can change from their constant and lively molecular movement into a merely progressive one, and vice versa; for they re-assume their molecular movement so soon as they have returned from their progressive motion into the cavity of the extremity. The observations for this view are specially given in the work above-mentioned, and I have subsequently made several similar observations on the cellular sap globules of higher organized plants, which are enumerated in the second volume of my Vegetable Physiology, in the chapter on the rotatory current in cells.

Sir W. J. Hooker $t$ has brought together numerous observations of great interest on the duration of the germinating power of seeds, on which subject various, and frequently almost incredible notices have appeared of late years. In the first place, the observations of Ch. des Moulins, from the memoirs of the Linnæan Society of Bordeaux, (which unfortunately are not at

* Wiegmann's Archiv, 1837, p. 426.

+ Information respecting seeds which have been found in Roman tombs, and which have retained their powers of germination, \&c.-Companion to the Botanical Magazine, 1837, vol. ii. p. 293. 
my disposal in Berlin) are related, according to which some Roman graves were opened in the Commune de la MouzieSt.-Martin, Canton Laforce (Dordogne), which contained in their coffins seeds of various plants, almost all retaining their powers of germination : they were seeds of Heliotropium Europaum, Medicago lupulina, and Centaurea Cyanus. Next follow the observations of Dureau de la Malle, according to which, seeds of birch, ash, brooms, Digitalis, \&c. can retain their powers of germination after a hundred years and more under ground; and birch and mustard seeds can lie for 20-30 years under water without losing this power. Finally, Sir W. J. Hooker communicates a letter from W. Burroughs, in which is announced that seeds of Centhranthus ruber were found in an old tomb at Wymondham Abbey, which germinated and produced flowering plants. The seeds were found in a small coffin of baked earth, closed air-tight; they were packed together with salt and odoriferous shavings with a foetus and wrapped in linen, which was coated with pitch. The tomb, in all probability, dated from the middle of the twelfth century.

In October, 1834, there was also a notice in Loudon's Gardener's Magazine on the opening of a British tomb; on which occasion, in a portion of the contents of the stomach, a quantity of small seeds were found which were declared to be seeds of the raspberry. These seeds germinated in 1836 and brought forth excellent fruit*. Mr. Lindley immediately concluded that the raspberry, at the time the tomb was placed there, somewhat about 2000 years ago, grew wild in England.

MM. Edwards and Collin $\uparrow$ have instituted a series of experiments on the influence of vapour on vegetation : they placed various seeds under exactly similar circumstances to germinate; only the amount of vapour in the surrounding media was different, in order to observe directly its influence on vegetation. It was observed that the influence of vapour was exceedingly great, and that it very much hastened the vegetation in this first period. The favourable circumstances which accelerate the germination of seed are, the presence of as much moist-

* Loudon's Gardener's Magazine, 1836, p. 695.

† Influence de la vapeur sur la végétation.-L'Institut, 1837, p. 193. 
ure as the seeds are in want of for absorption, an atmosphere which is almost completely saturated with vapour. This is also applicable to the other periods of vegetation (as is shown by the vegetation in the moist tropical forests.-Rep.). And it thence follows, that in the hot-houses of our gardens the influence of vapour on vegetables should be employed to a far greater extent than has hitherto been the case.

The Feuilleton du Temps, 18 Avril 1837, contains a more detailed communication of the memoir by MM. Edwards and Collin, from which I will mention some of the results obtained. In the open atmosphere, even when it is very moist, the seeds of plants are said not to germinate. I have, however, only in last year's Report mentioned exceptions to this rule. The seeds of grain germinate in an atmosphere saturated with moisture; under water they require eight times the length of time. With a simultaneous action of water and vapour, the seeds germinate earlier when the atmosphere is saturated with moisture.

\section{Morphology.}

From the great number of memoirs which appeared in the course of 1837 treating of the morphology of plants, I shall first select that of M. von Martius*, as the subject is there treated in a more general way.

First Lecture.-The plant, observes von Martius, is an organized body expanded between heaven and earth, free above, but below fettered in the bands of the earthly. The plant lengthens upwards and downwards, and differs in this twofold growth, the descending and the ascending, so completely, that the appearance of its twolarge systems is accompanied with and incloses totally distinct formations. The root is essentially the simple uniform portion (shut up as it were within itself) of the plant. It constantly persists in its downward direction; it increases in length and in breadth; can ramify by division; but neither is it as a whole, nor are its individual parts, capable of transformation. The ascending axis of the plant is its solar and aerial system; it is diametrically opposed to the

* Die Metamorphose der Pflanzen. Four lectures.-Reden und Vorträge, \&c., p. 111-223. 
root. In all of the more highly developed plants the ascending axis soon separates into two formations, differing essentially from each other, which, undergoing constant change, represent in various forms the whole super-terrestrial life of the plant. They are the axis or the stem and the leaf. The stem is the persistentpart of all the super-terrestrial formations; it is opposed to the leaf as the bearing part; it forms the centre, the axis; the leaf on the contrary appears as a peripherically secreted part, which can be imagined to be separated here and there from the stem. M. v. Martius thinks that the leaf may also be considered as a secondary and reramified axile formation, but that with respect to its inner form it is asymmetrical.

The axile formation increases in length and in breadth, and after some time divides into branches, thus resembling exactly the descending axis. But an essential distinction between the growth of the stem and that of the root is said to consist in the first being developed at fixed periods, while the root is less subject to periods of terrestrial life, and is therefore in a constant state of growth at all times of the year.

The leaf is developed by unfolding itself : it is not merely an extension and elongation, but an increase in breadth ; and this vital principle is the cause of its deviating from the perpendicular position of the axile formation. The common leaves are destined to increase and ameliorate the saps by the absorption and secretion of gaseous fluids : not so when the leaves have changed their form, when they have become metamorphosed; a phænomenon which constantly accompanies the production of the germ. A sexual function is the end of all leaf-metamorphoses: the pistil-leaf on the female side, the pollen-leaf or anthers on that of the male, wind up the beautiful play of metamorphosis. These sexual leaves do not immediately succeed the green ones, but a series of changes of other leaves intervene, which, however, also belong to the generative system. They differ from the foliage by their form and colour, and may be termed coloured leaves. The transformation of common leaves into coloured and into sexual leaves is called the ascending metamorphosis; the retrograde metamorphosis designates on the contrary the change of me- 
tamorphosed into green leaves. In the flower the axile formation seems to disappear entirely and presents itself as the receptacle. The transformed leaves now stand no longer one above another, but side by side, and are therefore developed nearly cotemporaneously.

There are three essential points in the ascending growth, in the development of which the whole formative principle is in action;-node, leaf, and internode. If we inquire into the origin of leaves, we find a thickening of the axis and a convergence of its vessels in the node, just beneath the lateral insertion of the leaf. Above a node the vessels again resume their regular ascending course; they return to perfect order and symmetry, until at the end of the internode they come to a new node and foliaceous formation, and thus several internodes stand one above another in the axile development. The formation of each collateral axis is also stated to be preceded by that of nodes and leaf.

Second Lecture.-Leaves with distinct sheath processes, with petiole and with the peculiar foliaceous expansion, are regarded by M. von Martius as perfect leaves; however, all leaves do not possess these three parts, but sometimes the one, sometimes the other exhibits a predominant development. From these differences three kinds of leaves may be distinguished: sheath leaves (Coelophylla), petiole leaves (Steleophylla), and surface or broad leaves (Placophylla). The succession of the green leaves from the root to the leaves of the inflorescence is of high importance for the history of the development of the plant. In general the formation of leaves commences with Coelophylla, further upwards on the stem both the other dimensions of the leaf occur, and when it comes to a ramification of the axis one or the other of these stages of the leaf is again lost. These changes are still more remarkable when a flower proceeds from the axis instead of a leaf-bearing branch. These are the bracts, called ante-leaves or bearing leaves, the functions of which still coincide with those of the common leaves. But the changes which the petals and sexual leaves exhibit are far more decided in form and colour. At the metamorphosis of the leaf into stamen the formation of the pollen proceeds in its interior. This metamorphosis takes place in the upper or 
superficial parts of the leaf, which has become converted into the anther, while the filament corresponds to the petiole of the common leaf. The fruit leaf is the upper and last stage of leafmetamorphosis, and here we find the three dimensions of the leaf each changed in a peculiar way; the sheath portion is converted into the germ, the petiole into the style, and the superficies into the stigma. The fruit leaf is in general not situated at or near the axis, but exactly upon it, and consequently the elongation of the axis is herewith at an end. The axile formation takes part in the formation of the fruit only in so far as it frequently ascends along the suture, which is formed by the cohesion of the margins of the coelophyllum, and becomes part of it. This is most evident when the pistil is formed of several leaves. When the margins of each leaf cohere inter se and with the intermediate ascending substance of the axis, several cavities are formed in the germ; but when the margins of each single fruit leaf do not cohere inter se but with the margins of the neighbouring leaves, one cavity is produced. The flower does not give rise to collateral axes which remain adherent to the plant, but produces axes of peculiar structure, which separate from the primitive axis and commence an independent life; these are the seeds whose development before and after impregnation is treated of at some length, according to the facts at present known.

The leaves belonging to the series of the calyx and corolla are to be regarded as leaves of two impulses following closely one upon another. They are the peripherical parts of two continuous portions of the stem which here indicate its metamorphosis by the considerable contraction of the axis and by the change in the form and colour of the leaves. The calyx consists mostly of leaves which correspond only to the inferior or sheath parts. They stand perhaps in the same relation to the following more finely organized leaves as the scales of the leaf-buds to their leaves. In a higher stage of development the leaf becomes coloured; in the young bud the colour of the petals is generally of a light green. The petal is however not a leaf metamorphosed in all its three dimensions, but it is especially the lamina or surface portion of the leaf which is most developed, and the petiole is reduced to the unguis in its development. When the petals are united in- 
to a single piece, the ungues form the tube, and the surfaces the limb of the monopetalous corolla. Thus we have seen, concludes von Martius, that the flower is that portion of the ascending axis, in which the leaf, having undergone a four-fold metamorphosis, ascends by degrees to its ultimate destination. It is a four-times metamorphosed shortened branch, which has departed from the nature of the leaf-bearing branch, \&c.

Third Lecture.-On closer consideration of the formative processes of the flower, several laws become apparent, such as, 1st, the succession of four great stages of formation, the whorl of calyx, corolla, stamens and pistil. In accordance with the second law, the calyx and corolla consist each of one whorl of leaves, on the contrary, the series of the stamens of two whorls. The third law is founded on the number in the structure of the flower, as in regular flowers the number of the members of all whorls is the same. The numbers three and five appear most frequent in the whorls of the flower: three prevails in Monocotyledons and five in Dicotyledons. Calyx and corolla generally remain constant to this number, i. e. duplications occur rarely. When these whorls consist of fewer members the case may be regarded as an exception. The series of the stamens is however more subject to duplications. The numerical relation of the last whorl or that of the pistil undergoes frequent reductions, especially in Dicotyledons, where instead of five frequently only one or two pistils occur; at times it is also increased. The difference in the numerical relation in the series and in the members of the whorl of the fructification is exceedingly great in various plants, sometimes the typical numbers remaining equal from the calyx to the whorl of the pistil, or increasing towards the centre of the flower, or decreasing in that direction. The position of the members in the various whorls of fructification depends on the consideration of the numerical law. It is said, the members of the next succeeding whorl are so arranged that they alternate with one another, whence it results that the position of each leaf in the flower is a regular one. The most general types of the flower, therefore, the Monocotyledons and Dicotyledons, may be represented by two diagrams, and M. von Martius then considers how this formation may be compared to the process in operation at the 
production of leaves and of branches, for it was demonstrated that the sepals and petals are only leaves and the flower a shortened branch.

Since the leaves are arranged either opposite or in a spiral, these two types may also be admitted in the process of the formation of the flower, namely that of whorls and of spirals. ' $\mathrm{l}$ 'he latter case is the most frequent, and it is proved by an examination of the doctrine of the position of leaves that nature acts after the same laws in the formation of the flower. Now since the flower is a shortened branch, the leaves united to form a whorl cannot always stand next one another so as to be in contact in their regular succession; for were this the case with a whorl of five members, each leaf would only be at a distance from the next of one-fifth part of the circle, while they are in reality two-fifths or three-fifths of the circle from one another. The arrangement of the sepals and petals is generally distinguished by their imbrication, those leaves being superposed which first separated from the stem, exactly as in the leaf-bud. We have already seen that the members in the successive verticils of the flower alternate, and this may be explained by the supposition that a different proportion is in action between the different whorls; - a proportion, which is one half greater than that which prevails between the members of the same period.

When the number of the members in the whorls does not remain constant through the whole flower, we may suppose two possibilities to explain it; either a reduction occurs in the members of one or more whorls which agree in proportion with the rest, or the several series of the flower follow different proportions. In both cases a dissimilarity occurs in the numerical relations, and frequently connected with it an irregularity of form also. The latter arises from unequal expansion and elongation.

Fourth Lecture.-Von Martius endeavours to demonstrate in this last lecture the general morphological laws which were developed in the preceding one in their special relations; those of the flower are first entered upon, and he then treats of the top, the bottom, the front, the back, the left and the right of a plant: the gradual passage of the carpel into fruit is treated of more at length, but this I can merely indicate. 
Shortly previous to this sheet going to press, I received through the kindness of Alex. von Humboldt the splendid work on the metamorphosis of plants, which M. Turpin has recently published*. It contains only seventy-nine pages, but of very small print, and in the largest folio ; three plates accompany it, designated by $3,4,5$, and drawn by M. Turpin, and on their account very probably the inconvenient folio size has been chosen.

We are already acquainted with M. Turpin from the ' Iconographie Végétale,' as a botanist who has his peculiar notions on the metamorphosis of plants, which however have met with great opposition, especially in Germany. In the present work he has brought forward the same views, only in a somewhat different form, without paying the least attention to the many valid objections made by E. Meyer in the seventh volume of the Linnæea. Upon the first plate M. Turpin has represented a typical or ideal plant to prove the "unité de composition organique," as well as the radiate or centrifugal development and the original identity of all the appendiculated parts. It is divided into a Système terrestre and a Système aérien; the former appears to me particularly incomplete, although it is correctly represented as an immediate continuation of the stem. The pith of the stem proceeds through the whole of the main root to its apex, while the collateral roots take their origin in the wood. The axis of the aerial system of the ideal plant is terminated by the embryo, which in one case is situated with its radical apex on it, and in the second case is attached to it by a kind of umbilical cord. On the second plate are represented a beautiful series of splendid monstrosities of various parts of the inflorescence, several of which may be quite new, and some of which I shall subsequently enumerate, without agreeing: with $\mathrm{M}$. Turpin as to their signification.

On the last plate three beautiful proliferous centifolial roses are figured with great art, the sepals have become converted into common leaves, and moreover the gradual change of the petal into anther is demonstrated. I regret from want

* Esquisse d'Organographie végétale, fondée sur le principe d'unité et de composition organique et d'évolution rayonnante ou centrifuge pour servir à prouver l'identité des organes appendiculaires des végétaux et la métamorphose des plantes de Guethe. Paris, 1837, fol. 
of space not being able to go more deeply into the doctrines of this work, which shall be done in next year's report, if in the mean time no other person shall have taken up the subject.

The profound researches of L. and A. Bravais* respecting the arrangement of the leaves have excited in the past year particular attention, especially on account of the difference in the exposition and in the results from the similar inquiries of German botanists. Several new terms have been added to the existing nomenclature in reference to this subject which I shall commence with. Secondary spires are those multiple parallel spires which by their union embrace all the leaves; the number of these spires is called the secondary number, and the divergence separating two consecutive leaves of one of these spires, the secondary divergence ; thus, when parallel and equidistant spires suffice to embrace all the leaves, eight will be the secondary number of these spires. By encyclical number is understood the number of circumvolutions requisite for the primitive spire to pass from one leaf to the next following of a secondary spire. For the sake of shortness the expressions dextrorsum and sinistrorsum are frequently replaced by their initials $D$. and $S$. : thus $2 S$. represents a system of two parallel spires comprehending all the leaves and proceeding from right to left ; $3 D$. a system of three dextrorsal spires, and so forth.

Although the leaf and the vital node are two decidedly distinct organs, yet they are not here separated; and frequently the word insertion is employed, which has the advantage of being equally applicable to the leaf and to the various foliaceous organs, such as the scale, bract, \&c. derived from it. Motherleaf is that leaf in the axilla of which any of these parts may have originated. The authors divide the leaves into two different groups; 1. curviseriate, arranged on all sides in spiral lines, never forming vertical series, each leaf being the only one on the vertical containing it; 2. rectiseriate, capable of forming series parallel to the axis of the stem.

The memoir is divided into two chapters; in the first the geometrical laws of the spirals are developed, and in the second

* Essai sur la disposition des feuilles curvisériées.-Annal. des Scienc. Nat. Bot. p. 42-120. 
the position of the curviseriate leaves treated of ; both are of such extent and go so deeply into the minutia, that we must here content ourselves with communicating the results which the authors themselves have drawn from their observations.

At the commencement of the first chapter the following suppositions are made before entering into a more accurate exposition of the question relating to the multiple spires: the point of the insertions forms a cylinder: the secondary spires are geometrical helices: the coils are all parallel to each other and equidistant. In the resumé it is further stated, that it frequently happens that the spires of an aggregation of leaves or of vital nodes are raised or depressed, and cease in consequence to be spirals in the most rigorous acceptation of the word. Nevertheless this arrangement can hardly be said to invalidate the results?

It is quite certain that some unknown cause at times disturbs in a greater or less degree the uniformity of the successive internodes; but this does not destroy the divergence. Just as the most depressed spires, for instance the primitive spires, are the most favourably disposed to allow of our appreciating by means of their deviations, the least variation in the vertical heights of the insertions, in the same way the most elevated spires, those approaching most to the vertical, being placed under quite opposite circumstances, will also be most advantageously situated to allow us to appreciate the least change in the secondary divergences, as these variations of different kinds occur in each of the two cases in the direction of a line which is almost perpendicular to the spiral. Now we find as a constant fact of observation, that the more the spires are of a higher order, the more regular are their forms and directions. When an insertion is driven out too much to the right or to the left by some alteration in the vegetative power it is only a local fact, an apparent deviation from the law, and the succeeding insertions do not generally participate in this displacement. Let us suppose that the place of the insertions is no longer a cylinder but a conical surface, which is even more conformable to nature, the secondary spires become Archimedean spirals on the plane of convolution. But it may also happen that the spires do not exactly follow the law of the spiral above expressed, they may either be too much raised or too much 
depressed in various portions of their course; it will be with these flexuosities, generally inconsiderable, as with those treated of above in the case of the cylinder, and we shall still be right in concluding generally on the constancy of the primitive divergence from that of the secondary divergence. And finally, in the general case, when the place of the insertions is conical, nothing prevents our conceiving it to be divided into horizontal sections, each of which would belong to various cones; and our results, true for each section, must also hold good for the whole.

With respect to the parallelism and equidistance of the secondary spires among themselves, this is a supposition rendered sufficiently evident by the direct observation of the plant; it is only occasionally changed by that force which at times disturbs the normal height of the insertions; and as soon as this normal height is re-established, the parallelism again makes its appearance.

These results (those namely of the preceding paragraphs) may be considered as general and independent of the geometrical form of the place of the insertions, and even of the regularity of the secondary spires.

The torsion of the stem must however not be neglected: sometimes it takes place in an opposite direction to the primitive spire, and then diminishes its divergence in appearance; at times it occurs in the same direction, and in this case the primitive divergence is on the contrary increased. This force rarely produces, in the opinion of the authors, any great effects; nevertheless it is highly important, in all cases where it is possible, to take into account this source of error.

The second chapter of this memoir contains the special consideration of all the cases occurring in the curviseriate leaves, to which I must refer the reader. The general results are however the following.

1. When an aggregation presents several spirals whose secondary numbers are prime to each other, the insertions are arranged on a single primitive spire, and are separated from each other by a constant divergence from one extremity of the aggregation to the other.

2. If the secondary numbers have 2,3 , or 4 for their common divisor, the insertions are arranged in whorls of 2,3 , 
or 4 leaves; and these whorls cross one another at a constant angle of divergence from one extremity to the other of the aggregation.

3. In the greater number of plants with alternate insertions the divergence of the primitive spire is an irrational angle equal to $137^{\circ} 30^{\prime} 28^{\prime \prime}$, which is but the small segment of the circumference divided into mean and extreme proportion : this angle corresponds to the series $1,2,3,5,8,13$, \&c.

4. Other arrangements may occur, but much more seldom, in which the divergence, still irrational, may equal $99^{\circ} 30^{\prime} 6^{\prime \prime}$, and correspond to the series $1,3,4,7,11 \ldots ; 77^{\circ} 57^{\prime} 19^{\prime \prime}$, and correspond to the series $1,4,5,9 \ldots \ldots ; 151^{\circ} 8^{\prime} 8^{\prime \prime}$, corresponding to the series $2,5,7,12$, \&c.

5. The constancy of each of these angles is not affected, at least in its mean value, by the inequality in height of the succeeding internodes and other local disturbing causes.

6. The insertions may present false whorls when they are grouped in twos or threes at the same height of the stem.

7. The primitive spiral is prolonged down to the subterranean stem, retaining the same invariable divergence, and sometimes even to the organs of the flower.

8. The direction of the spiral generally appears indifferent on the central stem and on the branch; it seems to be in no certain relation to the direction of the convolution of the voluble stems or to the torsion of the fibres on themselves; but on the branch this direction is determined by the position of the first leaf to the right or to the left of the primitive leaf.

9. All the series above cited may give rise to bijugate systems more or less frequently, and which will most frequently be present on plants with opposite stem leaves; the ordinary system may also give rise to corresponding trijugate aggregations.

10. The phænomenon of the convergence of two spirals into one must be explained by the partial abortion of one of these spirals, or by the cohesion of the two into one; a whole series may also suffer complete abortion; and this remark renders the existence of most of the recurrent series, which do not appear to belong to the series above enumerated, very doubtful. 
A second memoir of MM. Bravais* treats of the symmetrical arrangement of inflorescences; a work which is still more comprehensive than the first. On account of limited space I am merely able to communicate the summary which the authors have given at the end of the various paragraphs, believing that in this manner the results which they think they are able to draw from their laborious researches, will most prominently appear.

With reference to the inquiries respecting the uninodal cyme of Monocotyledons, we find the following summary.

1. The uninodal cyme is the type of the cymes presented by monocotyledonous plants.

2. The pedicel of each flower is furnished with a single bract, susceptible of abortion, whence a second pedicel does or may originate.

3. This bract indicates the spiral order of the pedicel.

4. The cyme may be helicoid, scorpioid or distichous, according to whether the pedicels are homodromous or antidromous or distichous.

5. It may be prolonged or contracted according to the state of the pseudothallus, with sessile or pedicellate, simple or double flowers; this last case happens when it is dichotomous at its origin.

6. It may be terminal or axillary, and in this second case the inflorescence is generally a thyrsus; as yet however we have not met with a terminal cyme among the scorpioids.

7. The double helicoid cymes have their two halves homodromous.

8. The double scorpioid cymes appear on the contrary to have their first pedicels antidromous to one another.

The following results have been taken from the paragraphs on the bracts of dicotyledonous inflorescences.

1. The greater number of dicotyledonous flowers have their pedicel furnished with two lateral bracts, sometimes developed, sometimes more or less entirely abortive.

2. These two bracts are most frequently the first leaves of a spiral proceeding from the primitive leaf and in continuation with the sepals; and when they are inserted at equal

* Essai sur la disposition symmétrique des inflorescences.-Ann. des Scienc. Nat. 1837, pp. 193, 291, 348, and vol. ii. p. 11-42. 
heights, this circumstance will suffice to indicate whether the pedicel is right-handed or left-handed.

3. In calyces with free sepals it is often easy to find out the direction of the calycinal spiral, and the direction of the pedicel spiral may be concluded from their æestivation.

4. In the Leguminosa the first sepal is closer than usual to the median line, which modifies the form of the flower without disturbing its general relations of organization.

5. The two bracts may be opposite-decussate: they may also not exist. In paragraphs 5 and 6 , the spiral and scorpioid uniparous cyme is treated of, and in conclusion the following summary communicated.

1. The binodal uniparous cyme is common in dicotyledonous plants.

2. To the upper bracts belongs constantly, or appears to belong, the germen.

3. The cyme may be helicoid or scorpioid according to whether the pedicels are homotropous or heterotropous ; it is clistichous when the distichous arrangement prevails on the pedicels.

4. It may be elongated or prolonged according to the state of the pseudothallus, sessile or pedunculated, with sessile or pedicellate flowers, simple or double.

5. It may be axillary or terminal : in the latter case it may be considered as formed of one or two partial axillary cymes and of a central terminal flower.

6. In a scorpioid cyme the æstivations of the flower of each series have a fixed relation indicating the nature of the cyme.

7. The involution is a necessary consequence of the axillary angle.

8. The floral series are organically opposed to the series of fertile bracts, but the excentric inequality approximates them, and separates on the contrary these latter one from another.

9. The sterile bract is frequently smaller than the fertile bract; it is frequently abortive; both may also prove abortive.

10. The primitive bract frequently coheres with its axillary pedicel.

11. The number of flowers is frequently variable; it diminishes above in the thyrsus, and the cyme may become uniflorous in consequence of this diminution.

12. The pedicels have sometimes a torsion in the direction 
of the secondary divergence of the fertile bract; this torsion tends to bring back the planes of the floral symmetry to parallelism.

13. An accessory branch may originate beneath the pedicel analogous to the central stem : a branch may originate analogous to the axis of the first bract.

14. Accidental exceptions to the preceding rules are now and then met with; the vegetables on which this exceptional state is constant are very rare.

The summary of the four following paragraphs is,

1. The biparous cyme is essentially descendant or ascendant: these two modifications do not appear to be met with together in one and the same natural group.

2. The biparous cyme is direct or inverse.

3. The biparous cyme frequently ends by becoming uniparous on its last branches; the direct ascending cyme and the inverse descending cyme then pass over to the scorpioid state; the inverse descending cyme and the direct ascending cyme on the contrary pass into the helicoid state.

4. The double uniparous cyme is a particular case of these modifications.

5. The central flower of a double scorpioid cyme belongs to the next concentric series to the primitive leaf.

6. The two partial axillary cymes of a double terminal cyme commence with pedicels parallel to each other: in the Boraginece it is the last node that produces the parallel pedicels.

7. The position of the terminal pedicel in the dichotomous ramifications is determined by the value of the complimentary divergences, and by the more or less excentric state of the pedicels.

8. The direct ascending cyme is not rare in the Apocynece and Polemoniacea.

9. The inverse ascending cyme appears to be characteristic of the Ranunculacea; several Ranunculi make exceptions among the dicotyledonous plants by their uninodal cyme.

10. The rectangular cyme is usually biparous, but sometimes it may be uniparous.

11. The trinodal cyme is frequently but a variety of the binodal, in which a node above the second, and heterotropous with it, would precede the terminal flower. 
In paragraphs 11,12 and 13 the multinodal cyme and serial cyme are treated of, as also the kind of cyme in the chief natural families enumerated, and in conclusion the following consequences drawn:

1. The accessory gem originates between a branch and its primitive leaf, proceeds from this branch in the same way as that from the central stem, and its primitive spiral has the same primitive leaf for its point of departure.

2. The other inferior accessory gems likewise grow the one from the other; the same leaf serves them in succession as a primitive leaf.

3. The gem produced between the branch and the axis may proceed from a vital node situated at the base of the branch and normally opposite to that of the angle of the leaf; or the branch is accessory to the gem, this latter remaining more or less stationary or becoming abortive.

4. The central axis, the principal branch, and the accessory branches may cohere in various ways among themselves.

5. The serial cyme is composed of peduncles superposed in this way: when these peduncles have their lateral vital nodes sterile, the serial cyme is simple, in the contrary case it is compound.

6. The accessory peduncle has constantly at least as many vital nodes beneath its flower as the peduncles produced from the first or second node of the central peduncle have beneath theirs: when this number is very considerable, it may be regarded as a leafy branch.

7. The multiple axillary embryos proceed directly or indirectly from a central axillary embryo; this latter is solitary in the angle of the leaf.

Finally, in paragraphs 14, 15 and 16, the thyrsus, the sirmentide, the laws of homodromy and antidromy are explained, from which the following conclusions are drawn :

1. When the successive axes of centrifugal inflorescences have a small number of lateral nodes, generally two or four, the second node is antidromous with the first, the third with the second, and the fourth with the third, and so on : these antidromes are the less constant as we arrive at axillary gems whose numerical order is higher. 
2. There result thence two distinct dispositions, according to whether the first node is homodromous or antidromous: these two kinds divide vegetables into two unequal, genenerally speaking very natural groups; but they may also be met with in nearly allied plants, or even in one and the same plant, according to circumstances of vegetation.

3. The vegetative ramification does not present any general law similar to the preceding, but in some rare cases, in which some constancy in the order of the spirals is found, the preceding laws determine the order of the first nodes, and the following three may be added to them : $3 a$. The opposite gems appear antidromous with respect to each other: perhaps the first law is merely a corollary of this. $3 b$. 'The consecutive distichous gems are antidromous with respect to each other, and are frequently given out unilaterally. $3 c$. On the curviseriate alternate axes, at a sufficient distance from the first nodes, the gems tend to become homodromous with respect to each other; sometimes homodromous, sometimes antidromous, to the central stem.

4. The accessory gems are most frequently antidromous with that which is immediately above them; this rule is nevertheless subject to exception when the gems are peduncles provided with a small number of nodes.

5. The dextrorsal accessory gems usually project to the right and the sinistrorsal to the left; the same effect is sometimes produced on non-accessory gems.

I must finally request indulgence if $I$ have not given various expressions in the sense of MM. Bravais, for I freely confess that a great portion of this immense labour has remained very unintelligible to me, and it is reported that many other botanists are in the same plight.

MM. Bravais have also published in a separate memoir the results of the observations of MM. Schimper and Braun on the position of the leaves of plants *.

M. Zuccarinit has published a very interesting memoir on the formation of leaves and gems in Cactea, which contains

* Résumé des travaux de MM. Schimper et Braun sur la disposition spirale des organes appendiculaires. - Ann. des Scienc. Nat. 1837. p. 161182.

† Knospen und Blätter der Cacteen.-Allgemeine Garten-Zeitung von Otto und Dictrich, No.25. 1837. 
a great treasure of positive observations : it is a work the more desired as we have recently obtained so complete a monograph of this family. The Cactece are, says the author, provided either with true leaves (Peireskia) or their rudiments (Opuntia, Rhipsalis, Epiphyllum, Hariota, Lepismium, many Cerei), or are actually leafless (Mammillaria, Melocactus, Echinocactus, the rest of the Cerei). From the axes of the leaves or, when these are wanting, from those places, where according to the laws of the arrangement of leaves they would be situated, bundles of thorns of various forms are developed, which may, according to analogy, be regarded as buds, and the thorns as thorny scales. In the Peireskia, in which alone true leaves occur, the petiole is separated from the leaf and is regularly thrown off. In the Opuntice the leaves are merely round, unarticulated, pointed or obtuse formations, properly speaking only rudiments of leaves, which gradually dry. In Rhipsalis, Epiphyllum, \&c., they are only small adpressed scales, ciliated at the border, which also subsequently dry. The development of the pulvinus stands in an inverse relation to the occurrence of leaves in the Cactere: thus in the Peireskie it is almost imperceptible, but appears prominently where there is no formation of leaf.

The thorns or bundles of spines are situated in, or somewhat above the axis of the leaves, whether these occur or not: in the latter case it will be evident from the spiral arrangement peculiar to the leaves. It may also distinctly be observed on the skeleton of the Opuntice that the ligneous bundles proceed to the thorn-bundles just as they do to the buds in other plants. Attention is also drawn to Barleria lupulina, one of the Acanthacee, where similar thorny buds occur together with the usual ones. Numerous similar cases however occur among the Syngenesiste.

The thorns of the Cactea, which consequently must be regarded as metamorphosed bracts, are never hollow, but always solid and of a firm corneous texture. They are smooth or finely and softly haired. In Opvintia exuviata, tunicata, \&c., the upper cellular layer disengages itself, beginning at the basis of the thorn, and then covers it as a sheath, which is easily drawn off. The thorns frequently grow for many years, each time advancing somewhat at the base, when the new-grown portion 
is easily discernible. In many Cerei, Opuntia, and Peireskia the number of the thorns in each bundle increases with age, new ones annually shooting forth from the centre. In some, especially in the Echinocacti, there is frequently a central thorn which seems to terminate the growth; and here the number of thorns is almost universally constant as soon as the plant is full-grown. The thorns are not always arranged in circles in the bundles, but in the Echinocacti with sharp edges stand in the form of an elongated ellipse, at whose upper end gradually the last thorns and lastly the flowers make their appearance. The flowers and new shoots of wood almost always appear above the bundle of thorns, and are consequently not encircled by them, which is even the case in Mammillaria prolifera The thorn bundles of the Mammillarice usually throw forth neither flowers nor branches, and consequently, with the exception of a few species (Mammillaria vivipara, parvimamma) which sprout from the mammillæ but do not flower, are constantly abortive; while in the Mammillaria the flowers proceed from the stem close above the pulvinus. Here therefore. sterile or abortive buds and wood- and flower-buds occur on the stem, and M. Zuccarini shows that this double formation of buds is also known in other plants.

M.J. Wttewaall has published a very elaborate memoir on the nature of the stem in a physiological and morphological point of view*. It is divided into four chapters: the first treats of the development of the annual stem, the second of the further growth of the stem, the third of the subterranean, and the fourth of the difference between root and stem: they are all written with a great knowledge of the subject and of its literature, and will be of great value to subsequent morphologists. In the consideration of the development of the annual stem, the author sets out from a view, which enjoys great favour also with us in Germany, viz. that of the composition of the cauliculus from the cohering petioles of the cotyledons, a notion which is completely refuted by actual observation of the development of those separate parts. It may indeed be replied, that. I ought to give the proof: however, I

* Jets over het onstaan, den groei, en de vormveranderingen van den stengel.-Tijdscrift voor natuurlijke geschiedenis en physiologie, Vierde Deel, $2^{\text {e }}$ Steek, 1837, p. 42-105. 
promise to produce it very soon; moreover it has already been given in part in the recent papers of Dr. Schleiden.*

That which was assumed for the cauliculus is also considered valid for the separate internodes ; for each of them is said to proceed from the petioles (which have remained in a state of cohesion, ) of the leaves becoming free higher up. The untenableness of these statements is already sufficiently shown by the observation respecting the division of the ligneous bundles of the stem and their course to the actual leaves, yet in this case the young and the old stem must be examined, and in fact, from immediately after its appearance between the cotyledons to the flower, \&c. But the history also of the development of the stem, and the leaves which proceed from it, which is constantly effected in a similar way as in the formation of the cotyledons, refutes this view of $\mathrm{M}$. Wttewaall, upon which he has founded the entire history of the development of the stem. The subject is treated very nearly in the same way as in E. Meyer's celebrated memoir in the 7th volume of the Linnæa.

In the second memoir, on the further growth of the stem, M. Wttewaall also shows the greatest circumspection and acquaintance with the literature on the subject, yet he holds more to the side of the French physiologists. The third chapter, in which the subterranean stem is treated of, deserves especial attention. The subterranean stem occurs in herbaceous plants as well as in shrubs and trees; it is thinner than the air stem, and the leaves occur in the form of rudimentary scales which occupy the same position as the leaves on the air stem. If the latter is, as the author says, provided with stripes of the remaining petioles, then we find them also on the subterranean stem. True subterranean stems occur in Corchorus olitorius, L., Spircea sorbifolia, Syringa, Rosa, Clethra alnifolia, where but lately they were regarded as true roots. Although the creeping roots of trees and shrubs are able to develope buds under favourable circumstances, yet this is peculiar in a much higher degree to the subterranean stem, for all its scales have buds in their axes. Not rarely do we find in the trees above mentioned some, the stems of which are sur-

* [Of the papers here referred to, translations have been given in Nos. 73 and 74 of the L. and E. Phil. Mag., and Part VI. of Taylor's Scicntific Memoirs.-W. F.] 
rounded with runners, while others exhibit none; the first appear to have been grown from cuttings, the latter from seed.

The subterranean herbaceous stem differs much more from the air stem than was the case in the arborescent ones above mentioned; under this head are reckoned the anamorphoses of the stem, which have hitherto been described under the names of rhizoma, radix repens, bulbus, tuber, \&c. Our author lays down three kinds of this subterranean herbaceous stem; in the first the creeping stem does not increase in thickness, in the second it does, and in the third kind the stem is erect. He also directs attention to the circumstance, that at times the terminal bud in the subterranean stem grows further horizontally, while the lateral buds are developed in the form of air stems in a vertical direction, and then the air stem frequently takes a horizontal direction. A number of excellent examples are enumerated ins upport of the three positions.

The inquiries relative to the difference between root and stem also abound in interesting observations.

A learned correspondence has begun between E. Meyer and H. Mohl*, which promises to explain some of the most difficult points of morphology; it relates to the morphological signification of fibres, which E. Meyer considers, from their position, analogous with branches.

M. Mohl perfectly coincides with E. Meyer respecting the origin of the stem from leaves, but he does not adopt Meyer's view of the formation of nodes, any more than the statement, that the collum of the plant should be regarded as the first node, and that to each internode would belong the node situated at its lower extremity, which are victoriously contested. It is incomprehensible to me how M. Mohl can dispute this latter statement, agreeing as he does to the first, on the origin of the stem from leaves, for it appears that the one proceeds from the other; in my opinion, observation shows that the leaves shoot forth from the stem, and this therefore cannot consist of the cohering leaves or petioles.

M. Mohl regards the fibre as an axis which originates from a descending current of sap, and merely represents the lower portion of the vascular bundle of a perfect axis; as on the

* Linnæa, for 1837, pp. 106, 487. 
other hand, the bud which originates from an ascending current only represents the upper portion of the axis. "But I cannot," says M. Mohl, "like you, regard the fibre as a series of internodes, and not be of opinion that a fibre can replace any branch; but I believe that fibre and eyes together form a perfect axis, but that they are really connected only in the dicotyledonous embryo; on the contrary, that they are separated in the lateral position on the primary axis, and that the one half is inserted at the upper end of the stem, the other at its lower end."

M. Unger has published the results of his continued observations on the development and destination of lenticells*, which we noticed in last year's report, p.64†. These inquiries have shown M. Unger, that in all cases where subsequently a lenticell is formed, a stoma existed in the green branch. Even in Ulmus suberosa he observed that the obliterated epidermal pore constantly passed into a lenticell; on the contrary, all the transitions from the normal pore, through all stages of its expansion, to its rupture through the epidermis, are seen in the annual shoots of Bignonia Catalpa. M. Unger agrees with M. Mohl in regarding the lenticell as a partial exuberance of the suberose layer of the bark; I have, on the other hand, proved in my Physiology, and more fully in last year's report, that the lenticells originate from the green cellular layer. They break through the suberose layer of the bark, and observation certainly affords no reason for considering this process as analogous to the original formation of the gemmæ, which opinion M. Unger again repeats at the conclusion of his paper.

We have obtained from E. von Berg $\ddagger$ a small but in many respects very important work on the nature of bulbs. The first chapter contains the observations and views which the author has collected in a morphological respect on bulbs, but the observations on the increase of bulbs are especially interesting ; - a subject which it is true has already been studied in various ways, but is yet capable of daily affording new re-

* Flora von 1837, p. 236.

+ Lond. and Edinb. Philosophical Magazine, vol. xii. p. 58.

† Die Biologie der Zwiebelgewächse oder Versuch die merkwürdigsten Erscheinungen in dem Leben der Ziebelpflanzen zu erklären.-Neustrelitz und Neubrandenburg, 1837. 8 vo. 
sults. Bulbs are divided into annual and perennial; with the consideration of the former, the history of the development and propagation of the daffodil, the tulip, the crown imperial, the crocus, the common onion, \&c., are detailed with the greatest accuracy. The hyacinth is taken as an example of the vital history of the bulbs of perennial duration, and the development of its bulbs very minutely described. The genera Muscari, Ornithogalum, Uropetalum, Amaryllis, Narcissus, Pancratium, Galanthus, \&c., resemble the hyacinth. The condition of the bulbs of Amaryllis formosissima is specially described. The lilies form a second chief division of permanent bulbous plants, in as much as they have scaly bulbs; a great number of liliaceous plants, which chiefly belong to our most beautiful plants, have been studied for a series of years, and the development of their bulbs fully described. Of the Allia, Allium Cepa, descendens, fragrans, moly, nigrum, sativum, Scorodoprasum and vineale are annual, and Allium acutangulum, fistulosum, senescens, and Victorialis are perennial, and to the same class belong also some kinds of Iris, Scilla, Gladiolus, Oxalis and others. All these observations are not only highly instructive to botanists, but must also prove very agreeable to the lovers of horticulture.

The second part of this work contains general observations on bulbous plants, from which I may extract the following. The regular, more or less rounded form of all bulbs arises, says M.von Berg, chiefly from this circumstance, that in these plants, more so than in all others, the antithesis between the inner formation and outer development appears most prominently, and that both actions begin contemporaneously and almost consist in the same act! M. v. Berg noticed a curious fact on the bulb of the narcissus, which commenced developing leaves of a bright violet colour like those of the flower; subsequently they increased considerably in length, but the coloured apices dried up while the larger inferior portions remained quite foliaceous.

A distinct chapter is devoted to the consideration of the individuality and death of plants. The question, whether plants die from age or whether their termination is brought about by accidents, is then treated of, and M. von Berg declares in favour of the first view, which in my opinion, how- 
ever, must be very much restricted. He even states himself, towards the conclusion of his work, that the bulb may be regarded as a symbol of immortality, just as much as the dying seed might serve as a general proof of the continuance in death.

M. Ohlert* has published some highly interesting observations on the position and further development of the buds of our common trees and shrubs. With the appearance of the young leaves on the bursting of the bud, appear almost contemporaneously in their axillæ the young buds for the next year, which are further developed in the summer and autumn; the scales of the buds are soon perfected, but the inclosed leaves appear still to increase during the winter, which as I have myself observed is at least the case in some plants. The number of scales is quite constant for each species, and at their opening in spring the buds have the same number of leaves. There is a relative definiteness in the number of the internodes, which the annual shoot, i. e. the developed buds, exhibits, the number of internodes in the different species never exceeding a certain maximum; moreover it often coincides with the number of leaves or leaf-pairs which are formed anteriorly in the bud. M. Ohlert adduces in a table some excellent proofs. Thus Fraxinus excelsior has two pairs of scales, five leaf pairs, and at the utmost 3 internodes in the annual shoot; Assculus Hippocastanum seven pairs of scales, five of leaves, five internodes; Acer campestre six pairs of bracts, five of leaves, ten internodes; Sorbus aucuparia three pairs of scales, five of leaves, eight internodes, \&c.

M. Ohlert then observes, that at times, as in Tilia, \&c. the axillary bud becomes apparently terminal, but that it is easily recognized on dividing it.

- In the buds of some trees and shrubs more leaves are formed than are to arrive at development, upon which the leaves at the apex of the branch dry and fall off, for instance, in $S y$ ringa, \&c., consequently no terminal buds originate in this case. In other cases there are fewer leaves in the bud than the young branch developes members, as in Ulmus campestris, Tilia Europcea, \&c., where also no terminal buds are formed; or as in Fraxinus, Acer, Cornus, Quercus, \&c., where terminal

* Einige Bemerkungen über die Knospen unserer Bäume und Sträucher. -Linnæa, v. 1837, p.632. 
buds arrive at development. Lastly, there are also trees and shrubs whose buds contain as many leaves as the future branch is to have members, as in Cytisus and AEsculus.

MM. A. Henry and Cl. Marquart have given descriptions* of various monstrosities of the carpel of Salix cinerea, which may most easily be explained according to the view above mentioned of the signification of the carpel. This and similar deformities in the carpel of the willow have been frequently observed and as often explained in different ways. The separation of the carpellary leaves and their metamorphosis into anthers, while the axile formation nevertheless produces the ovules, would be the most essential fact resulting from the descriptions given of the drawings.

There is besides, the drawing of a catkin of the same kind of willow, the carpels of which are intended to show the retrograde metamorphosis of the ovules into leaves. The cavity of the carpel is filled with a number of longitudinally folded leaves, variously serrated at the margin, as shown in the drawing: the ovules are said to be missing, but on this account the occurrence of leaves permits of a different explanation, and we cannot yet admit that the ovules are metamorphosed into leaves.

M. Dutrochet $\uparrow$ has also published some new observations on abnormal formations of various parts of the plant, and compared them with similar ones of other botanists, which is of interest for the theory of the metamorphosis of plants; however, I must refer the reader to the memoir itself, as the separate subjects appear to me to be too special for this place. We also find in it the observation, that we have no more reason for admitting the petal or the stamen to be a metamorphosed leaf, than the reverse, - that the common leaf is a modification of form of the petal or the stamen.

M. Dutrochet has made several additions in the new edition of his memoir on the generation of plants $\ddagger$, which are remarkable in several respects. It is well known that Grew described,

- Ueber abnorme Bildungen des Fruchtknotens der Salix cinerea, L. Mit einer Tafel Abbildungen.-Ersten Jahresbericht des botanischen Vereines am Mittel- und Niederrhein. Boin, 1837.

† Observations sur les transformations végétales.-Mém. pour servir à l'Hist. Anat. et Physiol. des Végétaux, ii. p. 163.

† De la génération sexuelle des plantes et de l'embryologie végétale.Mém. pour servir a l'Hist. Anat. \&c. ii. p. 115. 
as early as 1672, a small aperture in the outer epidermis of the seed of various Leguminosa, which, in his opinion, was destined to convey air to the embryo and to facilitate the passage of the radicle. Subsequent observers declared this small hole to be the aperture through which the ovule was impregnated, without, however, giving any positive observations on the subject. In 1806 Turpin proposed a view which also ascribed to the round aperture in the epidermis of seeds the function of receiving the fructifying substance, and called this point of the epidermis the micropyle, - a term which has been generally adopted, although it must in the present state of science also give way to a more rational denomination. In the memoir of M. Dutrochet we now learn that Turpin has abandoned his former opinion respecting the function of the micropyle, and at present supposes that it is an aperture without any physiological function*.

M. Dutrochet, on the contrary, regards the micropyle as a pneumatic tube which conveys to the interior of the seed the air requisite for respiration, in short he has adopted Grew's old notion respecting the function of the micropyle. I considered it to be my duty to prefix this short historical notice to the subject in dispute, but it must greatly surprise every botanist who is not acquainted with the subject from personal observations, that at the present day such a notion can be advanced by a member of the celebrated Academy of Sciences of Paris, after the most splendid writings have been laid before that

* In the most recent memoir of M. Turpin (Esquisse d' Organographie, \&c., p. 42) we find in fact these statements confirmed; the micropyle of $\mathbf{M}$. Turpin is nothing further than the aperture which an involute, and at its margins cohering, leaf exhibits at its extremities, therefore it has originated from imperfect cohesion. "This deficiency in cohesion may be," says M. Turpin, "divided into Micropyle foliaire, $M$. bractéen, $M$. anthérifère, $M$. ovarien, $M$. carpellaire, and $M$. ovuluire," \&c. The aperture of the cavity of the leaves of Nepenthes is considered by him as being something similar, and he would term it Macropyle, but he pays no attention to this aperture being provided with a lid. From this and several similar explanations of M. Turpin, we should perhaps be justified in limiting this term micropyle to the point of impregnation of the ovule; for the aperture in the ovule, through which the fructifying substance passes, is sometimes formed by the envelopes of the ovule, and then either by the outer, or by the inner one, sometimes by the apex of the nucleus, which frequently projects in a most remarkable manner, but sometimes also by the apex of the embryonal sac, which frequently projects far out of the nucleus or the round aperture of the envelopes, and thus grows to meet the fructifying substance, the pollen tube with its contents.-DR. MEYEN. 
assembly itself, giving a pretty complete explanation of the function of the micropyle and the structure of seeds, leaving out of question the researches of Rob. Brown. There is, it is true, a great deal to be observed on this subject in special, but in general we have so clear a knowledge of it that such a disregard of the observations of others must highly astonish us.

M. Dutrochet describes in the second part of his work the ovule of various plants, e. g. of Amygdalus communis, Evonymus europaus, Pisum sativum, Fagus Castanea, Galium Aparine, Spinacea oleracea, Mirabilis Jalappa, Nymphra lutea, and Secale cereale, and shows that he is well acquainted with a difference in the number of the envelopes of the seed in various plants ; but he nevertheless employs the terms for these parts invented by M. de Mirbel, which in the present state of observations are no longer suitable. M. de Mirbel has highly advanced our knowledge of the structure of the seed, previous and subsequent to impregnation, as every botanist will admit; and, though I would no longer recognize the terms which this learned naturalist has advanced to render the subject intelligible, it must not be regarded as a censure cast upon those admirable researches.

At the conclusion of the memoir, M. Dutrochet relates his observations on the formation of ergot; he does not consider it to be a fungus, but a diseased development of the grain. But it appears to him probable, that this diseased development of the grain into ergot is in consequence of the presence and increase of a microscopic fungus, which should be placed by the side of Uredo. I cannot however concur in this view, in consequence of my observations on the subject.

Another important work of M. Mohl* relates to the morphological signification of the organs of propagation of those Cryptogamia which are provided with leaves. In these inquiries he starts from the two following morphological positions, as their correctness is of the highest importance in every explanation of the organs of fructification of the Cryptogamia. They are :

1. That the anther in Phanerogamia is not formed by the involution of a leaf, and that consequently the pollen grains

* Morphologische Betrachtungen über das Sporangium der mit Gefässen versehenen Cryptogamen.-Eine Inaugural Dissertation. Tubingen, 1837. 8vo. 
do not proceed from the surface of the leaf, but that they originate in primitive cells which are situated in the interior of the metamorphosed leaf, and subsequently again disappear. This doctrine was already shown in last year's report to be well founded, and in the present one it is supported by Dr. Schleiden's observations.

2. That the carpel also, like the anther, proceeds only from the metamorphosis of a leaf, and that the axile system takes no part in it, but that the ovules always spring from the upper surface and from the margin of the carpel leaf. This second position is by no means to be considered as proved; nay, we shall some pages further on be acquainted with the observations by which it might be refuted, and consequently several explanations which M. Mohl has given of the sporangium might be resolved in some other way.

On account of the difference which the sporangium exhibits in various families with respect to structure, the single families must be considered separately, and M. Mohl commences with the Equisetacere. The sporidia of these plants are, on account of their origin in primitive cells, and partly from their composition of a double membrane, compared with the pollen grains of phænogamous plants, and even a similarity in the structure of the sporangium with that of the anther is supposed to exist. He also refutes the view according to which each of the angular receptacles in Equisetum is considered to arise from the cohesion of a whorl of leaves; observations on the fruit-bearing shafts of Equisetum Telmateja are also enumerated, which presented transitions from the verticillate shaftleaves, cohering into sheaths, to whorls of fructification, and which left no doubt that the so-called receptacle of Equisetum, covered with sporangia, does not arise from a cohesion of a whorl of leaves proceeding from a branch, but from a leaf of the shaft itself; that it represents as it were the connective of an anther developed to an extraordinary size, and that the sporangia situated on its under surface correspond to the separate loculaments of an anther.

In the consideration of the sporangium of ferns M. Mohl first adduces the proof that the fronds of ferns must be as much regarded as a true leaf, as the leaf of the Cycadece and palms; and the want of buds in the axillæ of the leaves of ferns is simi- 
larly circumstanced, as in the mosses, Lycopodinece and $C y$ cadece. (In these latter plants small buds not unfrequently occur at the base of the stem between the scales.-Rep.)

In the Ophioglossea M. Mohl compares the whole theca, in reference to its organization, with the anthers of a phrnogamous plant. The apex represents more or less distinctly the apex of a leaf; the receptacles of the sporidia are mere cavities in the tissue of the leaf, and the axis of the theca corresponds to the middle portion of a staminal leaf contracted to a connective.

In Botrychium the sporangia already become more independent; they are perfectly separated from each other,-a case which M. Mohl compares to the formation of the anther in the genus Geonoma. He also recognizes in the sporangia of all other ferns, which develope their fruit on the under surface of theleaf, an analogous formation with the theca of the anthers. At least it is clearly proved that the morphological functions hitherto ascribed to the capsules in ferns are erroneous, and M. Mohl finds another reason for his view in the formation of sporidia in primitive cells which are subsequently reabsorbed. No great weight can be laid on this last reason, for at present several other cases are known where the formation of new cells takes place in original cells. A series of objections which might also be brought forward against the analogy between the sporangium of a fern and the theca of an anther are refuted at length.

The ingenious idea that the capsules of ferns consist of metamorphosed leaves, the midrib of which forms the ring of the sporangium, appears to have been first advanced by C. H. Schultz; altogether M. Mohl seems to pay too little regard to the writings of that philosophical botanist, from whom the sporangia of the lower plants have already long ago obtained their morphological signification. Thus for instance the sporangia in Equisetum have originated from the metamorphosis of the foliaceous members of the stem, as those of the Polypodia from the metamorphosis of the leaves; and consequently the former also correspond to the articulation of the stem, the nodes of which have formed the capsule-shields, and the sheaths of the leaves the loculi of the capsule!

There are greater difficulties in the signification of the sporangium in Lycopodium, yet in this case M. Mohl seizes on 
the affinity which exists between Lycopodium and Isoëtes; and since in Isoëtes the sporangia do not stand isolated in the axis of the leaf but upon it; since further in Psilotum, and more evidently in Tmesipteris, the sporangium is situated on the leaf,-it becomes probable that the axillary position of the sporangia in Lycopodium also is merely apparent, and that they are rather a product of the leaf than of the stem. Yet these statements are merely ventured as suppositions, for M. Mohl found that the base of the sporangium is connected with the midrib of the leaf, in whose axis it is situated, as well as with the stem, so that we remain in doubt respecting its true point of insertion. Moreover the sporangium of Lycopodium may be much better compared to that of Botrychium, both in reference to the form and to the mode of bursting than to the carpel of phænogamous plants.

After these researches, the question should be asked: whether the sporangia of the higher Cryptogamia can be regarded as the same organ as the anthers in Phanerogamia, and the spores as the same organ as the pollen grains. This view was already advanced for various Cryptogamia by the ingenious Agardh, and founded indeed on the mode of germination of the sporidia, in which a similar process was supposed to be recognized as at the formation of the pollen tube. $M$. Mohl has already previously contested this view, but thought that the growth of the pollen tube was a mere mechanical act produced by the endosmosis and the peculiar structure of the pollen grain. These tubes were said to be projected both in pollen grains, which had been dried for years, and in fresh ones, when moistened by acids and alcohol, - statements which were adopted by almost all botanists, but the incorrectness of which I demonstrated ten years ago, and at the same time proved, against M. Brongniart's view, that the pollen tube did not arise from a mere expansion of the inner membrane of the pollen, but from actual growth.

An elaborate and highly important memoir by Dr. Schleiden* is closely connected with the preceding one ; the author commences with the admonition that the doctrine of the metamor-

* Einige Blicke auf die Entwickelungs-Geschichte des vegetabilischen Organismus bei den Phanerogamen.-Wiegmann's Archiv. [An English translation of the entire memoir appeared in the February and March Numbers of the London and Edinburgh Philosophical Magazine.-W. F.] 
phosis of the organs of plants can only be advanced by means of observation. The history of the development, which must be pursued from the earliest appearance, alone gives the correct solution respecting the destination of the various organs of plants.

The embryo in the seeds of plants, says M. Schleiden, originally consists of an axile formation, which is closed superiorly but is not limited inferiorly; the upper end expands in a globular form, and from the sides of this globe the cotyledons proceed, while the apex developes to form a bud. What takes place in the embryo is again repeated in the growth of the leaves on the subsequent stem, and consequently this cannot consist of adherent leaf-stalks. M. Schleiden is of opinion that in investigating the laws of position of the leaves we must set out from originally opposite ones, as exhibited in the cotyledons. That calyx and corolla are to be considered as foliaceous organs is generally admitted, and M. Schleiden also observed that the monopetalous calices and corollæ are in their early stage noncohering, as also that every flower has in its incipient development a regular construction. The grasses are mentioned as a highly remarkable example, in which the organs of fructification have, as is well known, been variously explained, since here non-cotemporaneous development, adhesion and suppression of individual parts, quite disfigure the original regularity. Nor can any longer doubt exist respecting the formation and signification of the stamens; they are modified leaves in whose diachyma four (this is the general law) cavities occur filled with pollen. Sometimes, though rarely, the original middle lamella is not developed, and then the division into two lateral cells does not exist, but it then appears bilocular.

The formation of the pollen takes place in these cavities, and in fact in the interior of primitive cells, in which probably for the most part four other cells are formed, in which the single grains of pollen are produced. The quadruple number is here the more general rule, yet, at times, as in Podostemon ceratophyllum, there are only two grains of pollen found in the large primitive cell. After the development of the pollen the re-absorption of the primitive cells takes place, which in some plants is effected entirely, in others less completely. Nay, even with respect to the re-absorption of the large and 
small primitive cells, we find in several plants considerable differences; in Pinus we may still see in March and April the large primitive cells separated into four distinct loculi. M. Link* assigns to the tissue of these cells a peculiar name; he calls it Collenchyma, from its similarity with gluten. M. Link also regards the well-known threads in the anthers of the Enotherce as remains of the membranes of the original cells.

M. Schleiden considers the placenta to be a formation of the axis, and the carpel leaves to be modified true leaves, which at the commencement are separated, and only cohere subsequently in various ways to form the different kinds of ovaria. In the Graminea and Cyperacece the ovarium consists of a single leaf, in the Coniferce it remains open, in the Resedacece three carpel leaves are united above to form one open basin; frequently the carpel leaves are bent towards the axis, and then again turned backwards. In the palms, the embryo is originally, soon after the impregnation, perfectly erect; the inner side of the ovarium does not however increase in height as the seed advances to maturity: thus the apex of the embryo becomes fixed and serves as a central point, about which the radicula, in the unilateral development, describes a quadrant, and in this manner the embryo horizontalis lateralis originates.

M. Schleiden commences his remarks on the ovulum and placenta, with the description of the female flower of Taxus, which is nothing more than the terminal bud of the collateral axis; the axis terminates in a small protuberance, which is the nucleus of the ovule; and since subsequently in the act of impregnation a union of this axile formation takes place with the pollen, impregnation consists in nothing more than in the conjunction and balancing of the two most important antagonistic forces the plant possesses, viz. those of the horizontal (leaves) and of the vertical (axis) structure.

The nucleus is the most essential part of the ovule ; its envelopes, which are termed ovular membranes, are only to be considered as collateral formations, and M. Schleiden regards them as amplexicaul integumental leaves, which are here combined into a sheath-like envelope. Now the nucleus either mains naked or is provided with a simple or double integu-

- Philos. Bot. ed. alterna, ii. p. 199. 
ment. Since the usual terms testa and membrana interna are not applicable to these envelopes, he proposes that of integumentum simplex for the one case, and those of integumentum externum and internum where the nucleus is inclosed in two envelopes. The difficulty in the investigation of the ovule is chiefly caused by its being in a great number of plants reflected, even long before impregnation, and this reflexion occurs both in the naked ovules and in those which are provided with simple or double integuments. M. Schleiden ascribes all reflexions of the seeds of plants to the axile formation, and therefore to the nucleus, with which I cannot agree; he moreover only enumerates the two cases where the axis remains straight (ovulum atropum), and the other where the axis is reflected and produces the ovulum anatropum. In a physiological respect these reflexions are very unimportant, for in many plants I have found some ovules not reflected, and nevertheless perfectly impregnated; but to systematic botany these reflexions of the ovule are very important, and the third division which even earlier botanists have established, that of the amphitropous seed, is quite indispensable. I shall endeavour to show in another place that the amphitropous seed must not merely be considered as a transition-form between the atropous and anatropous seeds ; and moreover the frequent reversions of the ovule by a subsequent curvature of the umbilical cord must be designated by distinct terms. The formation of the integuments of the nucleus is very accurately and minutely described by $\mathbf{M}$. Schleiden, and what $I$ have observed on this subject fully coincides with his statements; I also agree perfectly with him that Mirbel's quartine does not exist as a distinct membrane.

Although it is easy in cases with true placenta centralis libera or as in the Polygonea, in Taxus, \&c. to explain the nucleus as the mere apex of the axis, yet it might prove difficult to many botanists in the case of parietal placentæ : however M. Schleiden enumerates several examples which give to this view a high degree of probability; for example, the ovaria of the Fumariacee and Crucifere and the cones of the Abietince.

These views of M. Schleiden will certainly meet with great opposition: hitherto it was generally admitted that the ovarium consisted of buds which formed at the margins of leaves. 
M. Schleiden regards this explanation as a supposition totally unfounded, and thinks that he is able to establish as a general law that a bud is never formed upon a leaf. This law however is easily seen, by direct observation of nature, not to exist; the very supposition is the weakest point of Dr. Schleiden's excellent memoir, and has led him to many forced explanations. I believe that I am able to prove that, if we base the morphological signification of the ovarium on unprejudiced observation, and do not explain the observations according to preconceived views, we must admit a four-fold mode of origin of the ovules; viz. they originate most frequently at the margins of the carpel leaves, next at the sides of the midrib of the carpel leaves, more rarely upon their entire inner surface, and lastly also from the axis, where they occur either at the end of the axile formation, or at the side of the frequently much shortened axis.

I will here draw attention to some of the splendid monstrosities figured and described by M. Turpin in the work previously noticed $*$ : the explanation it is true frequently stands quite in contradiction to the figured observations. Fig. 19 is the drawing of a monstrous fruit of Aquilegia vulgaris, the five carpel leaves are almost completely rolled up and their lateral walls covered with ovules and leaves. Figs. 28 and 29 represent monstrous involucra of Trifolium repens; in one case the ovule-bearing margins of the carpel-leaves are not adherent and are clothed with six small leaves; in the other partly ovules and partly leaves have shot out from the margins. Immediately above, in figs. 20-22, M. Turpin gives his explanation respecting the formation of the legumen by the cohesion of the convoluted leaves.

Now, says M. Schleiden, as in the pollen-bearing organs the cellular tissue is converted by a peculiar modification into pollen, so also we observe in the summit of the axis, the nucleus, a peculiar modification of this tissue ; for in it is developed a single long cell which is subsequently converted into the sac of the embryo, and this happens at a period long previous to the so-called impregnation. The manifold variations, to which this sac is subject in various plants, are partially

* Esquisse d'Organographie Végét., \&c. Pl. IV. 
known; in Lathrea squamaria it was observed in the form of shapeless excavations. However, according to my observations, the sac is not constantly situated in the interior of the nucleus, and in fact M. Schleiden's description of the structure of the ovule previous to impregnation cannot be considered as a general rule, by the conception of which every case of deviation would appear very easily explainable. In numerous cases the sac of the embryo is only formed subsequent to impregnation ; and in others, where the nucleus occurs long before in the form of a hollow sac consisting of a simple cellular. layer, it then occupies itself the place of the embryonal sac.

M. Schleiden lastly arrives at the actual act of impregnation, the plastic processes of which have hitherto been described in the writings of Amici, Brongniart, Rob. Brown, and Corda. On the 31st of July 1833, Robert Brown made known that he had followed the pollen tubes in Asclepias phytolaccoides to the apex of the ovule, and therefore to the summit of the nucleus, since in Asclepias this is perfectly naked, which Mr. Brown did not then venture to advance: "to this point," it is stated in that short paper, "the tube adheres so firmly that I am inclined to think it actually penetrates, to some depth at least, into the substance of the ovulum," \&c. But on Mr. Brown's visit to Berlin, in the first days of September 1833, he had already advanced somewhat further in this inquiry, for he showed me with his accustomed kindness the entrance of the tubes into the summit of the nucleus, which was afterwards seen in Breslau also, although Corda subsequently took no notice of it. In a memoir which M. Corda presented to the Kais. Leopold. Akademie* in September 1834, he gave his observations on the act of impregnation in the Coniferce ; he saw the pollen tubes ascend through the cavity of the secundine to the opening of the nucula, enter this, become thinner in its cavity, and discharge their contents in the form of a turbid liquid mass. This mass M. Corda observed soon to fashion itself, forming the embryo-sac, but the connexion of the pollen tubes with the embryo-sac continues for some time after impregnation.

I have prefixed these historical statements in order to render Band.

- See the Jahresbericht for 1835.-Wiegmann's Archiv, $2^{\text {tem }} \mathrm{Jahrg} .2^{\text {ter }}$ 
as prominent as possible the new view which Dr. Schleiden has advanced on the act of impregnation in plants. He supposes that the course of the pollen tubes from the stigma to the ovule is the general process in the impregnation of Phanerogamia, and further that one, rarely a greater number, of these tubes penetrate the intercellular passages of the nucleus. The tube which reaches the embryo-sac presses it forwards, indents it, and appears in the form of a cylindrical bag, which forms the commencement of the embryo,-which therefore is nothing more than a cell of leaf-parenchyma ingrafted upon the summit of the axis; consequently it is formed by the membrane of the pollen tube and by the indented embryonal sac. (Much as I value the observations of Dr. Schleiden, and rejoice that many points of vegetable physiology will be considerably advanced by his profound researches to a more rapid solution than otherwise would have been the case, yet I must declare that these statements are not quite correct. The embryo-sac is certainly never indented by the penetrating pollen tube, nay, the embryo is even frequently of considerable size before any trace of an embryo-sac exists.-Rep.) In plants which possess several embryos, just as many pollen tubes are present as there are embryos. From these observations, says M. Schleiden, the important consequence proceeds, that the two sexes in plants have been named quite falsely, for each grain of pollen of the nucleus is a new individual, and the embryo-sac on the contrary should be regarded as the principle which only determines dynamically the organization of the material substratum.

It will hence be seen that the statements of MM. Corda and Schleiden respecting the plastic processes in impregnation in the interior of the ovulum are quite different: the former are, except the penetration of the pollen tube into the nucleus, which was previously observed by Robert Brown, entirely incorrect; not only does M. Schleiden say so, but Robert Brown also, and I likewise convinced myself of it soon after the publication of the observations ; nay, M. Corda has completely misapprehended the most essential facts in the structure of the ovule previous and subsequent to impregnation, notwithstanding the good observations already extant at the time. The question now is, whether the observations of $\mathbf{M}$. 
Schleiden on the act of impregnation are correct, and whether we must dismiss in consequence our old views respecting the sexes of plants. I am of opinion (and shall endeavour to prove it in the third volume of my ' Physiology') that M. Schleiden's observations have considerably advanced our knowledge respecting the plastic process in the impregnation of plants; but it will be shown that the old notions of the sexes of plants must be retained as before, even setting entirely aside the formation of bastards, which could not be explained according to the doctrine that the anther must be considered as a female ovarium.

We return at present to the consideration of the embryo. Upon its first appearance, says M. Schleiden, the embryo is to be recognized as a membranous cylinder, rounded and closed superiorly, open inferiorly, and filled with organisable matter, which is gradually converted into cells, beginning from above downwards, during which process the cellular nuclei become apparent, which appear at all times to perform a principal part in the formation of cells*. This cylinder M. Schleiden regards as an axile formation, the upper end of which expands into a globe, whence the cotyledons are developed, the apex (that is to say the axis) remaining more or less evidently free, by which it is proved that the axis exists before the leaves.

The first appearance of the embryo and the formation of its parts is naturally of the highest importance for the morphological explanation of the various parts of the grown plant:

* With respect to the function of the cellular nucleus several important discoveries have been made in the current year (1838), which in many cases perfectly explain the formation of the cellular tissue of plants. I have also observed in many cases that the cellular nucleus makes its appearance originally as a simple globular mucous cell provided with a solid spherical nucleus, and only at a subsequent period is converted into the disc-like formation which is very frequently attached by excessively delicate, and at times also ramified threads to the inner surface of the cell. From the substance of this disc, the first rudiments (the nuclei) of the amylum globules and of the other cellular sap globules, which for some time adhere to the disc and form a circle around the more solid nucleus, are formed. Subsequently the mucous substance of the disc disappears, the starch globules, \&c. increase in size and still remain for some time in that circular position, in which the green cellular sap globules are frequently found in the cells of the epidermis. In very young potatoes and in some species of Cactus I have been able to follow up this formation.-Rep. [Dr. Meyen here evidently alludes to M. Schleiden's admirable memoir on Phytogenesis, which at present occupies so much of the attention of continental botanists, and of which an English translation appeared in the 6th Part of Taylor's Scientific Mencoirs. -W. F.] 
I therefore communicate the results of my observations on this subject, which are somewhat different from those of $\mathbf{M}$. Schleiden. The membranous cylinder from which M. Schleiden starts is not always present, but where it occurs cellular nuclei are formed in it and cellular walls around them, and thus the cylinder is divided into cells ; the terminal cell, however, expands in a globular form, and from this is developed the entire embryo, which sooner or later separates from the articulated thread originating from the older parts of the cylinder and termed by De Mirbel " bearer ;" it does not belong, as it appears to me, to the essential parts of the embryo. Thus the embryo appears on its first occurrence to be a simple globular cell, and has consequently the form of the most simple of plants. This globular cell forms, from within outwards, into a cellular mass, and it is only after it has attained a certain size that the cotyledons are developed; but at the same time a growth of the globule takes place towards the opposite end, and consequently the formation of a true axis. I confess, however, although I regard the stem as that part from which the leaves proceed, and have anatomically demonstrated it, that I could not observe the apex of the embryo-globule (punctum vegetationis, Wolff.) to remain free between the projecting cotyledons, I only saw the appearance of the first trace of the future plumula at a subsequent period.

M. Kunth has shown* by observations on the seeds of Crucifere that the embryo of these plants adopts only towards the ripening of the seed, in consequence of external causes, the various forms which it exhibits in the perfectly developed state; and that those differences, since the causes which give rise to them must always re-occur in the same plant, afford very constant and important characters. He found in the young seeds of Erysimum cheiranthoides, L., and E. officinale, L., the radicula always situated laterally to the cotyledons, and these only became incumbentes with advancing maturity. In young seeds of Raphanus sativus the embryo was still nearly straight, merely curved at the radicula; the cotyledons were expanded and of unequal size, by which means the subsequent relations become intelligible.

* Ueber den Embryo der Cruciferen.-Wiegmann's Archiv, 3ten Jahrgang, 1 ten Theil, p. 232. 
A similar change of the original position of the parts during the process of ripening was also observed by M. Kunth in the fruit of the Cruciferc. The ovarium for instance is so placed in these plants that the axis corresponds to the dissepiment; but in fruits where the dissepiment expands it is situated laterally with respect to the axis.

M. Mohl* has given a complete description of a deformed hermaphrodite floral catkin of Pinus alba, which explains various points in the morphological signification of the flowers of the Coniferce in a very decisive manner, and which will evidently settle the differences of opinion that prevail among botanists on this subject. He found these monstrosities on several female catkins of Pinus alba, on the lower half of which the flowers formed more or less perfect transitions to male flowers, while the upper portion was covered with perfectly normal female flowers, which also commenced, in those specimens that were left for some time longer on the tree, developing very regularly into fruit. All those flowers which formed a transition to male flowers consisted, like the normal female flower, of two organs, the bract and its axillary carpellary leaf; each of these parts differed from the normal type, the bract for instance was more or less perfectly converted into a stamen, and the carpellary leaf was, the more completely this change of the bract belonging to it had taken place, developed of a smaller size, and less perfectly. The inferior flowers of these catkins were smaller, and the ovules had not developed on their carpel-leaf. In the upper flowers the carpel-leaf was smaller, it was somewhat bent forwards superiorly, and had become linguiform. In the highest flowers it represented a scale folded together, and was nearly quite green. In the same proportion as the carpel diminished the bract expanded, not only in respect to size but much more with reference to structure. In the inferior flowers there was on the outer side of the bract, above its base, a round protuberance of a yellowish green colour, which possessed in its interior a hollow cavity filled with pollen grains; the upper portion of the bract stood, like the carpel-leaf, erect. Upon the upper surface of this bract, along its middle line and from its point of insertion to its summit, proceeded a somewhat raised ridge, which corresponded to the connective of the normal an-

* Ueber die männlichen Bluithen der Coniferen. Tubingen, 1837. 
ther. At the basis the entire bract was indeed somewhat contracted, but not so much so that this part might be called a true filament. In those bracts which approached still more to normal anthers, (and this was the case in most of them) there were upon the outer side two protuberances, containing pollen, of a long oval form and yellow colour, which at their hinder end were partially separated from the bracts as in Araucaria. These formations differed from the normal anthers only from their being smaller, possessing a larger band and exhibiting a total want of the filament. A portion of these anthers burst longitudinally in the sutures, scattered the pollen, and then dried; others on the contrary remained closed and kept fresh for several weeks, thus again exhibiting their nature as bracts.

From the phænomena which the examination of these hermaphrodite catkins presented M. Mohl deduces the following conclusions :-

1. Each bilocular anther of Pinus and the allied genera has proceeded from the metamorphosis of a single leaf, which is also the opinion of Robert Brown and Lindley.

2. The anthers of Pinus originate from leaves that belong to the male catkin, and are not, as Mr. Lindley supposed, to be considered as lateral monandrous flowers, and consequently also are not analogous to the carpel-leaves of the female catkin.

Now it appears therefore necessary that the multilocular anthers of other genera of Coniferce should also be considered to have originated from the metamorphosis of a single leaf. M. Mohl is quite right in stating that the presence of a greater number of anther-loculaments cannot be advanced as a reason against this view, for it must not be overlooked that there is no reason why pollen could not be formed in the interior of a leaf as well at twenty different places as at one, at two, or at four. Moreover the male amentum of Juniperus presents in the number of anther-loculaments real transitions to various other genera of Coniferce. For instance, the inferior scales of the amentum of Juniperus very frequently possess only two loculaments, in which they coincide with Pinus; the trilocular are similar to those of Cunninghamia, and form the transition to the quadri- and multilocular anthers of other genera. M. Mohl here also touches on the explanation of the multilocular 
anthers of many Cycadea, which must evidently be explained in exactly the same way.

In conclusion, M. Mohl endeavours to decide in a very ingenious manner the question whether the male coniferous amentum should be regarded as a flower or as an inflorescence. The male amentum of the Coniferc, he observes, possesses only in outer appearance and in this, that all its stamina with the the axis upon which they stand are deciduous, a resemblance to a true amentum, and is therefore rather to be compared to a flower. The proof of this latter assumption presents, it is true, far greater difficulties than the proof that the view, according to which the cone of the Coniferce is to be regarded as an inflorescence, is incorrect. However, the examination of the female amentum in all stages of transition leads M. Mohl to the view that the male flowers of the Coniferce exhibit an approximation of the floral formation both to the inflorescence and to the vegetative parts of the plant. 'The lower stage of development, in which the male flower of the Conifera is found, is easily shown by the want of a floral envelope and by the slight shortening of its axis, and the only distinction from the vegetative axis consists in a short flower-stalk. (In young firs ( $P i$ nus sylvestris) which flower for the first time, it may very frequently be seen that one or more pairs of leaves are converted at the lowest portion of the new shoots into anthers, a phænomenon which throws great light on this subject.-Rep.)

Of especial interest also are the considerations on the female flower of Cycas, where the intimate connexion between stem, leaves, and carpellary leaves is far more remarkable than in the flowers of the Coniferce; for in those species of Cycas, says M. Mohl, in which the carpel-leaf still bears pinnules, the forms of both are strikingly similar; and the carpel leaves moreover retain the nature of stem-leaves in so far that they do not lie close on to one another, and the stem does not lose with their production the power of growing further and producing new leaves, on which account the portion of the axis covered with the leaves of fructification fluctuates, from its nature, between an axis of fructification and of vegetation.

M. Schleiden's views* on the morphological signification

* Einige Blicke, \&c. English translation in Lond. and Edin. Phil. Mag., vol. xii. pp. 172 and 241 . 
of the female cone of the Coniferce are very different from those ju st mentioned; he considers that which has been regarded since R. Brown as an open ovarium to be merely a scale-like expanded placenta, and R. Brown's bractea to be the actual carpellary leaf. In fact the placenta shows itself to be in the Abietinea a perfectly independent part in its growth from the carpellary leaf, and perfectly distinct. Nay, it here developes itself, when without the least constraint, to such an extent, that at length the carpellary leaf itself (bractea of authors) appears as a mere supplementary part. The detailed exposition of this highly difficult subject M. Schleiden promises at some future time. He too found an hermaphrodite cone of Pinus alba, and states that these views are confirmed by this monstrosity in the most beautiful manner.

I have very frequently found hermaphrodite cones, and the transformation of the actual spicular leaves into carpellary leaves or into bracts of authors, may most distinctly be followed on them, as well as the origin of anthers from the leaves which surround the base of the cone.

\section{On Phcenomena of Sensibility and Irritability of Plants.}

In a memoir with the title $*$ De la tendance des végétaux à se diriger vers la lumière et de leur tendance à la fuir", which M. Dutrochet has published in the collective edition of his memoirs*, various very obscure phænomena of the direction and motions of some plants and their parts have been investigated. The learned author begins this chapter first with the consideration of the direction of the roots in the germinating mistletoe (Viscum album), and arrives at results already known. The greatest portion of the memoir is occupied with the consideration of the direction of the root in creeping plants, and the causes. M. Dutrochet has observed that some plants, for instance Humulus Lupulus and Convolvulus sepium, avoid the light, while others constantly turn towards it. The stems of these two plants were placed in a glass with water, and observed near a small window. The apices of the stems were directed in the morning towards the window, but in the course of the day turned from it, while at night they returned to their original position. With the fading

* Vol. ii. p. 16-40. 
of the stems they lost their property of avoiding the light. The opposite direction during day and night was observed previously by Bonnet. M. Dutrochet draws from these observations the following conclusions :-1. certain plants avoid light, and this for the purpose of seizing hold of firm and opake objects ; 2. the flexion of the stem towards the light, as also from it, therefore in opposite directions, is the result of a physiological action, and not of a superfluous elongation of one side of the stem by which some botanists have endeavoured to explain it. The roots exhibit no tendency either to grow towards or from the light.

In the explanation of the causes which give rise to the windings and flexions of the stems of plants M. Dutrochet is very complete, but he starts from points which are purely hypothetical, and were demonstrated to be such in last year's report. All flexions of plants are, as M. Dutrochet thinks to have proved, produced by the action of two kinds of tissue, which differ from each other both by their texture and the principle of their action; these two flexible tissues are the cellular tissue and the fibrous tissue. The cellular tissue bends by the action of endosmosis, and the fibrous tissue by its filling with oxygen, \&c. M. Dutrochet thinks that be has observed that the inner cellular layer of the bark is in general thickest in those plants which turn towards the light, and considers the latter to be a natural consequence, that the cells predominating in such bark and becoming smaller and smaller from without inwards, swell by endosmosis. The contrary appearance is said to be exhibited in such plants as turn from the light: here for instance the cortical layer is said to be the thickest. Starting from this notion, M. Dutrochet has endeavoured to explain very completely all the difficult points of this questionable subject, and a number of special observations are enumerated, which however collectively might easily be refuted.

M. Brunner* attempts to explain the winding of plants to various sides from the different degree of irritability proper to them. Suppose a plant A. stand $\begin{gathered}\text { B. C. } \\ \text { A. }\end{gathered}$ at equal distance * Ganz anspruchsloser Versuch, das Links- und Rechts-winden der vor-
kommenden Pflanzen zu erklären.-Flora von 1837. No. 41. 
from two supporters directed towards the east, the elongation of the young shoots will move pretty generally in the arc between $B$ and $C$. (How is it then with those plants that turn from the light? - Rep.) If the plant only possess a high irritability, it will turn towards the early rays of the sun and seek a supporter to the left; but if the plant require a longer influence of the light to determine its direction the plant will turn to the right.

If this explanation were correct we should perhaps be able to determine at will the flexion or winding of plants; it would only be necessary to remove those supporters towards which the plant tends or to place them on the opposite side; but as observation shows, all this is of no use. And how would the turning to the right and left on one and the same tendril, as occurs in Bryonia, be explained?

In A. Curtis's Enumeration of the plants growing spontaneously around Wilmington, in North Carolina*, we find a description of the remarkable leaves of Dionca Muscipula, of which instructive figures have already been published in various works. Sometimes Mr. Curtis found the entrapped fly enveloped in a mucous substance which appeared to act upon it as a dissolving medium, upon which he came to the supposition that the insect might be employed in the nourishing of the plant. I will merely observe respecting the secretion of the fluid which is observed on the closed leaves, that it is a consequence of the water collected by the transpiration of the leaves and precipitated in the closed space. And this water is, in a climate so warm as that of South Carolina, the cause of the dissolution of the imprisoned insect.

M. Morren has published $\uparrow$ some new observations on the catalepsy of the flowers of Dracocephalum Austriacum and Moldavicum which are connected with those, respecting which we gave a notice in last year's report. The author observed these phænomena hitherto in Dracocephalum Virginianum, Austriacum and Moldavicum; in the first species the so-called catalepsy is perceptible to a high degree, in the second it is less considerable, and in the third still less. The outer relations are very completely and accurately described in this memoir, by which

* Hooker's Companion to the Botanical Magazine, vol. ii. p.5.

+ Notes sur la Catalepsie des Dracocephalum Austriacum et Moldavicum. -Bullet. de l'Acad. des Scienc. de Bruxelles, 1837, p. 390. 
the phænomenon termed catalepsy is produced in these species, and M. Morren again arrives at the conclusion that this phænomenon does not merely depend on a distinct property of the cellular tissue, or on a want of elasticity in the flowerstalks, but must be regarded in toto as a mechanical result, independent of the position of the parts.

M. Dassen*, who has published the beautiful memoir on the motion of the leaves of plants, of which Prof Wiegmann has inserted an extract in his journal, has drawn the attention of botanists to a phænomenon of leaf-motion hitherto little attended to. The leaves of those plants which move are frequently provided with swellings at their base; there are however other leaves which move without these swellings. The motion of these latter again presents in various plants considerable differences, which are more particularly described in this memoir ; it consists in the inversion of their natural position, which is sometimes performed in the space of a day, but sometimes takes a much longer time. M. Dassen displaced some branches of trees and various other plants from their natural position, and bound them fast to the stem, so that they hung downwards : in the course of a few days they had spread themselves out so much, that the upper surface of the leaves was again turned upwards. These experiments were made in June when vegetation was in full force, and the result was the same in all cases. The experiments were then repeated in October, when most of the branches remained motionless ; only those of rose trees, of Robinia, and of herbaceous plants endeavoured to regain their previous position. The following question then presented itself:-By what is the motion of the branches effected, whether by a cause seated in themselves, or by the leaves? To determine this question, M. Dassen repeated the experiments on branches with and without leaves, and observed that those branches which had been deprived of their leaves remained in their unnatural position; the leaves were therefore regarded as the cause of this motion of the branches. Subsequent experiments were made in order to discover the mechanism producing the motion of

* Onderzoek aangaande de Bladbewegingen, die niet door aanzwellingen ontstaan. Tijdschrift voor naturlijke Geschiedenis en Physiologie, 1837, IV. 1. 2. p. $106-131$. 
the leaves, whether the nerves of the leaves remained during the process active or passive, \&c., and the following results were arrived at: that leaves with simple nerves and without petioles change their position from the unnatural to the natural as well as those with petioles; and 2ndly, that the parenchyma is the cause and not the nerves. Further observations respecting the mechanism producing the motion of leaves with and without petioles gave the following results:-1. All leaves with simple veins have the power of self inversion; 2 . The apparently unpetiolated leaves in which the veins are diffused in a different manner, move by a bend in their point of attachment; 3. The short and stiff as well as the long and slender petioles are unfavourable to the motion; 4 . When the petiole is not too stiff or long, the inversion of the leaves is produced by a semi-inversion lengthwise and also by a bend of the petiole; 5. In folia peltata the motion takes place partly by a bend of the petiole itself, partly by a change in the direction of the leaf with reference to the petiole.

M. Dassen then proceeds to the examination of the causes which produce the motion of leaves: various plants stationed in pots were left to grow turned from the light, and some even without light in closed boxes. The result was highly remarkable: the leaves of those plants which could not turn themselves round died, but the remainder were inverted quite as quickly in the dark as in the light, whence M. Dassen arrives at the conclusion, that light was no more the cause of the direction of the leaves upwards than darkness is the cause of the downward direction of the root. Neither can the action of heat or that of moisture be regarded as the cause of this motion. Finally M. Dassen passes in review those motions of the leaves which take place constantly in the course of one day, and even without swellings; these are the phænomena which, as is well known, were regarded by Linnæus as the Sleep of Plants. M. Dassen considers Linnæus's explanation as an error into which that great man fell, as well as all those who have merely copied almost word for word from him respecting this point. The memoir On the Sleep of Plants, by E. Meyer, which I noticed in my report for 1835, as highly interesting: and full of laborious research, is especially attacked. I cannot however agree with M. Dassen : for all the valuable observa- 
tions which Meyer had enumerated respecting this phænomenon may be explained in a different sense, and in fact more in accordance with nature, if we start from the general point of view, by the periodical occurrence of sleep, which appears to be common to all animated beings. M. Dassen placed a pot containing Impatiens noli tangere during the night in a dark place, and the result was, that the leaves even during the following day retained the same direction. Another plant was placed during the day-time in a dark place, and for two entire days the leaves retained the usual direction which is proper to them in the daytime. From these and other experiments M. Dassen concludes that the motions of plants without swellings are caused solely by the process of vegetation, and that this is rendered evident as soon as the leaves are exposed to unnatural external influences.

I ask then, whether from the examples cited the phænomenon of vegetable sleep can be dénied? On the contrary, phænomena exactly similar may be proved to exist in animals.

\section{Diseases of Plants.}

I have published some observations on the development of smut in maize*, which demonstrate the origin of this incurable disease in the interior of the cells of the affected part. I consider it to be a settled fact, that the smut (Ustilago, Link, is not a contagious disease, but is inherited, and arises from the stoppage of the saps produced by superabundant manure foreign to the nature of the plant. At one or at several places of the inner surface of the affected cells small deposits of mucus are formed, from which filiform ramified bodies proceed, which are colourless and almost transparent, but contain a quantity of small molecules consisting of a somewhat more solid substance. These mucous filaments, in the interior of the cells, soon present constrictions at various places, first generally at the apices of the small lateral branches; and these constricted ends take an ellipsoidal and lastly a spherical form, become of a yellow colour, and change into those minute brown vesicles of which the smut consists. The destruction of the cellular walls by dissolution commences with the aggregation of these

- Wiegmann's Archiv for 1837, p. 419. 
smut vesicles in the diseased cells, and then these vesicles are found in great masses lying close together, filling entirely the diseased organ and frequently without leaving a trace of the original intervening cellular wall.

M. Léveillé* read a paper before the Philomathic Society of Paris on the Uredines, in which he contests both M. Turpin's view and that of M. Unger on the origin and signification of these formations. He considers the Uredines to be true parasitical fungi and not diseases of the plants on which they occur; they are said to originate from a byssoid tissue beneath the epidermis of the plants. Probably M. Léveillé will publish more detailed communications on this subject to prove his statements, with which, as far as they have been made known, I cannot agree; but his observations also prove that the view advanced by $M$. Unger, that these plants should be regarded as diseases of the respiratory organs, is not correct, for they all take their origin in the cells.

M. von Voith $\uparrow$ has described certain abnormal formations which he observed on the wood of the elm (Ulmus) : they are triangular bodies which proceed from the bark into the interior of the wood. Since the microscope was not at all employed in examining these formations, and I cannot find them in the wood of the elms occurring in the neighbourhood of Berlin, it is impossible for me to come at any correct notion of them from the description, for it is not even stated whether the foreign body consists of bark substance or of wood. I am rather inclined to suspect that these diseased formations are derived from bark substance and that the cause of this deformity must be sought, as M. v. Voith suspects, in the ascending of the trees with iron points, by which the bark has been squeezed into the wood, but not destroyed. The new annual rings of the wood forced their way afterwards through the apex of the impressed bark, \&c. If my suppositions are correct then all the rest is easily intelligible.

M. Dutrochet's communication on the formation of the ergot was noticed at p. 117.

Numerous experiments have again been performed on the

* L'Institut de 1837, p. 191.

+ Ueber ein sonderbares Gebilde in der Ulme.-Flora von 1837. No. 17. 
action of poisons on plants by M. Miquel*: for the most part sections of plants were employed, and the effect of caustic ammonia, acetate of lead, tincture of galls, camphor, cherry-laurel water, extracts of opium and Hyoscyamus on them observed. The effect of ammonia and camphor in a gaseous form also was noticed, and M. Miquel obtained in general from all his numerous experiments results quite similar to those already established by his predecessors. I will however here add one observation, namely, that the velocity with which the various poisons act upon the severed parts of the plant depends entirely on their evaporation, for only in consequence of this does the plant absorb the water with the poison, \&c.; it is consequently necessary that in all such observations, if in future it is desired to obtain coincident results, the state of moisture and the warmth of the air be observed.

\section{Geography of Plants.}

The interesting communications which Alexander von Humboldt $\uparrow$ has published on his ascent of the Chimborazo, contain some important facts relative to the geography of plants which at the same time must be regarded as correcting the statements of Major Hall, published in this journal (Wiegmann's Archiv) in 1835. Above the height of 9720 feet A. v. Humboldt found the Chimborazo surrounded with large plains which lie step-like one above the other; the first step is 10200 feet high, the second 11700, and they are so horizontal that it seems as if one were looking upon the bottom of an ocean. The very extensive downs (las Pajonales) are, on the Chimborazo, as well as everywhere around the high peaks of the Andes, so monotonous that the family of the grasses (species of Paspalum, Andropogon, Bromus, Deyeuxia, Stipa, ) are rarely supplanted by dicotyledonous plants, in which respect the vegetation exhibits great similarity to the Steppes of Northern Asia. Only Calceolaria, Compositce, and Gentiance (among which G. cernua, with purple-red flowers) present themselves in those elevated plains among the gregarious grasses, which, for the greater part, belong to North European genera. The mean temperature of these heights also nearly agrees with that of North-

* Proeven over de Werking van Vergiften of Planten.-Tijdschrift v. Nat. Geschied. en Physiol. 1837, iv. p. 154-208.

+ Ueber zwei Versuche den Chimborazo zu besteigen.-Schumacher's Jahrbuch für 1837, p. 176-206. 
ern Germany in $58^{\circ} 15^{\prime}$ lat. The highest point of the peak of Chimborazo reached by v. Humboldt was at a height of 18097 Parisian feet; only a few lichens were traced above the limit of eternal snow. The last collected were Lecidea atrovirens and Gyrophora rugosa, Achar., about 2820 toises high. The last moss, Grimmia longirostris, flourished 400 toises lower down.

M. von Baer's remarkable voyage to Nova Zembla* has filled up one of the greatest gaps in the sources for the study of the true geography of plants. All that we formerly knew of the vegetation in the polar zone above the limits of Europe was limited to a few scattered notices; at present however, now that a scientific person like v. Baer has visited the unknown Nova Zembla, we possess a description of the relations of vegetation of this zone, such as but few districts can offer.

Nova Zembla, it would seem, must be regarded as a continuation of the northern Ural, whence it becomes probable $a$ priori, that the vegetation of those islands may agree with that in the region of the alpine herbs of the southern Ural. However, we will pass on to Von Baer's descriptions of the climate and vegetation of Nova Zembla. Nowhere was a continuous grass-plat observed which might have deserved the name of a meadow, not even a continuous covering of moss; even the foliaceous lichens flourish but poorly on Nova Zembla, while the crustaceous lichens clothe every block of augitic porphyry, and occur also on the other stones, yet less frequently. On the other hand, Dryas octopetala, in continuous withered turfs, clothes the dry hilly declivities formed by the loose stones. There is no heath, no Empetrum nigrum, $A r$ butus alpina, Betula nana, Sedum palustre, Rubus Chamamorus, \&c.; in short all those plants are here wanting which I have mentioned in my Geography of Plants as characteristic of the southern portion of the polar zone, and which I attempted to separate under the name of arctic zone from the polar zone. Absence of vegetation, says v. Baer, is characteristic of the deserts of Nova Zembla ; isolated specimens of the genus Draba are found there. The loose masses of solid rock exhibit the incrusting lichens ; Verrucaria geographica is the most common, Stereocaulon paschale and isolated specimens of Cochlearia and Papaver nudicaule. The rocky rubbish, a more decom-

* Bulletin scientif. de l'Acad. impériale des Sciences de St. Petersbourg. 
posed stone, presents plants forming patches, as Silene acaulis, Saxifraga oppositifolia, Arenaria rubella. Among these grow Draba alpina and other species, Arenaria ciliata, Myosotis villosa, Dryas octopetala. The loamy soil, which in summer dries up and breaks into fissures $1-3$ inches broad (more or less regular polygons), exhibits Platypetalum purpurascens, species of Saxifraga, as S. Hirculus, and isolated specimens of Draba verna. The mosses gradually collect in the furrows, and among these grows Salix polaris, the most common of the shrubs, whose branches are very short and only send forth two leaves with the catkin from the protecting envelope, together with some species of Eriophorum.

As plants of the most sterile soil are enumerated Rhodiola rosea, Erigeron coniflorum, a Vaccinium, which is situated with its woody stem in narrow fissures of rock and only sends forth leaves, Papaver nudicaule, Ranunculus nivalis, which merely requires snow-water, and flowers when the soil is not warmed above $1^{\circ}$. Oxyria reniformis is almost as easily satisfied.

But there are also beautifully decorated spots in Nova Zembla, where vegetation breaks forth in all the splendour of colours, as it were on the ground, for the beautiful flowers never rise above a few inches high. The purple-coloured flowers of Silene acaulis and Saxifraga oppositifolia, the blue flowers of the tufts of Myosotis villosa, were varied with gold-yellow Ranunculuses and Drapa alpina, mixed with peach-blossomed Parrya, white Cerastia, blue Polemonia, and the sweet little Forget-me-not, and gave the impression of a variegated carpet. Although this vegetation evidently coincides with that of the alpine regions of southern mountains, yet M. v. Baer observes that here the individual plants occur in greater masses, while in Nova Zembla they are more scattered and mixed with one another, so that in a walk of half a werst almost half the Flora of Nova Zembla is found united.

Especially favoured spots, entirely clothed with a pretty dense covering of plants, are very rare on Nova Zembla; the Ranunculuses, with the exception of Ranunculus nivalis, are almost solely confined to those spots abundant in humus.

But how is it possible for a larger vegetation to occur in these inhospitable islands, since the warmest month in Nova 
Zembla brings with it only as much warmth as October in Drontheim, December in Edinburgh, and January in central France? M. v. Baer then shows that the idea of the vegetation proceeding very rapidly in the high north is, at least with regard to the extreme north, incorrect, for during a stay of three weeks in one district the progress of vegetation was found to be far slower than in lower latitudes; but there only such plants occur as require a very short time of vegetation, as for instance with us the spring flowers. The common cress was sown at St. Petersburgh in May, and in July in the latitude of Matotschkin-Schar, and the development at the latter place proceeded three times slower than at the former; it is therefore easily intelligible why scarcely anywhere ripe seeds were found in Nova Zembla towards the beginning of winter. Plants like Tussilago frigida, Salix Brayi, and the Vaccinium above mentioned, do not even appear to flower, whence one might probably be inclined to conclude that they had transmigrated from the neighbouring coasts. Although M. v. Baer characterizes the assumption of such a transmigration of plants as something scarcely admissible, yet he observes that whoever has travelled through these districts will certainly be determined in favour of it. The coasts generally always abound more in plants than the interior districts, and M. v. Baer regards the ice as being the best means for conveying the wandering seeds. The plants of Spitzbergen are almost without exception found in Nova Zembla, but there are also other plants in these islands which have hitherto been met with only in North America, and consequently might also be considered as having migrated to Nova Zembla.

M. v. Baer then treats at great length of the height of the limits of eternal snow on Nova Zembla, but arrives at the result that it is impossible to fix a general determination, for the local influences are surprisingly great. Notwithstanding the slight degree of warmth, all the snow in the plains melts towards the end of July; in the hollows and valleys it never entirely disappears. In so cold a country, where the mean temperature of the atmosphere is so exceedingly low, the higher warming of the soil by the sun's rays must have the greatest effect on the occurrence of vegetation, and M. v. Baer has devoted particular attention to this subject. By this 
higher calorification of the surface of the soil the lower stratum of air is in the first place warmed, and then the immediately subjacent surface of the soil; and, as observation shows, the whole vegetation on Nova Zembla occurs in these two small regions. Only very short roots descend into the earth, and the longer roots run just beneath the surface. In general they proceed almost horizontally and form with the stem a right angle. The giant of the shrubs of Nova Zembla is Salix lanata; it grows to about a span high, while the roots, or perhaps more correctly the subterraneous stem, is about an inch thick, and was laid bare for the length of from 10 to 12 feet without exhibiting the termination. On account of the slight warmth of the air, which, properly speaking, is restricted merely to the lowest stratum, the plants there grow to a height of from 2-3 inches, those of from 4-5 are much less frequent, and those of 6 inches very rare. Salix Brayi seems to show very distinctly that the air at the height of 8 inches does not contain sufficient warmth for it to develop a bud.

We are also indebted to M. v. Baer for similar interesting observations on the vegetation at various spots of the coasts of the White Sea*, which exhibit the greatest coincidence with those of Lapland, with which we are so accurately acquainted. On the east coast of the White Sea in $65^{\circ} 20^{\prime}$ northern latitude the declivities of the Winter Mountains were richly clothed with trees and shrubs, and abounded in luxuriant Peonies (P. intermedia, Meyer,), Aconites, Rosa spinosissima, Hedysarum neglectum, Polemonium caruleum; but in heights of from 150 to 200 feet the northern character again returned in all its force. On the south coasts of Lapland $\left(66^{\circ} 10^{\prime}\right.$ north lat.) the vegetation was very different from the one just described. Here the plains were covered with lichens and mosses, interspersed with Rubus Chamamorus and Vaccinium uliginosum. In $67^{\circ}$ lat. M. v. Baer found patches of Diapensia Lapponica, Arbutus alpina, Azalea procumbens, Empetrum nigrum, and heath forming extensive turfs. However in the neighbourhood of the coasts there are still some patches of arboreal vegetation to be seen. There is no corn cultivated in these districts.

- Bullet. scientif. de l'Acad. de St. Petersbourg, ii. p. 132-144. 
From A. Ermann's journal of voyage* we select the following additions to the geography of plants. In the neighbourhood of Tobolsk in $58^{\circ}$ northern latitude, the hilly districts are clothed with dense forests of firs, pines, poplars and very high birch. Near Irkutsk and its environs $\left(52^{\circ} \mathrm{N}\right.$. lat.) Pyrus baccata grows, bearing fruit of about the size of a pea, in Kjachta they attain the size of a cherry. Moreover near Neotschinck the true apricot grows with a juiceless pericarp but well-tasted kernel, and close to it the Siberian Stonepine.

M. Ermann gives some very interesting climatological notices on Jakutzk $\left(62^{\circ}\right.$ lat.) which are of high importance to the geography of plants. The temperature of the soil presented at a depth of 50 feet $-6^{\circ}$ Reaum. and coincident with this is the mean warmth of the atmosphere $\dagger$. Every year the temperature falls below $-40^{\circ}$ Reaum., on the 25th Jan. 1829 even to $-46 \cdot 4^{\circ} \mathrm{R}$. The last night-frost occurs on the 12th of May, and then the summer lasts till the middle of September. The mean warmth of Jakutzk is in June, July, and August, 11, 15, and $13^{\circ} \mathrm{R}$., and frequently the thermometer is seen in the shade to mount to $20^{\circ} \mathrm{R}$. Several kinds of corn, as summer wheat and rye, are sown in the neighbourhood of the town, and bear 15-, and even in some cases 40-fold, although the soil is thawed only to a depth of 3 feet. In the gardens potatoes, cabbages, turnips, and radishes are cultivated, and even cucumbers are forced in dung beds.

The isothermal lines do not extend from the Lena straight eastwards, but ascend strongly towards the north. Near Antschá, one degree north of St. Petersburg, and $2244 \mathrm{~Pa}-$ risian feet above the sea, the vegetation was more luxuriant than the summit of the Brocken in the Hartz. Lofty-stemmed trees (not coniferous) graced the forests. In the journey across the Aldamic Mountains Betula nana was frequently met with, which is more sensitive than the larch to the cold mountain air. At 3444 Par. feet near the end of the Antschá valley several larches were found, by which the relations of tempe-

- Reise um die Erde durch Nord-Asien und der beiden Oceane in den Jahren 1828-1830, erste Abtheilung.

+ The ground ice there is said according to recent communications to be 382 feet thick. 
rature show themselves to be more favourable in the eastern portion of the Aldamic mountains than in the west, where the limit of trees is said to be $\mathbf{1 0 0 0}$ feet lower. On the Kapitan mountain there were still larch at a height of 3780 feet; at 4000 feet nothing but lichens could be found. M. Ermann observes, that the larch does not form any knee-wood like the Coniferce of our German mountains. In the neighbourhood of the Arka he noticed a peculiar Conifera, the stem of which was 3 inches in diameter and 10-12 feet in length: it grows quite straight and slender, sending several stems from one root, but in winter is bent so much to the earth that it is enveloped in snow, and thus it is ridden over without its presence being suspected. The cones are about half the size of those of the Siberian Cedar, and likewise contain wellflavoured seeds.

In the journal of voyage of M. G. Rose* we find the very important notice for the geography of plants, that M. Federhoff had ascertained by measurement the summits of the northern Ural to be from 8 to 9000 feet high, and that these are even in $66^{\circ} \mathrm{N}$. lat. free from snow. The snow occurs there only in the saddle-shaped hollows between the separate peaks, and on the eastern and northern declivities.

M. Gœppert + has observed the vegetation on a drift of coal burning beneath the surface near Plænitz, not far from Zwickau. At some places the drift comes up to the surface, and its extent is defined in winter by the green turf remaining free of all snow, while in summer it is parched. At the chief places of evolution of the hot gases M. Gœppert found it to be from 50 to $54^{\circ} \mathrm{R}$.; upon the hilly prominences, principally clothed with moss, $35-36^{\circ}$; in the parts covered with grass $14-30^{\circ} \mathrm{R}$. He enumerates a great number of plants which grew on this hot soil ; it is true they were also found in the immediate vicinity, but far less developed and not in full vegetation. The warmest point was a portion covered with a turf six inches thick; which indicated, at a depth of three inches, $45^{\circ} \mathrm{R}$. Although

* Reise nach dem Ural, dem Altai, und dem kaspischen Meere, ausgefiihrt im Jahre, 1829, von A. v. Humboldt, Ehrenberg, und G. Rose, Berlin, 1837, p. 381.

+ Bemerkungen über das Vorkommen von Pflanzen in heissen Quellen und in ungewöhnlich warmen Boden.-Wiegmann's Archiv, 3ten Jahrgang, p. 101. 
this high temperature of the soil is something unusual in our country, yet similar circumstances occur very commonly in certain tropical regions. On the coast of the island Lantao (China) in August at half-past three P.M., I ascertained the water of some rice fields to be $36^{\circ} \mathrm{R}$. : evidently the adjacent sand, which was completely clothed with plants, was still higher, for towards mid-day I had observed the black sides of the vessel to be heated to $49^{\circ} \cdot 2 \mathrm{R}$.

M. Gœppert has given as an introduction to this work some very complete historical notices of the occurrence of plants in hot sources and in unusually warm soils, which will be of great service to future writers on this subject.

M. Zuccarini in his monograph of the Cactea* has treated very fully of their geographical distribution. Cactus plants have been observed in the New World from $49^{\circ}$ north lat. to the southernmost parts of Chili, and it is to be presumed that they go as far south in the southern hemisphere as they ascend northwards in the northern. Their vertical distribution goes through all regions, from the hot plains of the tropics to the neighbourhood of eternal snow. Some species of this family were collected on the west side of North America in $44-45^{\circ}$ lat. at great heights, and Nuttall has discovered several Cactea in similar latitudes on the high mountains in the Mandan district. Opuntice bave been observed up to $41^{\circ}$ lat. on the east side of North America. "So extensive a distribution of the family," says M. Zuccarini, "leads us naturally to expect a great variety in the peculiar habitats of the different species. But it must be observed, that with the exception of cultivated Opuntia and Cerei, all the other species are limited in their occurrence to small districts, and therefore statements like that of Meyen of the occurrence of the Mexican Cereus senilis on the Andes of Chili are probably founded on errors arising from want of comparison." I am glad to be able to give some explanation on this point. I have not seen the Cereus senilis on the Andes of Chili, I do not understand therefore how the author can make such a remarkable statement; but I saw a Cereus in the Cordilleras of southern Peru, which resembled in habit the Cereus senilis of our hot-houses; nay, I did not

* Denkschriften der mathematisch-physikalischen Klasse der königl. Acad. der Wissenschaften zu München, vol. ii. 1837. 
even see this quite close in my rapid journey, much less examine it attentively, so that it may very likely be some other species; yet this must not be asserted too hastily, for the relations of climate in which Cereus senilis occurs in Mexico and those of southern Peru, at the height in which I found this plant, are exceedingly similar. Moreover, M. Lehmann has described a Cereus bradypus from Brazil, which M. Pfeiffer considers to be synonymous with $C$. senilis, Haw. These statements however must be founded on actual comparisons, and even then it would be incorrect to ascribe generally a very restricted occurrence to the Cactece. Besides, plants of very limited stations allow rarely of wide artificial distribution, which we however find to be the case with the Cactece.

"The Cactea seem to be pretty indifferent as to the nature of the soil, for the individual species are found without distinction on limestone, sandstone, primary formations, and on strata which have been altered by volcanic action." They are even frequently found on the sea-shore, especially Cerei and Opuntia; but I cannot agree with the author, that all Cactea, with the exception of the Peireskia, require an open sunny situation. All those Cactece which require a permanent warm and moist climate, and frequently occur parasitical, $i . e$. on the bark of other trees, as the Epiphyllece according to Hermann's statement, and also many species of Rhipsalis, vegetate most luxuriantly in the shade; the Peireskia on the contrary that I met with in their native country stood quite exposed to the sun. M. Zuccarini further enumerates a series of observations, whence it results, that the climate which suits the various Cactere passes from the heat of tropical countries to the temperature of the colder temperate zone; that therefore it is impossible in their cultivation to keep all the species, in accordance with nature, under similar external influences, although most species allow of considerable latitude. M. v. Karwinski has given the natural habitats and heights at which they occur, for a great number of Mexican Cactea, and has published them in this work. The Echinocactus macrodiscus occurs there at an altitude of from 9 to 10,000 feet.

In the consideration of the distribution of the Cactece, not American, M. Zuccarini inclines to the view that Rhipsalis Cassytha is indigenous to the Isle of France and Bourbon, and 
Cereus flagelliformis to Arabia, and that they have not there passed into a wild state. That Opuntia occur in India must be regarded as a well-established fact, but few well-founded notices exist respecting the distribution of Opuntice in Africa and southern Europe. Desfontaines mentions the yellowflowered Opuntia for Barbary; in Greece it is very frequent. In Tyrol the Opuntia occur up to $47^{\circ}$ lat.; in northern Italy only O. Italica, Tenore, and O.vulgaris, Müller, are found, but in southern Italy several species. In Spain the Opuntice are so common that the question almost arises whether some species have not been transported from Spain to America or from America to Spain. The Opuntia Tuna de Castilla is especially cultivated in America on account of its beautiful fruit.

M. Zuccarini also describes very fully the uses of the various Cactea. The Opuntia and the tall thorny Cerei are employed for fences and for fortifying entrenchments; the wood of the Cactere affords a most excellent material for burning, which is used in various ways in lands poor of wood,-in the neighbourhood of Copiapo even for the smelting of copper. I have frequently employed the dry wood of the Cerei and Opuntice for burning, and found it preferable only from its being consumed very quickly in a dry state; the copper smelting in the province of Copiapo, the northern part of Chili, with Cactus wood has been discontinued, nay, one may frequently journey there for days together without seeing a single Cactus. Probably these plants were so unsparingly exterminated at the time when the working of the copper ore was begun there with the greatest enthusiasm about 100 years ago. On the high Mexican plains, the copses, miles in length, of Cerei, Opuntice, and Echinocacti afford in the dry season a means to the herds of horned cattle of quenching their thirst. In Mexico the delicate shoots of Opuntia Nopalitio are eaten like cabbage, and the flesh of Echinocactus cornigerus boiled in sugar like melons. The fruits of the Opuntia are, as is well known, eaten everywhere, and in some places with great gusto. The species most sought after in Mexico are the Alfajayuca and the Tuna de Castilla: the first bears fruit of the size of a thick fist, it is of a green or yellowish colour, almost without thorns, and contains a sweet soft flesh. The fruits of the Cerei are also eaten in many districts (the fruits of Cereus chilensis have a 
very insipid taste, but are much eaten by the people.-Rep.). These fruits are also greatly improved by cultivation.

We have obtained a similar work from $\mathbf{J}$. Bateman on the distribution of the Orchidacea*. This splendid family of plants contained in Linnæus's time only 100 species, and has at present increased to 2000. Europe possesses but few $\mathrm{Or}$ chidacere; they occur more numerously and beautifully the nearer we approach the torrid zone, in the moist districts of which they appear in astounding numbers of species and splendour of colour, and in this surpass all other families of plants. Africa, Asia and America are probably equal in the present number of Orchidacea, but each of thesequarters of the globe seems to possess some characteristic forms peculiar to it, so that the botanist might already tell from the physiognomy of the plant its country. The forms with pendent stems and splendid flowers of many Dendrobia, Aerides and their allies give the character of the beautiful orchidaceous Flora of India, which is strongly contrasted with the forms of the Bulbophylla or the long appendages of the species of Angracum of Africa. America presents on the other hand the erect forms of the Epidendrum, the long isolated branches of many Orchidere, and a greater variety of gigantic and more wonderful forms than any other portion of the globe. It is hardly possible at present to enter into any further statistical investigation of the distribution of the various forms of Orchider.

$\mathrm{Ph}$. Writgen $†$ has published a valuable memoir on the geographical relations of the plants of the Prussian province of the Rhine. First the physical relations of the superficies of the district are described, such as position, boundaries, size, climate, and distribution of the mountains, with a statement of their highest points, for which purpose a large number of measured heights are enumerated. The surface of the Rhenish province may be divided, according to the state of cultivation, into

Corn fields Acres.

Woods 4,337,691.

.

Waste lands............ $870,396$.

Acres.

Land gone out of tillage 673,467 .

Roads and rivers........ 297,573.

Gardens and plantations 240,841 .

Vineyards

$\frac{44,756 .}{10,217,450}$

- The Orchidacea of Guatemala and Mexico, 1 Fasc., fol.

+ Erster Jahresbericht des botanischen Vereins am Mittel und Niederrhein. Bonn, 1837, p. 62, \&c. 
From these statements it will easily be perceived, that the Rhenish province, where at present more than one-half of the surface consists in a carefully cultivated soil, where only onethird is now covered with light woods, and only one-eleventh of the lands lies waste, - that such a land must have worn some centuries back quite a different appearance to that of the present day, and consequently that the character of the vegetation must have changed essentially from the thinning of the woods and the draining of marshes.

In the consideration of the vegetation of the Rhenish province in a statistical point of view the author gives a table of the number and of the arithmetical proportions of the wild plants, from which I have selected some statements respecting the chief families. The number of Phanerogamia amounts to 1480 ; the Dicotyledons are to the whole number as $1: 1 \cdot 29$, the Ranurculacee $=1: 30 \cdot 8$, the Papaveracee and Polygalece $=1: 296$, the Cruciferce $=1: 18 \cdot 5$, the Rosacea $=1: 30^{\circ} 8$, the Leguminos $=1: 18 \cdot 7$, the Umbellifera $=1: 24 \cdot 3$, the Compositce $=1: 10$, the Cichorince being as $1: 28$. The Labiatce $=1: 21 \cdot 1$, the Scrophularine = $1: 26 \cdot 8$. The Monocotyledons $=1: 4 \cdot 1$, the Graminece $=1: 12 \cdot 9$, and the Cyperacea = $1: 18$. To all these statements are added comparisons with the proportional numbers of the same families in adjacent countries. Besides which there is a table of the duration of life of the Rhenish plants; the 1480 Phanerogamia may be divided accordingly into 307 annuals, 117 biennials, 913 perennials, and 143 woody plants, \&c.

In the third chapter the physiognomy of the vegetation of the Rhenish province is characterized: the woods there are almost entirely formed of deciduous trees, as the red beech, the oak, and the birch, while the white beech, the elm, the oak, the Norway maple and others generally occur only isolated. Among the shrubs may be named the hazel, the alder, chiefly. Alnus glutinosa, the common dog-wood, the common maple (Acer campestre). The rocks of the valley of the Moselle present a peculiar appearance from the immense number of box (Buxus sempervirens), which clothes the declivities with its dark brownish-green, and imparts to this district a foreign character. The arboreal vegetation was most powerful on basaltic soil. From the slight elevations that occur in the Rhe- 
nish province, the highest point, the top of the Hochwald, being only 2405 Rhenish feet, all true mountain plants are wanting; only the shade-loving wood-plants, such as Corydalis bulbosa and tuberosa, Anemone ranunculoides, Vinca minor, Dentaria bulbifera, \&c., decorate the ground of the higher mountain declivities, as well as the woods of the plain. Fir woods present themselves properly speaking only on the highest points of the Hundesrücken, but here they cannot reach, from the nature of the soil, to any great extent. The vegetation of these districts is divided into an upper and lower region; the highest limit of the cultivation of the vine (about 800 feet absolute height) is fixed as the boundary, and numerous plants are enumerated which as it appears do not extend beyond this.

In examining the influence of the geognostic peculiarities of the soil, M. Writgen arrives at the conclusion that a far more important influence must be ascribed to the temperature, moisture, and aggregate condition of the soil than to its geognostic character. Observations are enumerated to show how differently limestone and slate, in combination with light, warmth, and moisture, act on the development of the vegetation. Cypripedium Calceolus was observed on the slate mountains of the Rhine! In the Eifel, on the limits of the clay slate and of the limestone, spelt is cultivated on the latter and rye on the first, and the farmer therefore distinguishes spelt ground and rye ground; but in the valley of the Rhine the cultivation of grain is so especially favoured by the climate and outer properties of the soil that this distinction is not known.

There are also some interesting communications in this work on the separate distribution of some species of plants.

M. Siegmund Graf* has communicated some similar observations on the relations of vegetation of the duchy of Krain, and although this country also possesses no well-defined natural boundaries, yet such special investigations of small districts add more or less important facts to the great structure which vegetable geography tends to erect. Krain is a very uneven land, and comprises $1 \cdot 735 \cdot 696$ Vienna yokes (of 1600 square fathoms) of superficies, of which nearly one-third is

* Versuch einer gedrängten Zusammenstellung der Vegetations-Verhältnisse des Herzogthums Krain. Laibach, 1837-8. Also contained in the Linnæa for 1837 . 
covered with forests, one-seventh cultivated, and about onethird consists in meadows and pasture land, there being but little unproductive land. The highest mountain in Krain, the Terglon, is 9036 feet high and covered with eternal snow. In the plains of Krain there are vineyards and orchards; in the warmer Innerkrain, even figs, pomegranates, Laurus nobilis, Zizyphus vulgaris, \&c. grow. The chief portion of the wood in Krain consists however of just the same ordinary trees as adorn the woods of Germany; the heights of these woods are it is true entirely wanting, although this is most important; yet I suspect that they are situated above 15 to 1600 feet, since the greatest number of ascertained heights in this country lie between 2 and 3000 feet; consequently here, according to the rules laid down by me, the region of deciduous trees must predominate, and the character of the vegetation accordingly be similar to that on the northern side of the Alps. The underwood, i. e. the shrubs, are also quite the same as those that principally occur in the plains of Germany.

In the garden at Laibach $\left(46^{\circ} 2^{\prime}\right.$ north. lat.) a number of plants of the subtropical zone, such as Magnolia, Laurus Sassafras, Aucuba japonica, \&c. pass through the winter. Krain is so rich in plants that M. Graf has found there nearly onethird of all the plants of Germany, viz. 1654 species. The family of the Composita contains 8.7 of the entire number, the Graminea 13.8, the Papilionacea 15.6, and the former are more numerous in individuals. The Umbelliferce amount to $19 \cdot 2$ of the number, the Cruciferce 20.4 , the Personate $21^{\circ}$, the Labiata $21 \cdot 2$, the Rasacea $23^{\circ} 0$, the Cyperoida $25^{\circ}$, the Ranunculacere $27 \cdot 1$, and the Caryophyllacece to $27 \cdot 5$.

M. Graf* has also enumerated a number of plants which flower in various months on the Grosskahlen mountain near Laibach.

We have obtained a highly valuable memoir from M. Aug. de Saint-Hilaire + on the primitive vegetation of a portion of Brazil, the botanical treasures of which have been so carefully investigated by him. Just as the vegetation in the most cultivated lands of Europe must have at present an appearance

* Der Grosskahlenberg bei Laibach.-Flora von 1837. No. 42.

+ Tableau géographique de la végétation primitive dans la Province de Minas Geraes, Paris, 1837, 8vo. Extr. des Nouv. Ann. des Voyages. 
entirely different from that of 1000 years ago, we observe already at the present day in various parts of Brazil a great change in the character of the vegetation from the influence of the cultivation of the soil.

A very extensive portion of Brazilian America, says M. de St. Hilaire, has changed its physiognomy; a large Fern (Pteris caudata) and Saccharum Sape replace the grotesque forests, and in the immeasurable open spaces all the plants appear to fly before the Capim godura (Melinis minutiflora). European, African, and North American plants follow on the other hand the steps of man. Nevertheless, the primitive vegetation presents, in the province of Minas Geraes, such great differences, that distinct appellations have been given to them. The whole land is divided into Matos and Campos. The woods are either primitive (Matos virgens) or formed by man. The Catingas are less luxuriant woods which yearly throw off their leaves; they have been admirably described by M. v. Martius. The Carrascos are lower wood which consists of tall shrubs 3 to 4 feet high; the Carrasquenos form a transition between the Carrascos and the Catingas; their trees are higher than in the former. The Campos are plains which, covered with herbs, surround the Matos; they are original or produced by man on the soil of destroyed forests. It must not however be thought that the above-mentioned distinctions of the Brazilian vegetation are so accurately defined as is stated in books: we shall everywhere find transitions from the one to the other, and even from the Carrascos to the true Campos.

M. de St. Hilaire then gives an interesting account of the physiognomy of the vegetation which is presented in the different above-mentioned districts of the province of Minas Geraes, of which our German naturalists, who have travelled in those countries, have given such beautiful descriptions.

In Hooker's Companion to the Botanical Magazine for the year 1837, we also find some very important memoirs for the geography of plants, of which, however, I can only mention the names, as they enter too much into special details for me to give extracts of them here. Above all, the beautiful memoir of Allan Cunningham* must be mentioned, which

* Floræ Insularum Novæ Zelandiæ Precursor; or a Specimen of the Botany of the Islands of New Zealand. Companion, ii. p. 222, 337 and 358, and continued in the Annals of Natural History. 
contains an arrangement of all the plants hitherto found in New Zealand according to their natural families. Further, the observations of $\mathrm{J}$. Backhouse* on the Esculents of Van Diemen's Land, among which, the roots of Pteris esculenta play a chief part; they are often of the thickness of a man's thumb, and go deep below the surface of the earth. The root tubers of some Orchidea, as Gastrodia sesamoides, form the potatoes there, \&c. The natives eat the heart of Cibotium Billardieri and Alsophila australis. The other edible plants are of no importance, and can only satisfy hunger to a certain degree.

There is also in Hooker's Companion a memoir of the unfortunate Douglas, consisting of letters which he had addressed to his friendst. There are numerous very useful communications relating to the geography of plants scattered in it ; the most remarkable of all appears to me to be the notice of a gigantic Cactus which Douglas observed on the Gallopagos : its stem is from 2 to 3 feet in diameter, and 40 to 50 in height.' It belongs to the genus Opuntia, and has long and large yellow flowers and very long flexible thorns.

M. Beilschmid $\neq$, to whom botany and especially the geography of plants is indebted, for the greater diffusion of many of the most interesting works, has translated Watson's ' Remarks on the Geographical Distribution of British Plants, chiefly in connexion with Latitude, Elevation, and Climate,' and appended to it some interesting additions and observations : this work is as it were republished by M. Beilschmid, for hitherto we did not even know of its existence at Berlin.

We may regard $R$. Schneider's memoir $\S$ as a sequel to the publication of the above work; it contains a very excellent comparison of the vegetation of Silesia with that of Great Britain, and the numerical proportions between the British and Silesian plants, which are arranged in a table side by side,

* Some remarks on the roots and other indigenous Esculents of Van Diemen's Land.-Companion, ii. p. 39.

+ Memoir of the Life of David Douglas, with a portrait. His sketch of of a journey to the North Western parts of America.- His letters from the Columbia.-His journey across the Rocky Mountains to Hudson's Bay, \&c. -Companion, p. 79-178.

† Bemerkungen über die geographische Vertheilung und Verbreitung der Gewächse Grossbritanniens, besonders nach ihrer Abhängigkeit von der geographischen Breite, der Höhe und dem Klima, Breslau, 1837.

$\S$ Vergleichung der schlesischen Flora mit der britischen nach Watsons Angaben.-Flora von 1837. Nos. 33, 34. 
are very striking. The same author has also published some additions to the Silesian Flora (Breslau, 1837), which however I have not been able to see.

In a very complete memoir on the Peculiarities of the Flora of the Peat Bogs in the neighbourhood of Greifswald*, M. Hornschuch has specially enumerated all the plants which take part in the formation of peat in that district, and also those which grow preferably on such turf soils. The various peat moors of that district exhibit in their composition great differences, and each one possesses something peculiar which is also expressed in its Flora. The following is the account of the formation of the peat in the turf pits. Sphagnum cuspidatum gradually covers the whole surface of the water of the pit, sinks from its own weight together with the other plants growing on it, and either fills it up or forms floating islands, and its place is then occupied by Sphagnum acutifolium. This gradual change in the vegetation in these pits is distinguished by the following stages. The Sphagnum cuspidatum fixes itself to one side of the pit and densely together, but still swims in, and is surrounded by water, in which Equisetum limosum and Carex filiformis vegetate; while, on the other sides of the pit, Juncus uliginosus begins to spread over the surface of the water, proceeding from the sides. In older pits Sphagnum covers the whole surface; on and between it vegetate isolated individuals of Schœnus albus, Eriophorum vaginatum, Comarum palustre, Drosera intermedia; and the submerged rhizomas of Equisetum limosum break with their culms through this covering of plants, \&c.

M. Unger read a paper + before the meeting of Naturalists at Prague, in which he brings forward some new statements to defend his view respecting the dependence of certain forms of plants on the nature of the soil $\ddagger$. The new observations have been collected in the neighbourhood of Gratz in Styria; he there found a number of plants which he designates as always occurring on limestone, and again others which belong to the Kalk-holden §. It is sufficiently well known how differ-

* Flora von 1837. Nos. 47, 48.

t Flora von 1837. No. 40 .

I See last year's Report,

$\$$ In the German Kalkstete in opposition to Kalkholden. I have some doubt about the meaning of this last word, but if formed of hold=loving would be plants preferring limestone but not confined to it.-W. F. 
ent are the views of botanists on this subject. M. Unger's opponents are however able to mention as many facts against this dependence of plants on the geognostic character of the soil as M. Unger has advanced in support of it.

I can only mention the interesting and important memoir of Sauter v. Bregenz on the Relations of Vegetation in the district of the Boden lake and in a part of the Voralberg*, as also the descriptions of MM. Tommasini $\uparrow$ and Brunner $\ddagger$, as they are more of local interest, and their numerous special statements do not permit a general representation of the results.

Highly important for future writers on the Vegetable Geography of the South Sea Islands is M. Guillemin's $§$ Zephyritis Taitensis : it is most especially adapted, in connexion with M. Endlicher's remarks on the Flora of the South Sea Islands, and the beautiful memoir of Allan Cunningham, mentioned at page 153, on that of New Zealand, to a special statistical research.

M. F. A. Miquel || has published a memoir on the occurrence of the Sargazzo in the sea of Sargazzo, named after it, in which there are some points intimately connected with the geography of plants. M. Miquel is also convinced that Agardh's two species S. vulgare and S. bacciferum are identical, and only form one species, for which he proposes the name of $S$. Columbi, as this enterprising navigator touched on the Sargazzo sea on the 16th Sept. 1492. According to the laws in force among botanists, such a change of names can certainly meet with no good reception; the plant which floats in this sea was named by Linnæus Fucus natans, and is identical with Fucus natans, Turn.; Gmelin certainly did wrong when he called it Fucus Sargazzo. The generic name has, it is true, been changed, but there exists no reason for altering Lin-

* Flora von 1837, i. Beiblatter, p. 1.

+ Ausflug von Görz auf die Kron-Alpe und in das Reibler-Thal in Kärnthen.-Flora von 1837. Nos. 5, 6.

$\ddagger$ Ausflug in's Zermatt-Thal im Julius, 1836.-F'lora von 1837. No. 10.

$\S$ Enumération des plantes découvertes par les voyageurs dans les Isles de la Société, principalement dans celle de Taiti.-Ann. des Scienc. Nat. $1837, \mathrm{i}$.

II Over het Sargasso of Zeekroos.-Tijdschrift voor Natuurlijke Geschiedenis en Physiologie, 1837, iv. p. 25-41. 
næus's specific name; this fucus must therefore be called Sargassum natans, although it was subsequently found sessile as well as floating.

M. Miquel treats of the question respecting the origin of this floating fucus, and thinks that if we admit that it has been torn from its place of growth and only remains afterwards living for some time, we should not depart much from analogy. Hereupon various doubts are raised against views advanced by me, who have observed that the small floating specimens show quite distinctly that they have never been sessile, that consequently we have not to look for the ground upon which they may have originated, but that the surface of the water on which they float must be regarded as such. The doubts which $\mathbf{M}$. Miquel advances against my actual observations are however very easily obviated; in every case where he suspects that my observation (I did not advance a mere opinion on this subject, but actual observation.-Rep.) is without analogy I have enumerated actual analogous cases, and subsequent observations have increased my knowledge on this point. All the specimens of this floating fucus which M. Miquel has obtained from the Sargazzo sea have a short foot-stalk, which appears to me very intelligible, for this fucus floats in masses of greater or less size, some individuals even attaining to a length of $2,3,5$, and more feet, and each one has hundreds, nay thousands, of stalks, branches and shoots*. But it is the large specimens which the sailors fish up to bring home for their friends, and especially those with stalks and branches. I was very soon convinced that the examination of the large specimens could lead to no result; I therefore fished for the smallest, which very soon solved the enigma, and the specimens brought home by me confirm my statements. I did not observe dying or dead specimens in the Sargazzo sea, consequently they can only be very rare.

Since the question of the floating gulph-weed is now annually repeated, and very frequently spoken of in the Academie des Sciences of Paris, I forwarded a specimen of this

* It must not be overlooked that all these parts are only foliaceous formations, and that a Fucus has neither stem nor root in the sense of the higher plants; on which account these are no reasons at all in favour of M. Miquel's view, that this fucus cannot have been developed in a floating state, but must have grown erect. 
plant to that celebrated Society, that at least one fact might be established, viz. that this plant had never been sessile. Now although this point was very easy to decide on the specimen sent, yet a learned member of the Academy, evidently without examining the specimen, supposes nevertheless that it may have been torn loose.

After the establishment of this fact, that the floating perfect fuci in the Sargazzo sea have not been sessile, we arrive at the question, whence then have the seeds of this plant come? But this question also is not difficult to answer if we consider the powerful currents which prevail in and about this sea, especially as we know that the sessile specimens of the Sargassum natans on the American coast, and probably on the coasts of the Azores, \&c., bear fruit.

THE END.

ERRATUM.

Page 52, 3rd line from bottom, for flower read flower-stalk.

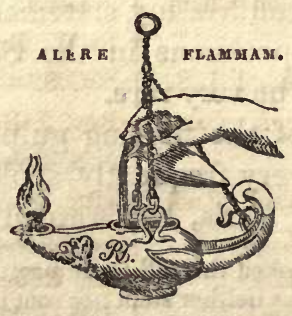

PRINTED BY RICHARD AND JOHN E. TAYLOR, RED LION COURT, FLEET STKEET. 


\title{
LIST OF SUBSCRIBERS.
}

\author{
John, Duke of Bedford, K.G., F.A.S., L.S., \&c.
}

C. G. B. Daubeny, M.D., Prof. Chem. and Bot. Oxford, F.R.S., L.S., G.S. Sir W. J. Hooker, K.H., LL.D., Reg. Prof. Bot. Glasgow, F.R.S., L.S., G.S. (Two Copies.)

J. Lindley, Ph. D. Prof. Bot. Univ. Coll. Lond., F.R.S., L.S., G.S.

David Don, Esq., Prof. Bot. King's Coll. Lond., Libr. L.S.

Ch. Morren, Professeur ordinaire à l'Université de Liège, Membre de l'Academie Royale des Sciences de Bruxelles, \&c.

Edward Forster, F.R.S., Treas. L.S.

Sir W. Jardine, Bart., F.R.S.E.

R. Dickson, M.D., F.L.S., Lecturer on Botany at St. George's Hospital.

J. Pereira, Esq., Lecturer on Chem. London Hospital.

Charles C. Babington, M.A., F.L.S., G.S., St. John's College, Cambridge.

T. Bell, F.R.S., L.S., Prof. Zool. King's College. (Four Copies.)

R. H. Solly, Esq., F.R.S., L.S.

G. Dickie, A.M., A.L.S., Lecturer on Botany, Aberdeen.

Dr. Balfour, F.R.S.E.
J. E. Gray, F.R.S., President of Bot. Soc. London.

Richard Taylor, Esq.,UnderSec. Linn.

Soc., F.A.S., G.S.

E. Charlesworth, F.G.S., \&c.

W. B. Carpenter, F. Bot. Soc. E. (Two Copies.)

E. Forbes, For. Sec. Bot. Soc. Edinburgh.

N. B. Ward, Esq., F.L.S.

W. Campbell, Esq., Sec. Bot. Soc. Edinburgh.

J. L. Drummond, M.D., Prof. Anat. Belfast.

Daniel Cooper, Esq., A.L.S., Curator Bot. Soc. Lond.

G. E. Dennes, F.L.S., Sec. Bot. Soc. Lond.

E. W. Brayley, Jun., Esq., F.L.S., G.S.

Rev. J. B. Reade, F.R.S.

J. S. Bowerbank, Esq., F.G.S.

Hon. W. Harvey, Cape Town.

Edwin J. Quekett, F.L.S.

Dr. Robert Wight, Madras.

Joshua Milne, Esq., F.L.S.

Dr. Murray, Ceylon.

J. Farish, Esq., Gov. pro tem. Bombay. 
William Griffith, Esq., Calcutta.

Jos. Prestwich, Esq., F.G.S.

J. Morris, Esq.

W. A. Leighton, Esq.

G. E. Sowerby, F.L.S.

R. Rigg, Esq.

W. H. White, Fsq.

J. Yelloly, M.D., F.R.S.

W. Brand, Esq.

W. Gourlie, Esq.

J. C. Hall, Esq.

W. Stark, Esq., Norwich.

Belfast Library.

A. Pritchard, Esq.

R. Phillips, F.R.S., L. \& E. F.G.S., \&c.

E. F. Teschemacher, Camberwell.
J. Percy, M.D., F. Bot. Soc. Edinburgh.

F. J. Farre, M.D., F.L.S.

A. Farre, M.B.

J. R. N. Morson, Esq.

Capt. Portlock, R.E., Belfast.

C. A. Stephens, Esq.

Miss Lonsdale.

W. Robertson, Newcastle-on-Tyne.

R. B. Bowman, Newcastle-on-Tyne.

Major Best Jervis, F.R.S., G.S., \&c.

Maclachlan \& Stewart. (Twelve Copies.) Edinburgh.

Currie and Bowman. (Four Copies.)

Newcastle-on-Tyne.

Mr. Pamplin. (Two Copies.) 




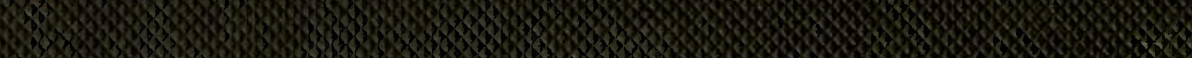

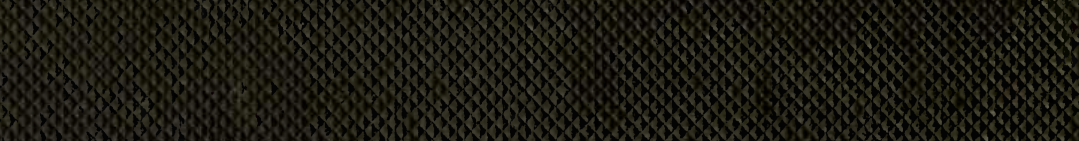
7.6.

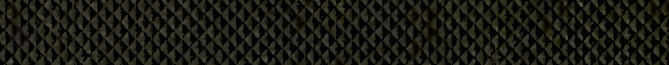

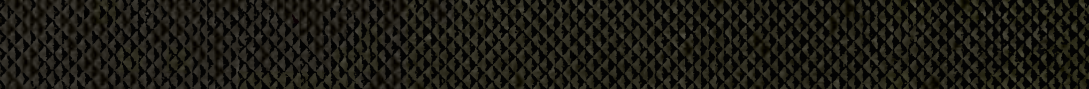

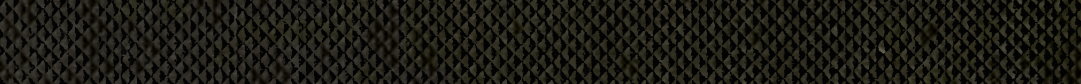

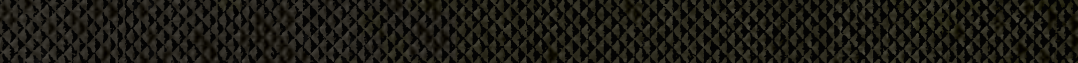
3 3 .

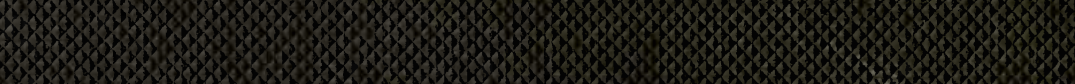
r.

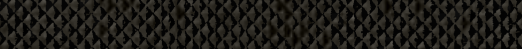

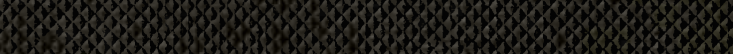

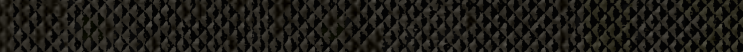

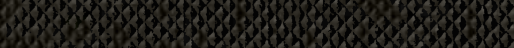

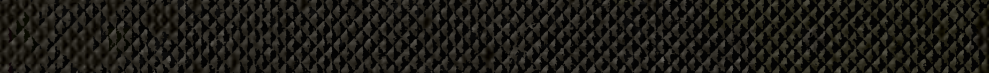

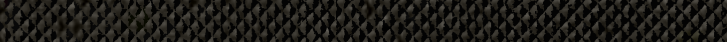
0,00030 